\title{
Rational Design and Synthesis of Low-Temperature Fuel Cell Electrocatalysts
}

\author{
Na Tian ${ }^{1} \cdot$ Bang-An Lu ${ }^{1} \cdot$ Xiao-Dong Yang ${ }^{2} \cdot$ Rui Huang $^{1} \cdot$ Yan-Xia Jiang ${ }^{1} \cdot$ Zhi-You Zhou $^{1} \cdot$ Shi-Gang Sun $^{1}$ (1)
}

Received: 28 November 2017 / Revised: 11 January 2018 / Accepted: 8 February 2018 / Published online: 19 March 2018

(C) The Author(s) 2019, corrected publication April 2019

\begin{abstract}
Recent progresses in proton exchange membrane fuel cell electrocatalysts are reviewed in this article in terms of cathodic and anodic reactions with a focus on rational design. These designs are based around gaining active sites using model surface studies and include high-index faceted Pt and Pt-alloy nanocrystals for anodic electrooxidation reactions as well as Pt-based alloy/core-shell structures and carbon-based non-precious metal catalysts for cathodic oxygen reduction reactions (ORR). High-index nanocrystals, alloy nanoparticles, and support effects are highlighted for anodic catalysts, and current developments in ORR electrocatalysts with novel structures and different compositions are emphasized for cathodic catalysts. Active site structures, catalytic performances, and stability in fuel cells are also reviewed for carbon-based non-precious metal catalysts. In addition, further developmental perspectives and the current status of advanced fuel cell electrocatalysts are provided.
\end{abstract}

Keywords Fuel cells $\cdot$ Platinum $\cdot$ Non-precious metal catalysts $\cdot$ Nanocrystals $\cdot$ Active sites $\cdot$ Electrocatalysis

PACS 82.45.Yz Nanostructured materials in electrochemistry

\section{Introduction}

Low-temperature fuel cells, as an emission-free power source, possess great potential in clean electric automotive applications to solve serious environmental and energy challenges. Currently, Pt is the mainstay element of fuel cell technologies, and many investigations, both fundamental and practical, have been conducted to prepare efficient electrocatalysts for fuel cell reactions, including anode hydrogen oxidation reactions (HOR), methanol oxidation reactions (MOR), ethanol oxidation reactions (EOR), and cathode oxygen reduction reactions (ORR) [1, 2]. However, Pt catalysts employed in the membrane electrode assembly (MEA) of low-temperature fuel cells are expensive and rare, presenting a large obstacle for commercialization and the replacement of

Shi-Gang Sun

sgsun@xmu.edu.cn

1 State Key Laboratory of Physical Chemistry of Solid Surfaces, Department of Chemistry, College of Chemistry and Chemical Engineering, Xiamen University, Xiamen 361005, China

2 College of Materials Science and Engineering, Huaqiao University, Xiamen, Fujian, China traditional internal combustion engines. In addition, the cost of these Pt-group metal (PGM) catalysts does not reduce with scaled-up production and might increase as market demands for fuel cells increase. According to the developmental roadmap of the US Department of Energy (DOE), the target for PGM is set at $0.125 \mathrm{~g}_{\mathrm{PGM}} \mathrm{kW}_{\text {rated }}^{-1}$ in 2020 or about $11.3 \mathrm{~g}_{\mathrm{PGM}}$ per vehicle ( $90 \mathrm{~kW}_{\text {gross }}$ ) [3]. This can be converted to 0.125 $\mathrm{mg}_{\mathrm{PGM}} \mathrm{cm}_{\text {MEA }}^{-2}$ with a power density of $1 \mathrm{~W}_{\text {rated }} \mathrm{cm}_{\text {MEA }}^{-2}$. Considering that $5 \mathrm{~g}$ of PGM catalysts per vehicle is used in the exhaust gas converter for cleaning duty, a stretch target of $0.0625 \mathrm{~g}_{\text {PGM }} \mathrm{kW}_{\text {rated }}^{-1}\left(\sim 6 \mathrm{~g}_{\text {PGM }}\right.$ per vehicle $)$ is proposed by General Motors at which proton exchange membrane fuel cell (PEMFC) vehicles can truly become competitive with traditional internal combustion engine vehicles [4]. Unfortunately, the catalyst loading of current state-of-the-art PEMFCs is about $0.25 \mathrm{~g}_{\mathrm{PGM}} \mathrm{kW}_{\text {rated }}^{-1}$ [4], which is about four times that of the stretch target, presenting a large and challenging gap to commercialization. Accordingly, two common strategies are applied to solve this issue: one is to decrease Pt loading without sacrificing activity [5], namely high-performance Pt-based catalysts; the other is to search for earth-abundant materials to replace PGM catalysts.

Therefore, the exploration and design of new Pt-based catalysts with enhanced activity and stability is key to the 
commercialization of PEMFC vehicles. Because fuel cell electrocatalytic reactions only occur at the catalyst surface and are mainly influenced by the top layers of atoms of the catalyst, the enlargement of catalytic surface areas can enhance efficiency. It is well known that low-coordinated step, edge, and kink atoms on nanoparticles serve as catalytic active sites [6]. Because of this, to improve the activity of Pt, two general strategies are viable: (1) increasing the density of active sites and (2) increasing the intrinsic activity of each active site through the optimization of surface atomic arrangement, electronic structure and ligand environment. For example, tetrahexahedral Pt nanocrystals (THH Pt NCs) with high-index facets (HIF) possess a catalytic activity 2.5-4.6 times higher than that of commercial Pt/C catalysts for ethanol oxidation [7]. In another example, $\mathrm{Pt}_{3} \mathrm{Ni}(111)$ skins, stimulated by atomic arrangement effects and electronic structure effects, exhibit the highest ORR activity among $\mathrm{Pt}_{3} \mathrm{Ni}(111), \mathrm{Pt}_{3} \mathrm{Ni}(100)$, and $\mathrm{Pt}_{3} \mathrm{Ni}(110)$, and is 90 -folds more active than current stateof-the-art Pt/C catalysts [8].

There are also considerable efforts to replace PGM catalysts with earth-abundant materials. A wide range of non-precious metal catalysts have been reported as ORR catalysts in acid electrolytes, including metal oxides (particularly group IV and V metal oxides), metal nitrides (MoN [9], TiN [10], etc.), metal chalcogenides [11], carbon-based non-precious metal catalysts, and metalfree catalysts. Carbon-based catalysts have been highly developed in recent years, especially iron-/nitrogen-doped carbon (Fe/N/C) catalysts and nitrogen-doped (metal-free) carbon catalysts.

This review aims to highlight current developments of high-performance Pt-based fuel cell electrocatalysts, including anode electrocatalysts for the oxidation of small organic molecules, and cathode electrocatalysts for ORR. In this review, an overview of the typical results of $\mathrm{Pt}$ single-crystal model catalysts along with progresses made in Pt-based nanoparticles with high-index facets and summaries of other distinctive Pt-based electrocatalysts will be provided for anode electrocatalysts. Subsequently, Ptbased cathodic electrocatalysts and non-precious metal electrocatalysts are reviewed. In the case of Pt-based ORR electrocatalysts, representative extended Pt-based surfaces are introduced and Pt-based nanoparticles with high ORR activities are explored. Lastly, proposed atomic structures for active sites of carbon-based non-precious metal catalysts are reviewed, and recent exciting breakthroughs in carbon-based catalysts of PEMFCs are discussed. This review will conclude with discussions on the challenges of PEMFCs, including activity decay and mass transportation.

\section{Anode Noble-Metal Catalysts}

\subsection{Pt Single-Crystal Model Catalysts}

Metal single-crystal planes with well-defined surface atom arrangements are used as model catalysts to study surface structure catalytic functionality. It is well established that open structured surfaces possess much higher reactivity than densely packed surfaces $[6,12]$. Face-centred cubic (fcc) PGMs possess high-index planes that are open surfaces and have a high density of atomic steps and kinks, as shown in Fig. 1a-b. These low-coordinated steps and kinks easily interact with reactant molecules and serve as active sites for breaking chemical bonds. Therefore, the catalytic activity of these high-index planes is generally superior to low-index planes, which consist of densely packed atoms, such as $\{111\}$ and $\{100\}$ planes.

Due to high costs and low surface area, bulk metals high-index planes cannot be directly used as practical catalysts. Based on fundamental studies, the best way to use model catalysts of single-crystal planes in practical applications is to synthesize metal NCs bound by high-index facets [13]. For $f c c$ metals, the stereographic projection (unit triangle) of single-crystal planes corresponds to the polyhedra of the crystallographic single form, as shown in Fig. 1c. These single forms located at the three triangle vertexes represent octahedron, cube, and rhombic dodecahedron, corresponding to $\{111\},\{100\}$, and $\{110\}$ facets with coordination numbers of 9,8 , and 7 , respectively [6]. The polyhedra lying on the three triangle sidelines (crystalline zones) are bound by 24 high-index facets, (i.e. tetrahexahedra (THH) by $\{$ hk0 $\}$, trapezohedra by $\{$ hkk $\}$, and trisoctahedra by $\{\mathrm{hhl}\}$ with corresponding coordination numbers of 6,7 , and 7 , respectively). The polyhedra inside the triangle are hexoctahedra $(\mathrm{HOH})$ enclosed by $\{\mathrm{hkl}\}$ $(\mathrm{h}>\mathrm{k}>1 \geq 1)$ high-index facets. Overall, kink atoms are abundant on these high-index facets.

\subsection{Pt nanocrystals with High-Index Facets}

Metal nanoparticles with high-index facets are promising practical catalysts. However, the synthesis of these catalysts is challenging due to high surface energies. For $f c c$ metals, the surface energy of different crystalline planes increases in the order of $\gamma_{\{111\}}<\gamma_{\{100\}}<\gamma_{\{h k 1\}}$. In NC growth, a high growth rate along high-index facets with high surface energy results in the rapid disappearance of high-index facets, resulting in the final shapes being usually bound by lowindex facets, such as octahedra and cubes.

Therefore, the stabilization of high-index facets during NC growth is key to successfully synthesis NCs with 

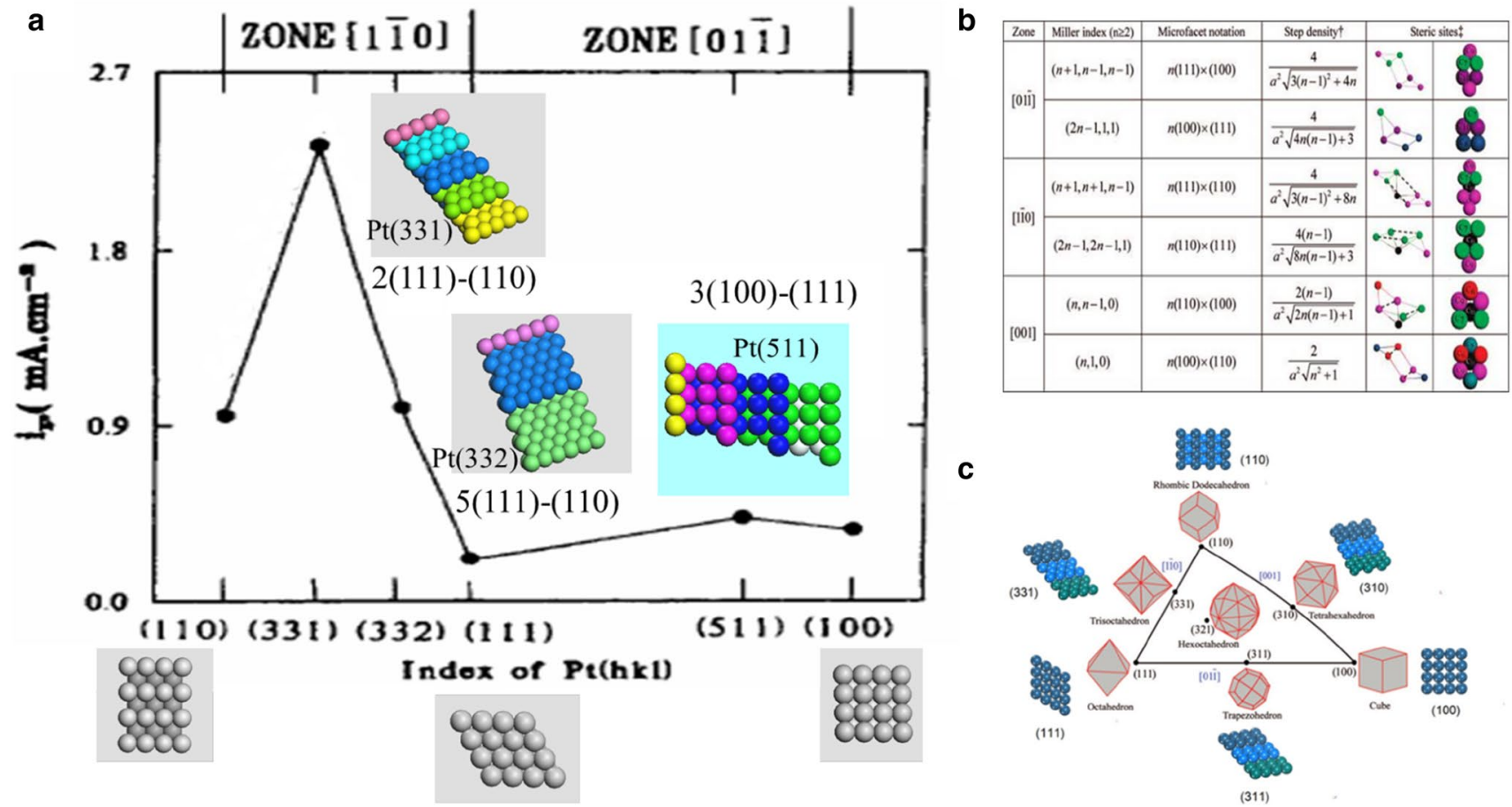

Fig. 1 a Dependence of electrocatalytic activity on surface structure of Pt single-crystal plane towards ethylene glycol electrooxidation [12]; b Densities of step atoms and configurations of steric sites on

HIFs. Concerning this issue, an electrochemical squarewave potential (SWP) method was developed to synthesize THH Pt NCs with high surface energy, and a series of studies were conducted in the past decade $[1,2,6,7,13]$. These studies found that periodic oxygen adsorption at high potentials and desorption at low potentials induce place exchange between oxygen and surface metal atoms, leading to the formation of HIFs. Considerable progress has also been made in the preparation of NCs with HIFs using wet-chemical synthesis through capping agents to stabilize low-coordinated sites or through controlling NC growth kinetics [14, 17-21].

THH Pt NCs synthesized using a SWP method were first reported in 2007 [7]. As shown in Fig. 2a, these singlecrystal THH NCs are enclosed by 24 high-index facets (i.e. $\{730\},\{210\}$, and/or $\{520\}$ surfaces) and possess a high density of atomic steps. Strikingly, despite high surface energies, these NCs exhibit superior thermal (up to $800^{\circ} \mathrm{C}$ ) and chemical stability. In comparison with commercial $\mathrm{Pt} / \mathrm{C}$, these THH Pt NCs exhibit much higher activity and longer durability towards both ethanol and formic acid electrooxidation in which THH Pt NCs provided steady activities 2.5-4.6 times larger for ethanol oxidation and current densities 2.0-3.1 times higher for formic acid oxidation.

Electrochemical SWP is a powerful and general method for the preparation of NCs with high surface energy. Pt NCs
Pt-stepped surfaces [6]; c Unit stereographic triangle of polyhedral single forms bound by different facets [13]

with various surface structures have been synthesized by adjusting precursor concentrations, electrolytes, frequency of SWPs, oxidative etching potentials (upper limit), and reductive deposition (lower limit) potentials. For example, TPH Pt NCs with $\{522\}$ high-index facets were prepared using an electrochemical SWP method with well-controlled potential limits [15]. The prepared TPH Pt NCs were also found to possess higher activity towards the electrooxidation of small organic molecules. Formic acid electrooxidation at $0.60 \mathrm{~V}$ in a positive potential scan using TPH Pt NCs produced a peak current density of $4.1 \mathrm{~mA} \mathrm{~cm}^{-2}, 2.9$ times greater than using commercial Pt/C $\left(1.4 \mathrm{~mA} \mathrm{~cm}^{-2}\right)$. Methanol electrooxidation using TPH Pt NCs produced a peak current density of $8.1 \mathrm{~mA} \mathrm{~cm}^{-2}, 5.1$ times greater than using commercial Pt/C $\left(1.6 \mathrm{~mA} \mathrm{~cm}^{-2}\right)$.

Parallel to the great successes made in the electrochemically shape-controlled synthesis of convex NCs with HIF, the synthesis of concave NCs with HIFs through wetchemical methods have also received extensive attention. Zheng et al. [14] demonstrated that concave Pt NCs can be solvothermally prepared using PVP as a surfactant in the presence of methylamine. The uniform four-armed star-like concave Pt NCs were synthesized using amine as capping agents and possessed $\{411\}$ facets (Fig. 2i). These concave Pt NCs exhibited electrocatalytic activities 5.6 times higher than that of Pt/C for formic acid electrooxidation (Fig. 2j), 

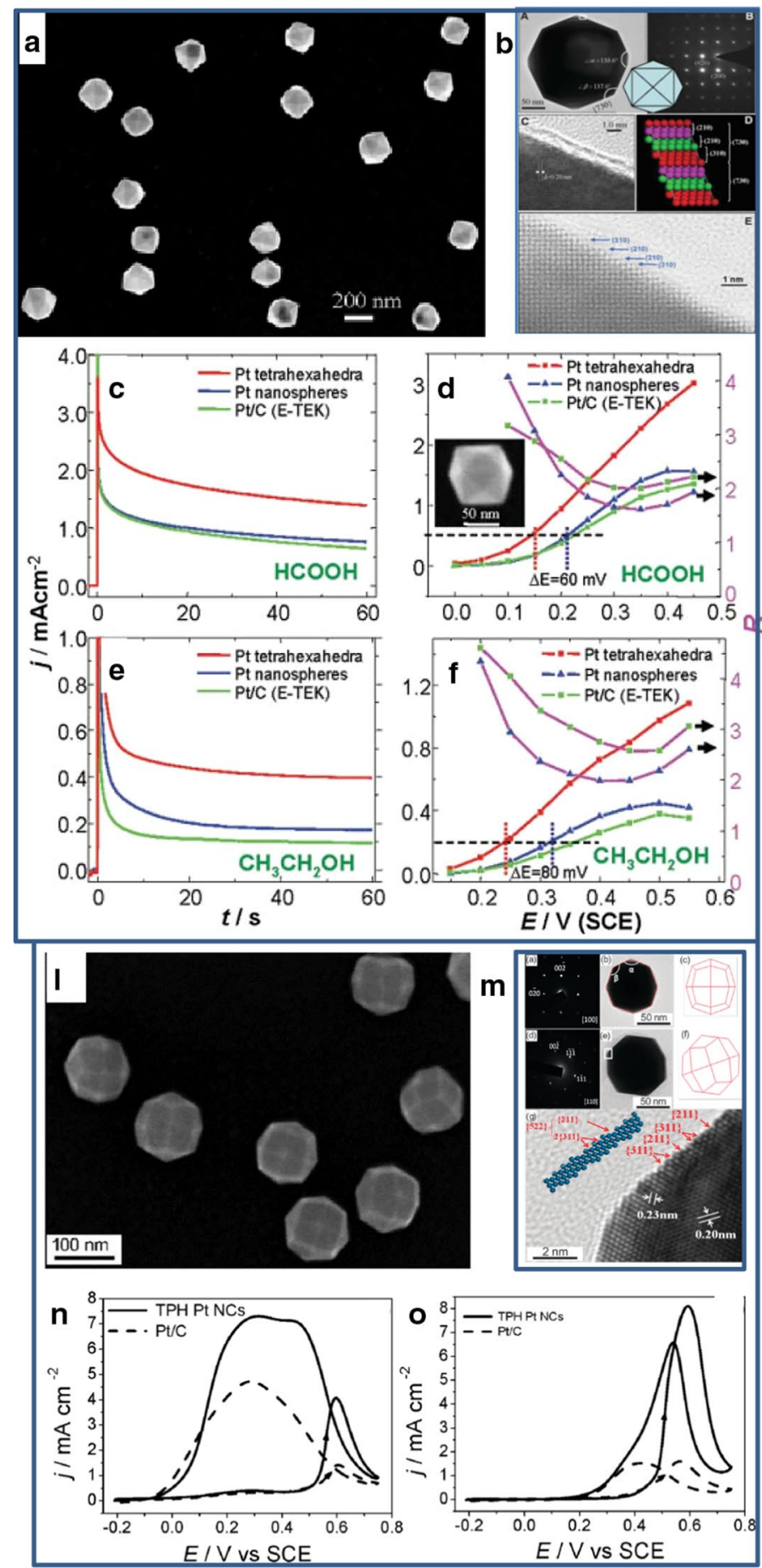

Fig. 2 a, b SEM and TEM images of Pt THH NCs with $\{730\}$ facets and corresponding atomic models. c-f Comparison of area-specific catalytic activities among THH Pt NCs, polycrystalline Pt nanospheres, and 3.2-nm Pt/C catalyst [7]. g-i SEM and TEM images of concave Pt NCs with $\{411\}$ facets [14]. j, k Comparison of catalytic activities towards formic acid (j) and ethanol (k) oxidation among concave Pt NCs, commercial Pt black, and Pt/C catalyst [14]. I, m SEM and TEM images of trapezohedral Pt nanocrystals with $\{522\}$

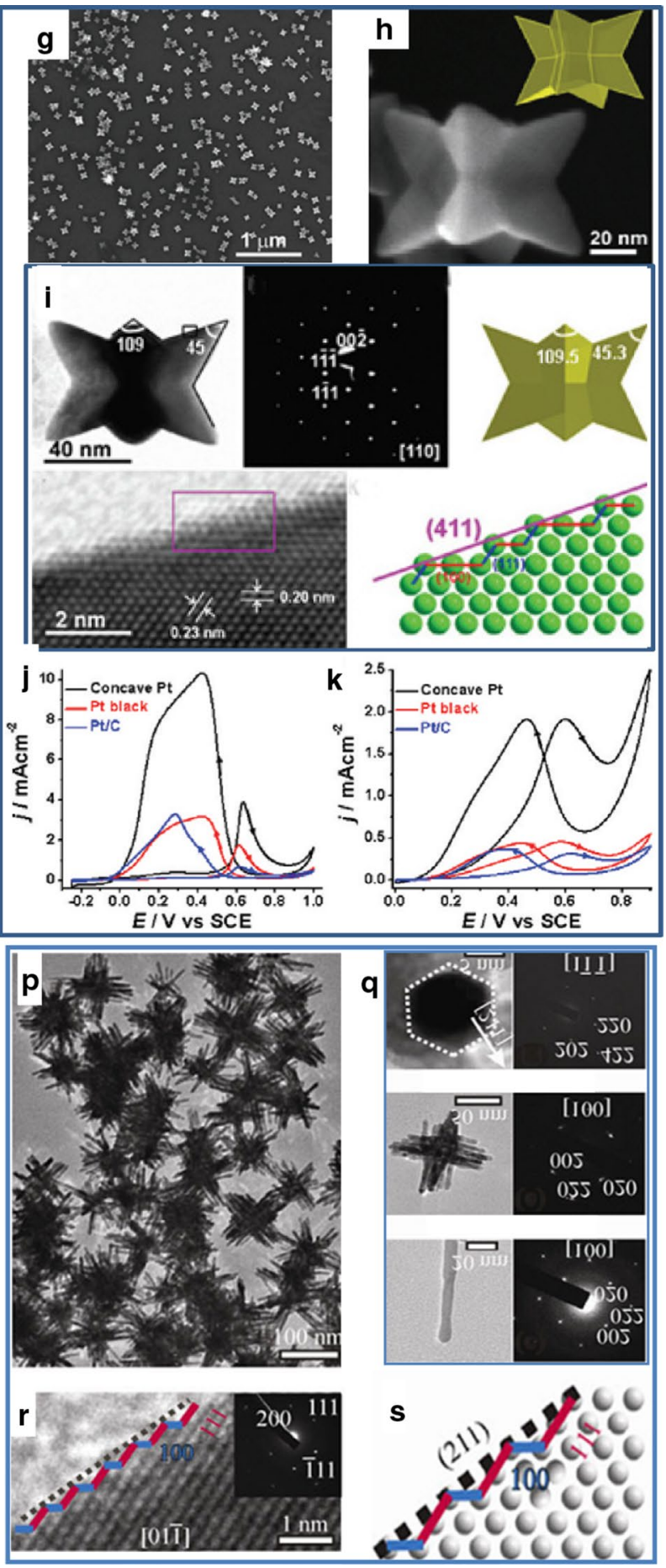

facets. $\mathbf{n}, \mathbf{o}$ Cyclic voltammograms of the electrooxidation of formic acid (n) and methanol (o) by the as-prepared TPH Pt NCs and commercial Pt/C [15]. $\mathbf{p}$ TEM images of multipod Pt NCs; $\mathbf{q}$ TEM image and corresponding SAED patterns of a single nanorod; $\mathbf{r}$ HRTEM image of the edge region of the nanorod projected along the [011] direction, showing the atomic arrangements of the surface. $\mathbf{s}$ Atomic model of the Pt(211) surface projected from the [011] direction [16] 
and 6.0 times higher for ethanol electrooxidation (Fig. 2k). The introduction of amine was found to be crucial for the formation of the concave NCs.

Aside from well-defined nanoparticles, other complex nanostructures can also be bound by HIFs. Multipod Pt NCs with $\{211\}$ facets (Fig. 2p) were synthesized using formaldehyde as an additional surface structure regulator by Zhang et al. [16], and they found that concave Pt NCs with $\{411\}$ facets formed in the presence of formaldehyde, whereas multipod Pt NCs with $\{211\}$ facets formed in the absence of formaldehyde. The researchers suggest that the reason for this is that amine mainly stabilizes monoatomic step edges, resulting in $\{211\}$ exposed facets, whereas the addition of formaldehyde decomposing into $\mathrm{CO}$, leads to the formation of $\{411\}$ facets. The Pt NCs with $\{211\}$ and $\{411\}$ facets exhibited significantly better catalytic activities towards the electrooxidation of ethanol as compared with commercial Pt/C catalysts or Pt nanocubes with low-index $\{100\}$ surfaces.

One issue with HIF Pt NCs is that it is usually larger than $20 \mathrm{~nm}$, resulting in low Pt utilization with the synthesis of small-sized $(<10 \mathrm{~nm})$ HIF Pt NCs being challenging. Zhou et al. [22] reported that 2-10 nm HIF Pt NCs can be prepared through the SWP treatment of carbon-supported insoluble $\mathrm{Cs}_{2} \mathrm{PtCl}_{6}$ particles. These small-sized HIF Pt NCs possess high densities of low-coordinated $\mathrm{Pt}$ atoms on the surface and are effective for splitting $\mathrm{C}-\mathrm{C}$ bonds in ethanol electrooxidation (Fig. 3a-c). Alternatively, small-sized Pt NCs with low surface energies can also be converted into small-sized HIF NCs. For example, Zhou et al. [23] demonstrated that $10-\mathrm{nm}$ cubic $\mathrm{Pt} \mathrm{NCs}$ can be converted into THH Pt NCs with a size range of 6-20 nm, and as a result, electrocatalytic activity for ethanol oxidation enhanced considerably (Fig. 3d-f). Sub-10-nm THH Pt NCs supported on graphene were also obtained using $3 \mathrm{~nm}$ Pt NPs as seeds (Fig. 3g, h) [24]. These as-prepared small-sized THH Pt NCs exhibit higher mass activities than commercial Pt/C catalysts towards ethanol electrooxidation (Fig. 3i). In addition, these strategies are also valid for reshaping commercial $\mathrm{Pt} / \mathrm{C}$ to create high-index facets on the surface and thereby improve both mass activity and stability.

\subsection{Pt-Based Bimetallic Nanocatalysts}

Compared with pure Pt catalysts, Pt-based bimetallic NCs usually exhibit higher catalytic activity, more tolerance to poisoning species, and higher stability, resulting from electronic structures, third body effects, and bifunctional effects. Based on elemental distributions, bimetallic NCs can be categorized into two types: surface decoration and bulk alloy. Surface decoration can be achieved either by direct electrodeposition of target atoms with controlled coverage from a solution containing foreign metal ions, or by galvanic replacement of underpotential deposition (UPD) $\mathrm{Cu}$ monolayers with target metals. Previous results have demonstrated that the catalytic activity of THH Pt NCs decorated by adatoms can be significantly enhanced (i.e. Ru for methanol electrooxidation [25], and $\mathrm{Bi} / \mathrm{Au}$ towards formic acid electrooxidation) [26, 27]. Even for low-index covered Pt nanoparticles such as Pt cubes with $\{100\}$ facets, decoration with a $\mathrm{Sn}$ submonolayer significantly enhances catalytic activity for ethanol oxidation [28].

\subsubsection{Surface Modification of High-Index Faceted Nanocrystals}

The electrooxidation of formic acid on Pt is generally acknowledged to be through a dual path mechanism in which reactive intermediates are believed to be $-\mathrm{COOH}$, or HCOO-, and the poisoning intermediate to be $\mathrm{CO}$ [29]. Although the catalytic activity of pure THH Pt NCs is higher than commercial Pt/C, pure THH Pt NCs are prone to poisoning by $\mathrm{CO}$ at low potentials. Results from extended $\mathrm{Pt}$ single-crystal planes have revealed that $\mathrm{CO}$ formation requires an adjacent ensemble of several $\mathrm{Pt}$ surface atoms. Therefore, to effectively suppress $\mathrm{CO}$ formation, the amount of available adjacent ensembles needs to be decreased. Chen et al. [26] used Bi modifications to accomplish this and the resulting THH Pt NCs exhibited higher oxidation currents towards formic acid electrooxidation with the onset potential negatively shifting from 0.30 to $0.08 \mathrm{~V}$ (vs. SCE). These results provide concrete evidence of the disappearance of CO poisoning with high Bi coverage (Fig. 4d). In addition, durability was also significantly improved. Modified $\mathrm{Au}$ atoms on THH Pt NCs were also found to provide this promoting role in formic acid electrooxidation with increased activity and durability being observed [27].

\subsubsection{Alloy High-Index Faceted Nanocrystals}

Alloying is another strategy to tune catalyst reactivity by uniformly adding foreign atoms into the crystal lattice. Alloying elements can modify electronic structures by tuning the binding energies of adsorbed intermediates or by playing the role of bifunctional mechanisms. Therefore, by benefiting from the synergistic effects between surface structure and electronic structure, Pt-alloy NCs with HIFs possesses superior catalytic activity compared with pure THH Pt NCs.

Alloy nanoparticles can be deposited electrochemically either on indium-tin oxide (ITO) electrodes or glassy carbon (GC) electrodes. Sun et al. [33, 34] deposited concave TOH and $\mathrm{HOH}$ AuPd nanoparticles onto ITO electrodes in which the concave $\mathrm{TOH}$ and $\mathrm{HOH}$ AuPd nanoparticles obtained under SWP conditions displayed a similar lower potential of $0.3 \mathrm{~V}$ (vs. SCE) and different upper potentials of 0.64 and 

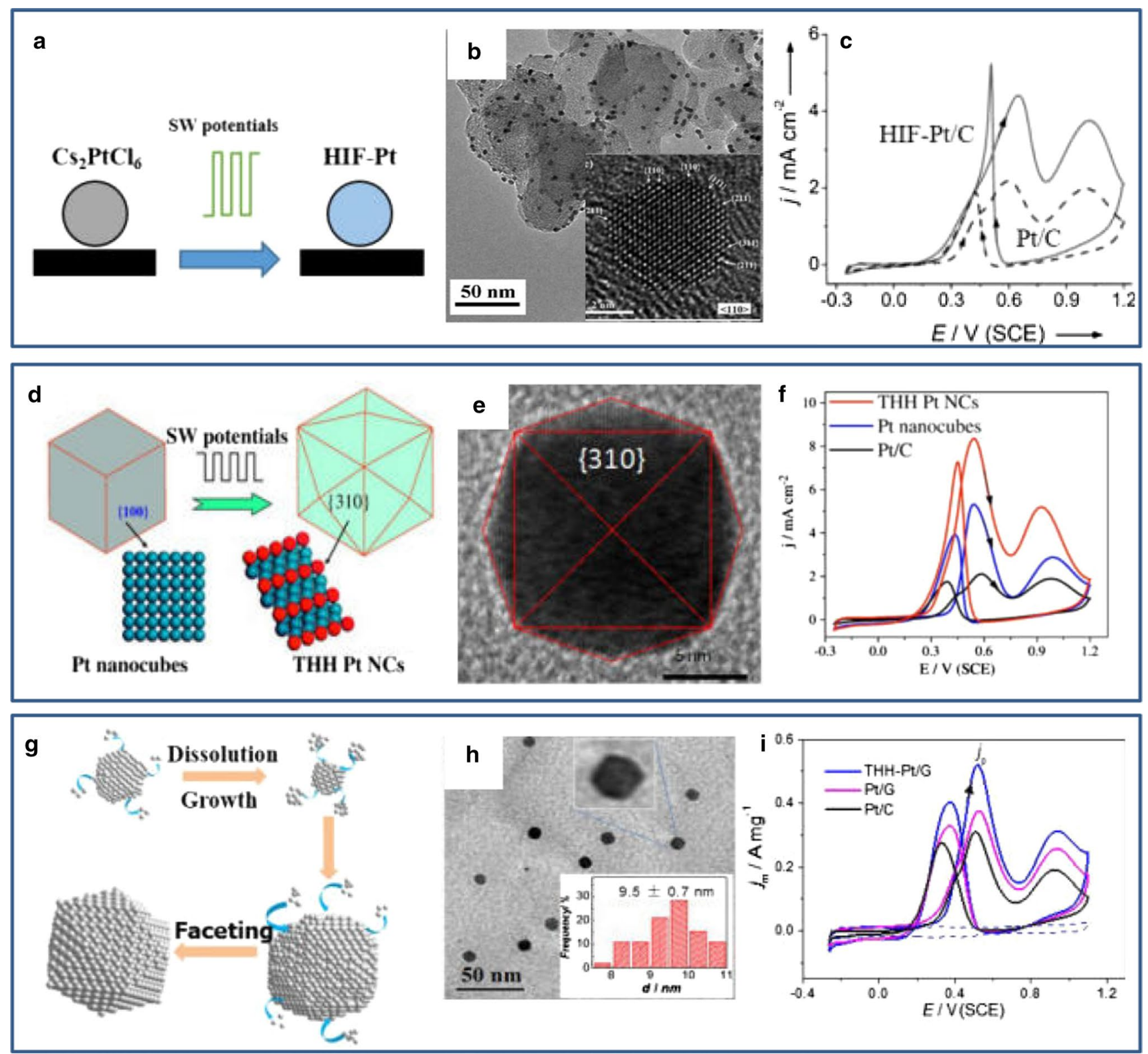

Fig. 3 a Illustration of the preparation of HIF Pt/C catalysts from $\mathrm{Cs}_{2} \mathrm{PtCl}_{6}$. b Low-magnification TEM image and aberration-corrected HRTEM image along the $<110>$ direction (inset) of $\mathrm{HIF} \mathrm{Pt/C}$ catalysts. c Cyclic voltammograms of $\mathrm{HIF} \mathrm{Pt} / \mathrm{C}$ and commercial $\mathrm{Pt} / \mathrm{C}$ for ethanol oxidation $\left(100 \mathrm{mV} \mathrm{s}^{-1}\right)$ [22]. d Illustration of the shape transformation from Pt nanocubes to THH Pt NCs. e High-magnification TEM images of THH Pt NCs. f Electrocatalytic properties of

$0.70 \mathrm{~V}$, respectively. Tian et al. [30] directly electrodeposited alloy THH $\mathrm{Pd}_{0.9} \mathrm{Pt}_{0.1} \mathrm{NCs}$ with $\{10,3,0\}$ facets on GC electrodes in a mixed solution of $\mathrm{PdCl}_{2}+\mathrm{K}_{2} \mathrm{PtCl}_{6}$ through the SWP method. Their results given in Fig. 4e showed the uniform elemental distribution of Pd and Pt with the exception of a slight edge enrichment of Pt. As for the formic acid electrooxidation on alloy THH PdPt NCs, the peak current density increased with increasing Pt content and
THH Pt NCs/CNTs, Pt nanocubes/CNTs, and commercial Pt/C for ethanol oxidation [23]. $\mathbf{g}$ Illustration of the growth processes of sub10-nm THH Pt NCs from Pt nanoparticles using an electrochemically seed-mediated method. $\mathbf{h}$ TEM images of sub-10-nm THH Pt NCs. i Cyclic voltammograms of $\mathrm{THH}-\mathrm{Pt} / \mathrm{G}, \mathrm{Pt} / \mathrm{G}$, and commercial $\mathrm{Pt} / \mathrm{C}$ at $10 \mathrm{mV} \mathrm{s}^{-1}$ in $0.1 \mathrm{M}$ ethanol $+0.1 \mathrm{M} \mathrm{HClO}_{4}[24]$

reached a maximum of $70 \mathrm{~mA} \mathrm{~cm}^{-2}$ at a Pt content of $10 \%$. This was 3.1 times higher than that of pure THH Pd NCs $\left(22.4 \mathrm{~mA} \mathrm{~cm}^{-2}\right)$ and 6.2 times higher than that of commercial Pd black (11.3 $\left.\mathrm{mA} \mathrm{cm}^{-2}\right)$ (Fig. 4f). Additionally, the peak potential for formic acid oxidation of THH PdPt-alloy NCs shifted negatively in comparison with Pd black, demonstrating large enhancements in catalytic activity at low potentials. Similarly, alloying with $\mathrm{Rh}$ is an effective method 

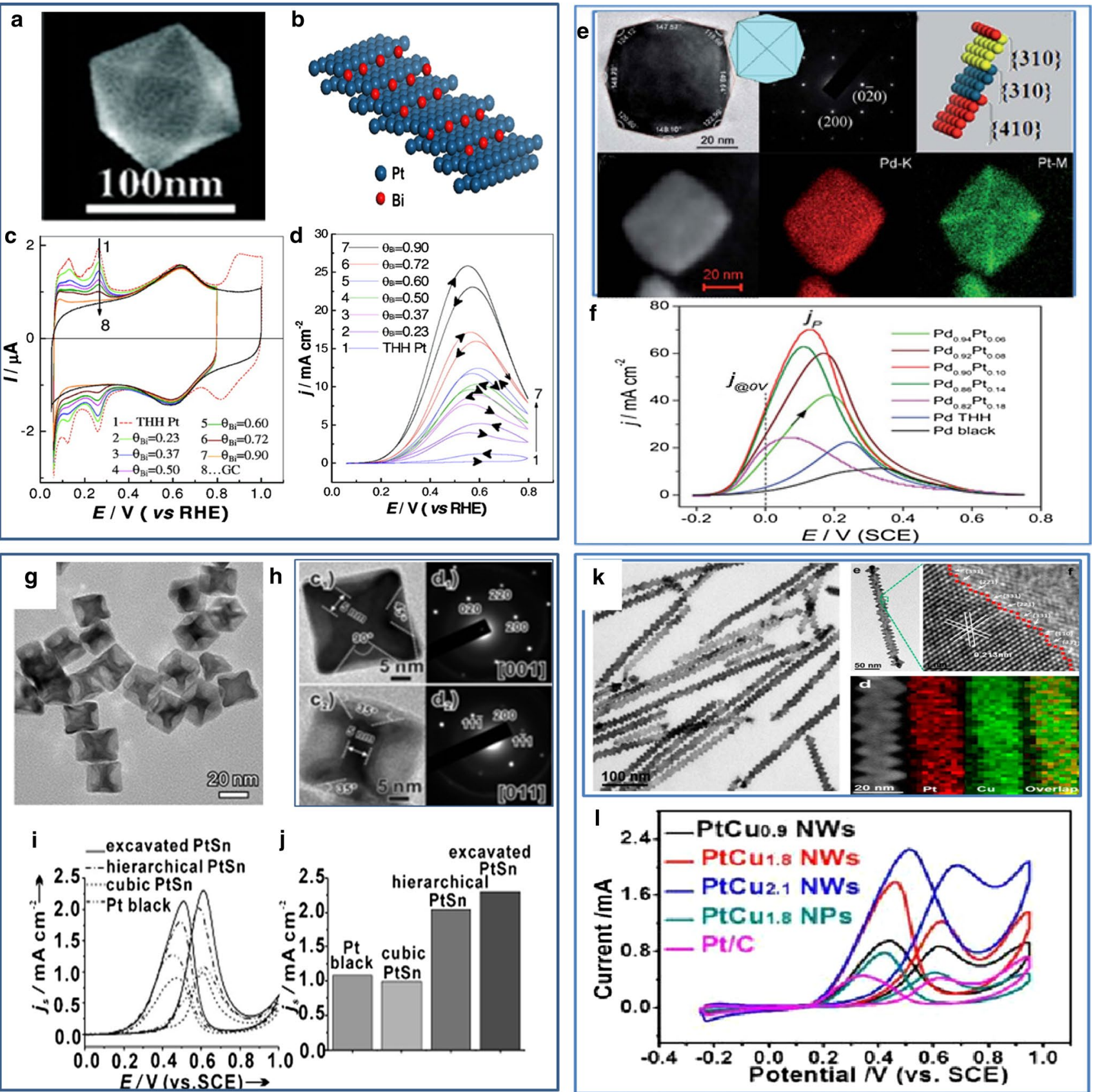

Fig. 4 a SEM images of individual THH Pt and $\mathbf{b}$ Model of Bi modified Pt $\{730\}$ surface. c Cyclic voltammograms of Pt THH NCs with different $\mathrm{Bi}$ coverages in $0.25 \mathrm{M}$ formic acid $+0.5 \mathrm{M} \mathrm{H}_{2} \mathrm{SO}_{4}$. d Comparison of electrocatalytic activity for formic acid oxidation on $\mathrm{Bi}$ modified THH Pt NCs with various Bi coverage [26]. e TEM image and SAED pattern of a $\mathrm{THH} \mathrm{Pd}_{0.9} \mathrm{Pt}_{0.1} \mathrm{NC}$ recorded along the [001] crystal zone with the atomic model, STEM image and EDS elemental mapping of Pd and Pt [30]. f Current-potential curves of THH PdPt NCs with different Pt content in $0.25 \mathrm{M}$ formic acid $+0.25 \mathrm{M}$ $\mathrm{HClO}_{4}$. g TEM images of excavated cubic Pt-Sn alloy NCs. h TEM images, corresponding SAED patterns, schematic models, and corresponding perspectives of excavated cubic $\mathrm{Pt}-\mathrm{Sn}$ alloy NCs projected along the [001] and [011] direction [31]. i CV curves measured with Pt-Sn alloy NCs and commercial Pt black towards methanol oxidation. $\mathbf{j}$ Comparison of the specific area activities of different catalysts towards methanol oxidation. $\mathbf{k}$ low-magnification TEM image, high-magnification TEM image, HAADF-STEM image and mapping image of $\mathrm{PtCu}_{1.8} \mathrm{NWs}$ [32]. I Electrocatalytic performance of commercial $\mathrm{Pt} / \mathrm{C}, \mathrm{PtCu}_{2.1} \mathrm{NWs}, \mathrm{PtCu}_{1.8} \mathrm{NWs}, \mathrm{PtCu}_{0.9} \mathrm{NWs}$, and $\mathrm{PtCu}_{1.8}$ NPs for methanol oxidation 
to enhance ethanol electrooxidation activity [2]. However, these alloy NPs are usually large, decreasing mass activity greatly, and the fabrication of small-sized alloy NPs with HIFs is a major challenge.

Concave NPs are usually bound with HIFs [35, 36]. Xie et al. [31] reported the synthesis of excavated cubic Pt-Sn alloy NCs which consist of ultrathin nanosheets with highenergy $\{110\}$ facets in the presence of PVP. The key factor in the formation of these excavated cubic alloy NCs is that PVP significantly changes the growth kinetics of Pt-Sn alloys. Because of its unique excavated structure, the surface area of the as-prepared $\mathrm{Pt}-\mathrm{Sn} \mathrm{NC}$ is comparable to that of commercial Pt black, although with apparent particle sizes of over $20 \mathrm{~nm}$. Owing to high-energy facets, large surface areas, and synergistic effects, the Pt-Sn alloy NCs exhibited very high electrocatalytic activities in terms of both specific area current density and mass current density towards methanol electrooxidation (Fig. 4i, j). Similarly, excavated rhombic dodecahedral (ERD) $\mathrm{PtCu}_{3}$ alloy NCs exposed by $\{110\}$ facets also exhibit excellent mass activity towards formic acid electrooxidation [37]. The long-term stability of these structures needs to be evaluated by MEA tests however.

As previously reported, established HIF NCs are usually large, greatly reducing mass activity. To take full advantage of HIFs in enhancing electrocatalysis, better nanostructures are required to allow for high surface areas and high-index facets. Zhang et al. [32] reported three-dimensional screw thread-like $\mathrm{Pt}-\mathrm{Cu}$ alloy nanowires (NWs) that possessed high densities of high-index facets and a controlled composition (Fig. 4k, 1). Their reported NWs also possessed a high surface area of $46.9 \mathrm{~m}^{2} \mathrm{~g}^{-1}$. And although this surface area is smaller than commercial $\mathrm{Pt} / \mathrm{C}\left(\sim 51 \mathrm{~m}^{2} \mathrm{~g}^{-1}\right)$, it much larger than other reported HIF NCs. This study provides a new strategy to maximize the electrocatalytic performance of NCs with high-index facets by optimizing structures.

\subsection{MEA Performance of High-Index Faceted Pt Nanoparticles}

As demonstrated above through electrochemical tests, $\mathrm{Pt}$ NCs with HIFs present high activity towards the electrooxidation of ethanol, methanol, and formic acid. However, there are few reports concerning MEA tests, which are important for fuel cell techniques. By carefully tuning the deposition conditions of SWP, Sun and coworkers [38] successfully synthesized THH and TPH Pt NCs with different sizes ranging from 40 to $200 \mathrm{~nm}$ supported on carbon paper directly, as illustrated in Fig. 5a-d. MEA tests were carried out in a direct formic acid fuel cell (DFAFC) by using the HIF Pt/C on carbon paper as the anode, which holds an ultralow $\mathrm{Pt}$ loading of $0.069 \mathrm{mg} \mathrm{cm}^{-2}$, and $3 \mathrm{~mol} \mathrm{~L}^{-1}$ formic acid as fuel. As shown in Fig. 5e-f, the maximum power density of this single cell was $10.6 \mathrm{~mW} \mathrm{~cm}^{-2}$ at $30{ }^{\circ} \mathrm{C}$, and $95 \%$ cell voltage was maintained after $50 \mathrm{~h}$ of testing at a current density of $20 \mathrm{~mA} \mathrm{~cm}{ }^{-2}$, demonstrating reasonable stability under the test conditions. Here, the Pt mass-normalized maximum power density was $153.5 \mathrm{~mW} \mathrm{mg}^{-1} \mathrm{Pt}$, which is 8.4 times higher than cells using commercial $60 \mathrm{wt} \% \mathrm{Pt} / \mathrm{C}$ as the anode catalyst ( $\mathrm{Pt}$ loading of $1 \mathrm{mg} \mathrm{cm}^{-2}$ ). It is evident that in order to further decrease Pt loading in MEAs and increase power density, three options can be applied: (1) minimize the size of the HIF Pt NCs; (2) disperse as much of the HIF Pt NCs as possible on the carbon paper; (3) add nonprecious metal elements into the Pt NCs without disrupting the high-index surface structure, creating HIF Pt-based alloy NCs as discussed in previous sections.

\subsection{Other Representative Pt-Based Anode Catalysts}

The main mechanisms for improving the activity and selectivity of nano-electrocatalysts are summarized by Strasser et al. [43]. In terms of structure, low-coordinated sites can facilitate catalytic reactions and act as active sites, highlighting the importance of NCs with HIFs. For multi-metallic catalysts, other mechanisms can contribute, such as geometric and ligand effects as well as interactions between NCs and support. Aside from these mechanisms, electrolytes, nanopores, and inter-particle distances are also crucial but often overlooked parameters that can be manipulated to control the diffusion and re-adsorption of reaction intermediates and, therefore, the reaction selectivity. Under electrochemical environments, it is especially important to consider the effects of electrolytes and ions in solution which can strongly adsorb on catalyst surfaces to alter surface structures and local environments.

\subsubsection{Intermetallic Alloys}

The commercialization of PEMFCs is hindered by the $\mathrm{CO}$ poisoning of $\mathrm{Pt}$ anodes. This is because industrial $\mathrm{H}_{2}$ fuels derive mainly from reformed hydrocarbons and such fuels contain trace $\mathrm{CO}$ impurities. To alleviate the $\mathrm{CO}$-poisoning effect in PEMFCs, three types of Pt-based bimetallic NPs can be used: (a) Pt-M random alloys (e.g. PtRu), (2) ordered intermetallics (e.g. PtBi), and (3) core-shell bimetallic (e.g. $\mathrm{Ru}$-core/Pt-shell (Ru@Pt)). However, there are few direct comparisons of these three structures in a specific $\mathrm{Pt}-\mathrm{M}$ alloy being conducted. A study conducted by Eichhorn et al. [39] prepared PtSn intermetallic NPs of $~ 3.5 \mathrm{~nm}$ through the co-reduction of $\mathrm{Pt}(\mathrm{acac})_{2}$ and $\mathrm{SnCl}_{4}$ in octadecene using $\mathrm{NaBEt}_{3} \mathrm{H}$ as the reductant. The results of TEM and XRD indicated that the as-prepared PtSn NPs were intermetallic (Fig. 6a). These PtSn intermetallic NPs were significantly more stable and possessed superior performances to $\mathrm{PtSn}$ alloy in acidic electrolyte solutions towards the electrooxidation of $\mathrm{CO} / \mathrm{H}_{2}$ mixtures (Fig. 6b). In addition, PtSn@Pt 
Fig. 5 SEM images of THH (a) and TPH (b) Pt NCs supported on carbon paper. THH (c) and HIF (d) Pt NPs on XC-72-modified carbon paper. e, $\mathbf{f}$ Comparison of direct formic acid fuel performance with different anode catalysts. Current was normalized by geometric area (e) and Pt mass (f) [38]
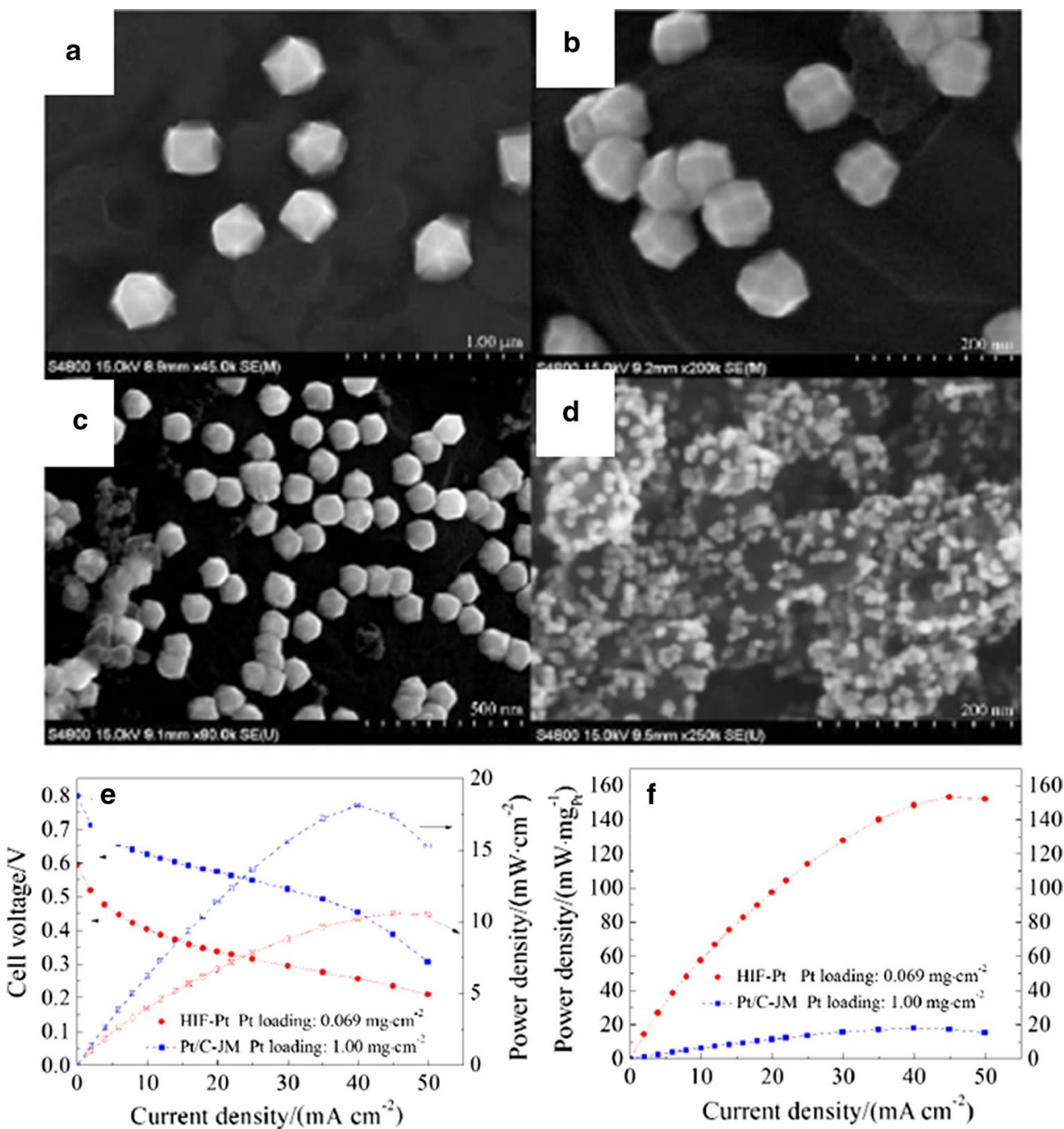

core-shell particles converted from PtSn intermetallics displayed significantly better CO tolerance than PtSn intermetallic NPs. Similarly, Kang et al. [44] also reported that their intermetallic $\mathrm{Pt}_{3} \mathrm{Zn}$ demonstrated better performance than alloy phased Pt-Zn towards methanol oxidation.

\subsubsection{Multi-metal Alloys}

Improving heteroatomic interactions through alloying enhances electrocatalytic activity and stability. However, Pt-based bimetallic alloys face limitations (e.g. Pt dissolution) in terms of compositional or structural stability under harsh conditions. Therefore, multi-metallic catalysts with stable and active components need to be developed through direct metal-metal interactions, linking component effects with well-defined surfaces to enhance activity and stability. Inspired by this issue, Yu et al. [40] designed quaternary PtPdRuTe nanotube (NTs) catalysts for MOR with low Pt content and tested their electrocatalytic performance. As quaternary Pt-based catalysts, each component of the NTs fulfils an important role in electrocatalysis (Fig. 6c): (1) Te atoms support NTs and minimize the loading of the other three precious metals; (2) $\mathrm{Pt}$ atoms serve as active sites for MOR; (3) oxyphilic Ru sites facilitate $\mathrm{CO}_{\mathrm{ad}}$ oxidation; and (4) $\mathrm{Pd}$ atoms promote $\mathrm{Pt}$ surface reactivity towards methanol oxidation. As illustrated in Fig. 6d, compared with ternary PtRuTe catalysts, the quaternary system demonstrates both enhanced catalytic activity and stability.

\subsubsection{Bifunctional Catalysts}

MOR using Pt progresses on two parallel paths: indirect $\mathrm{CO}$ poisoning and direct formate. The removal of $\mathrm{CO}$ intermediates requires $\mathrm{OH}_{\mathrm{ad}}$ which is generated at potentials higher than $0.6 \mathrm{~V}$ (vs. RHE). And because MOR reactions occur at $0.3-0.5 \mathrm{~V}$ in DMFCs, pure Pt catalysts become heavily poisoned by $\mathrm{CO}$. In this sense, alloying Pt with a more active metal to create a bifunctional catalyst to provide reactive $\mathrm{OH}_{\mathrm{ad}}$ at lower potentials is an effective strategy to enhance MOR kinetics. PtRu bimetallic catalysts are an example of 

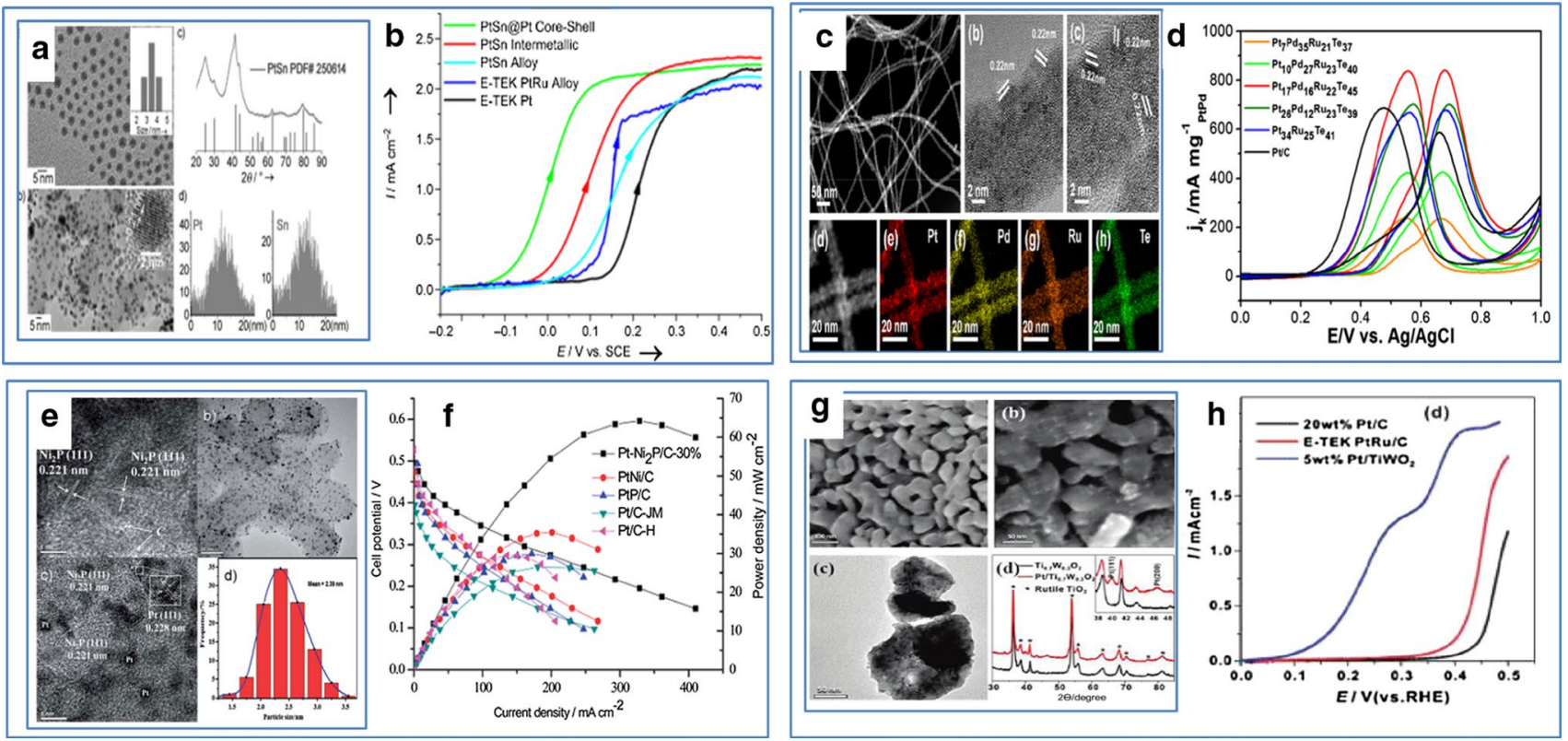

Fig. 6 a TEM image of Pt-Sn intermetallic NP and carbon-supported Pt-Sn, XRD profile and TEM-EDX line scan of Pt-Sn intermetallic NP. b Polarization curves for the electrooxidation of $\mathrm{CO} / \mathrm{H}_{2}$ mixtures (1000 ppm CO, balance $\mathrm{H}_{2}$ ) on different Pt-Sn catalysts with E-TEK $\mathrm{Pt}$ and $\mathrm{PtRu}$ catalysts as comparison [39]. c Morphology characterization and mapping of $\mathrm{Pt}_{17} \mathrm{Pd}_{16} \mathrm{Ru}_{22} \mathrm{Te}_{45}$ NTs. d CV curves of PtPdRuTe NTs, PtRuTe NTs, and Pt/C catalysts for MOR [40]. e TEM

this strategy. However, due to the high price and scarcity of $\mathrm{Ru}$, finding earth-abundant and non-precious co-catalysts to replace $\mathrm{Ru}$ is necessary and several metal oxides and phosphides have been tested to promote the activity of $\mathrm{Pt}$ in methanol oxidation. Xing et al. [41] showed that $\mathrm{Ni}_{2} \mathrm{P}$ nanoparticles are excellent promoters for Pt-catalysed methanol oxidation and provide significantly higher catalytic currents. The $\mathrm{Ni}_{2} \mathrm{P}$ nanoparticles can be identified by a finger lattice of $0.221 \mathrm{~nm}$ corresponding to its (111) lattice and the average size of the catalyst is roughly $2.4 \mathrm{~nm}$ (Fig. 6e). A DMFC using $\mathrm{Pt}-\mathrm{Ni}_{2} \mathrm{P} / \mathrm{C}-30 \%$ as its anode catalyst exhibited a maximum power density of $65 \mathrm{~mW} \mathrm{~cm}$, which is more than twice of that of an analogous fuel cell using $\mathrm{Pt} / \mathrm{C}$ as the anode catalyst (Fig. 6f). This work is a significant step towards the development of more active and practical catalysts for DMFC. However, the long-term stability of such non-precious co-catalysts under real fuel cell operating conditions remains unclear.

\subsubsection{Support Effects}

Strong metal-support interactions are used to describe the contributions of the support to the multifunctional reaction mechanisms, in which the support can adsorb one or more reactants or allow for the spillover of activated intermediates to secondary sites. Strong interactions between $\mathrm{Pt}$

and HRTEM images of a $\mathrm{Pt}-\mathrm{Ni}_{2} \mathrm{P} / \mathrm{C}-30 \%$ sample. f Steady-state polarization and power-density curves for DMFC employing $\mathrm{Pt}-$ $\mathrm{Ni}_{2} \mathrm{P} / \mathrm{C}-30 \%, \mathrm{Pt}-\mathrm{Ni} / \mathrm{C}, \mathrm{Pt}-\mathrm{P} / \mathrm{C}, \mathrm{Pt} / \mathrm{C}-\mathrm{JM}$ and $\mathrm{Pt} / \mathrm{C}-\mathrm{H}$ as anode catalysts [41]. g SEM, TEM, and XRD patterns of $\mathrm{Ti}_{0.7} \mathrm{~W}_{0.3} \mathrm{O}_{2}$ and $\mathrm{Pt} /$ $\mathrm{Ti}_{0.7} \mathrm{~W}_{0.3} \mathrm{O}_{2}$. h Polarization curves for $\mathrm{H}_{2}$ oxidation on different catalysts in the presence of $2 \% \mathrm{CO}$ at room temperature [42]

electrocatalysts and support materials have the potential to increase electrocatalytic activity and stability. Wang et al. [42] studied the synthesis and characterization of nanoparticles of Pt supported on conducting $\mathrm{Ti}_{0.7} \mathrm{~W}_{0.3} \mathrm{O}_{2}$ and the corresponding unique $\mathrm{CO}$-tolerant electrocatalytic activities. In their study, the uniform distribution of Pt nanoparticles was verified using TEM imaging and XRD (Fig. 6g), and the diffraction peaks of $\mathrm{Ti}_{0.7} \mathrm{~W}_{0.3} \mathrm{O}_{2}$ can be completely indexed to a tetragonal unit cell, shifted slightly from that of pure rutile- $\mathrm{TiO}_{2}$ due to $\mathrm{W}$ doping. Here, $\mathrm{Pt} / \mathrm{Ti}_{0.7} \mathrm{~W}_{0.3} \mathrm{O}_{2}$ exhibited the lowest onset potential for $\mathrm{H}_{2}$ oxidation (ca. $0.05 \mathrm{~V}$ vs. $\mathrm{RHE})$ relative to both $\mathrm{Pt} / \mathrm{C}$ and $\mathrm{PtRu} / \mathrm{C}$, with the latter two exhibiting onset potentials over $0.30 \mathrm{~V}$ (Fig. $6 \mathrm{~h}$ ). This promoting effect by $\mathrm{Ti}_{0.7} \mathrm{~W}_{0.3} \mathrm{O}_{2}$ supports have not been evaluated by MEA tests however.

\section{Pt-Based ORR Electrocatalysts}

Compared with anode reactions in fuel cells, cathodic oxygen reduction reactions are more challenging due to severely sluggish kinetics. For example, in fuel cells, Pt loading remains as high as $0.4 \mathrm{mg} \mathrm{cm}^{-2}$ on cathodes, whereas $\mathrm{Pt}$ loading can drop to $0.05 \mathrm{mg} \mathrm{cm}^{-2}$ on anodes [45]. Therefore, ORR is the main obstacle to achieving desired performance, and is responsible for most observed overpotentials. 
Accordingly, enormous efforts have been devoted to the improvement of ORR catalyst performance beyond that of current state-of-the-art Pt/C. A more active catalyst can reduce energy loss and decrease precious metal loading with ideal catalysts being made from more abundant elements, consisting of no Pt. Recently, many non-precious metals stabilized in non-metallic forms, such as metalorganic complexes, enzymes, oxides or $\mathrm{N}$-doped graphene-based materials, have being tested and have been found to possess catalytic activities close to or even better than Pt. However, these materials suffer from poor stability cause by the acidic and oxidative environments of PEMFCs. Furthermore, the active site densities of these materials are much lower than Pt. The following sections will review recent developments in ORR catalysts, focusing on both Pt-based alloy and carbon-based non-precious metal electrocatalysts.

Given the challenges, most efforts in relation to ORR catalysis have been focused on improving Pt activity, which can be achieved by tuning surface structure effects of ORR on Pt. Inspired by results of model catalysts, many efforts are being devoted to engineering new Pt surface structures to improve ORR activity.

\subsection{Model Pt-Based Surfaces}

Model catalyst surfaces can link the understanding of microscopic surface processes with the macroscopic measurements of kinetic rates of electrochemical reactions, avoiding trial-and-error research. In the context of ORR, several types of model surfaces have been developed, including Pt single-crystal electrodes [46, 49-51], Pt skin surfaces [8], Pt monolayers [52, 53], and near-surface alloys [54]. Through results obtained using these surfaces, researchers have gained important insights into ORR: (1) kinetics of ORR is sensitive to atomic arrangements, (2) composition of the topmost surface atomic layer can greatly affect ORR kinetics, and (3) chemical properties of the surface can be tuned by strain and ligand effects.

\subsubsection{Pt Single-Crystal Electrodes}

ORR rates of $\mathrm{Pt}$ single-crystal planes $[\mathrm{Pt}(\mathrm{hkl})]$ are well known to be structure dependent. As shown in Fig. 7a, through the systematic investigation of a series of Pt highindex surfaces, Feliu et al. concluded that ORR activities generally increased with increasing step densities (or decreasing terrace widths) on high-index planes with the exception of (110)-(111) surfaces in acidic environments [46]. In contrast, stepped surfaces are less active than smooth $\mathrm{Pt}(111)$ surfaces in alkaline environments [51]. There is also disagreement on the role of undercoordinated sites in ORR resulting from contradicting data between Pt single-crystal planes and theoretical evidence. Recently, Bandarenka et al. provided a reasonable explanation in which concave defects of stepped surfaces are very active for ORR, whereas convex defects are inactive. And based on these results, many new active ORR catalysts have been fabricated. More importantly, because of these single-crystal electrochemistry
Fig. 7 a ORR polarization curves of select $\mathrm{Pt}(\mathrm{hkl})$ electrodes of the [11 0 ] zone in $0.5 \mathrm{M} \mathrm{H}_{2} \mathrm{SO}_{4}$ [46]. b ORR polarization curves in electrolytes with various cations [47]. c Influence of the surface morphology and electronic surface properties on the kinetics of ORR on $\mathrm{Pt}_{3} \mathrm{Ni}(\mathrm{hkl})$ surfaces [8]. d Kinetic current density at $0.9 \mathrm{~V}$ on polycrystalline $\mathrm{Pt}_{5} \mathrm{M}$ electrocatalysts versus the lattice parameter of bulk $\mathrm{Pt}_{5} \mathrm{M}$ (lower axis) and bulk Pt-Pt (upper axis) [48]
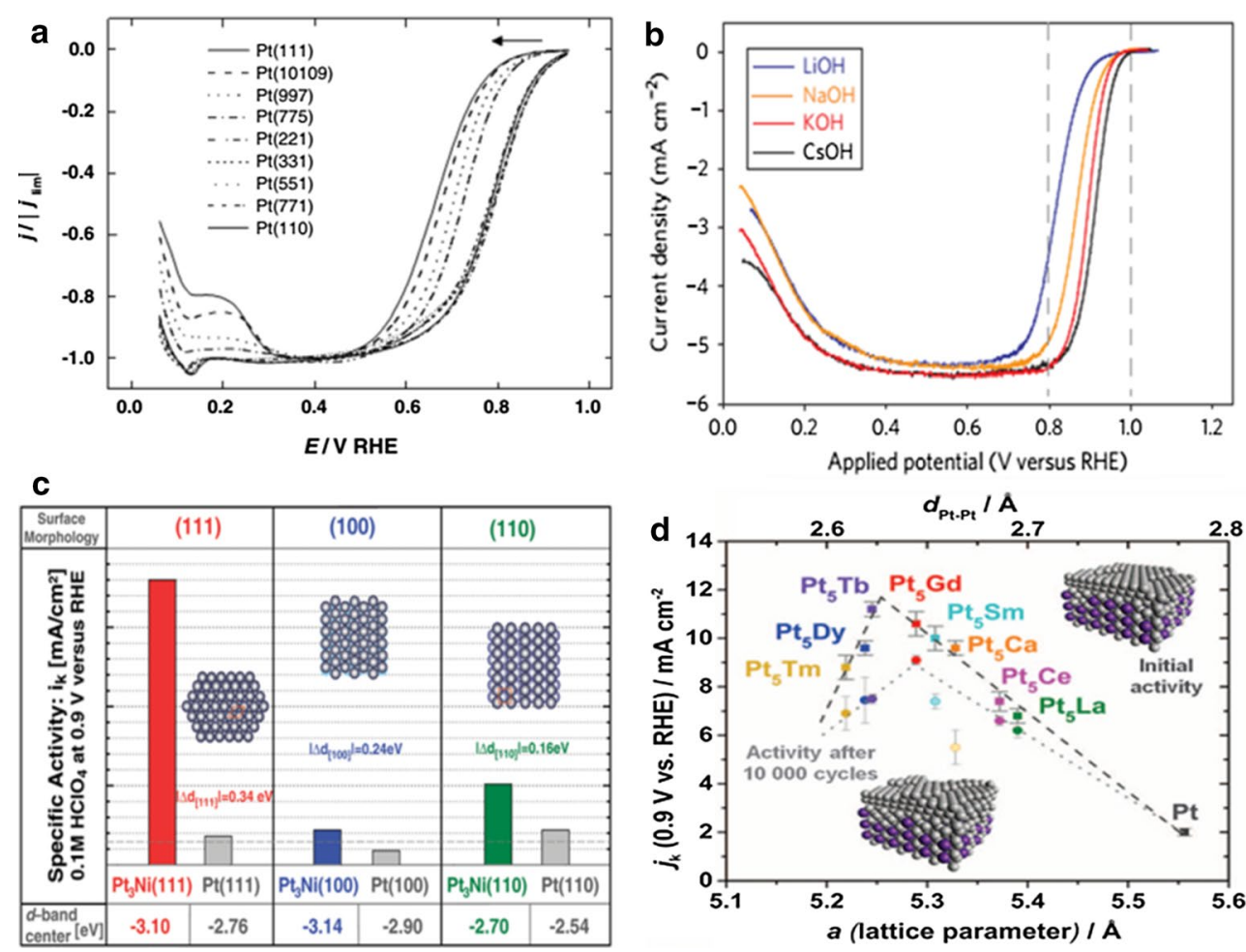
studies, the direction of contemporary electrocatalysis has recognized that the science of electrode processes goes well beyond the design and synthesis of materials. Aside from electrode materials, Markovic et al. revealed in their study that electrolytes also have great influence on the reaction rates of ORR (Fig. 7b). This discovery paved new directions beyond the current generation of materials and electrolytes.

\subsubsection{Pt Monolayer}

Compared with bulk $\mathrm{Pt}$, all $\mathrm{Pt}$ atoms of $\mathrm{Pt}$ monolayers are on the surface and thus can be completely utilized [55]. Therefore, Pt monolayer approaches can maximize Pt utilization efficiency. By changing the substrate, the activity of Pt monolayers can be tuned through strain and ligand effects [52]. For example, $\mathrm{Pt}_{\mathrm{ML}} / \mathrm{Pd}(111)$ is more active than $\mathrm{Pt}(111)$ towards ORR. To mimic the bulk surface, Adzic et al. developed $\mathrm{Pd} @ \mathrm{Pt}_{\mathrm{ML}}$ nanocatalysts with a monolayer Pt on Pd nanoparticles possessing very attractive qualities for practical applications. Similarly, other types of Pt monolayer nanocatalysts have been developed [56-62].

\subsubsection{Pt Skin}

Pt skins can be obtained by the thermal annealing-induced segregation of a pure Pt atomic layer on top of an alloying metal-rich second layer. The unique near-surface structure of Pt skins exhibits an unusual electronic structure (d-band centre position), showing weakened interactions between Pt surface atoms and oxygenated species, thus increasing ORR activity [63, 64]. This structure is also effectively stable in the potential region of ORR. Here, the ORR activity increases in the order of $\mathrm{Pt}<\mathrm{Pt}$ skeleton $<\mathrm{Pt}$ skin, in accordance with the order of weakening $\mathrm{OH}$ adsorption on Pt [65]. Stimulated by atomic arrangement effects and electronic structure effects, $\mathrm{Pt}_{3} \mathrm{Ni}(111)$ skins exhibit the highest ORR activity among $\mathrm{Pt}_{3} \mathrm{Ni}(111), \mathrm{Pt}_{3} \mathrm{Ni}(100)$, and $\mathrm{Pt}_{3} \mathrm{Ni}(110)$, as illustrated in Fig. $7 \mathrm{c}$ [8].

\subsubsection{Pt-Early Transition Metal Alloy}

Recently, Chorkendorf et al. [48] reported that Pt-lanthanide and Pt-alkaline earth metal electrodes can present enhanced ORR activity by a factor of 3-6 over Pt, with ORR activity versus bulk lattice parameter following a high peaked "volcano" relation. The researchers discovered in their study that the strain effort can weaken the binding of $\mathrm{H}$ and $\mathrm{OH}$ species on the catalyst surface, and enthalpy contributions can help to stabilize these Pt alloys under operating conditions.

\subsection{Pt-Based Nanoparticles Towards ORR}

Studies of model surfaces help in identifying structural sensitivities of catalytic reactions and provide guidelines for

Table 1 List of reported ORR activities for up-to-date Pt-based alloy nanocatalysts

\begin{tabular}{|c|c|c|c|c|}
\hline Composition & $\begin{array}{l}\text { SA at } 0.90 \mathrm{~V} \\
\left(\mathrm{~mA} \mathrm{~cm}^{-2}\right)\end{array}$ & $\begin{array}{l}\text { MA at } \\
0.90 \mathrm{~V} /(\mathrm{mA} \\
\left.\mu \mathrm{g}_{\mathrm{Pt}}^{-1}\right)\end{array}$ & Stability & References \\
\hline $\mathrm{Pt}_{3} \mathrm{Ni}$ nanoframes & - & 5.7 & Negligible, $0.6-1.0 \mathrm{~V}, 10 \mathrm{k}$ cycles & [69] \\
\hline $\mathrm{Mo}-\mathrm{Pt}_{3} \mathrm{Ni} / \mathrm{C}$ & 8.2 & 6.98 & $-5.5 \%, 0.6-1.1 \mathrm{~V}, 8 \mathrm{k}$ cycles & {$[67]$} \\
\hline 1D PtNi/C & 9.2 & 4.15 & $-4.6 \%, 0.6-1.1 \mathrm{~V}, 8 \mathrm{k}$ cycles & [74] \\
\hline $1 \mathrm{D} \mathrm{Pt}_{3} \mathrm{Co} / \mathrm{C}$ & 7.12 & 3.17 & $-8.1 \%, 0.6-1.1 \mathrm{~V}, 8 \mathrm{k}$ cycles & {$[75]$} \\
\hline Octahedral Pd@ $\mathrm{Pt}_{1.8} \mathrm{Ni} / \mathrm{C}$ & $\sim 0.48$ & 0.79 & - & [76] \\
\hline Octahedral Rh-Doped Pt-Ni/C & $\sim 2.7$ & 0.82 & $-12 \%, 0.6-1.1 \mathrm{~V}, 8 \mathrm{k}$ cycles & [77] \\
\hline Octahedral Pt-Ni/C & 3.4 & 3.3 & $-40 \%, 0.65-1.0 \mathrm{~V}, 5 \mathrm{k}$ cycles & [78] \\
\hline Tetrahexahedral Pt-Ni Nanoframes/C & 6.37 & 2.95 & - & [79] \\
\hline $\mathrm{PtNiN} / \mathrm{C}$ & 1.65 & 0.86 & $11 \mathrm{mV}$ loss in its half wave potential, $0.6-1.05 \mathrm{~V}, 35 \mathrm{k}$ cycles & {$[62]$} \\
\hline Ordered- $\mathrm{Pt}{ }_{3} \mathrm{Cr} / \mathrm{C}$ & 1.23 & 0.043 & - & {$[80]$} \\
\hline Ordered $\mathrm{Pt}_{3} \mathrm{Co} / \mathrm{C}$ & 1.1 & - & $10 \mathrm{mV}$ loss in its half wave potential, $0.05-1.0 \mathrm{~V}, 5 \mathrm{k}$ cycles & {$[81]$} \\
\hline Octahedral PtNi/C & 3.14 & 1.45 & - & {$[82]$} \\
\hline Octahedral $\mathrm{Pt}_{1.5} \mathrm{Ni} / \mathrm{C}$ & 3.99 & 1.96 & $-51 \%$ loss, $0.6-1.0 \mathrm{~V}, 4 \mathrm{k}$ cycles & {$[83]$} \\
\hline fct-PtFe/C & 2.3 & 1.6 & Negligible, $0.6-1.0 \mathrm{~V}, 10 \mathrm{k}$ cycles & {$[84]$} \\
\hline Pt octahedral nanocages/C & 1.98 & 0.75 & $-36 \%, 0.6-1.0 \mathrm{~V}, 10 \mathrm{k}$ cycles & {$[70]$} \\
\hline Concave decahedral Pd@Pt & 1.66 & 1.6 & $-57 \%, 0.6-1.0 \mathrm{~V}, 10 \mathrm{k}$ cycles & {$[85]$} \\
\hline $\mathrm{Au} @ \mathrm{Ni}_{2} \mathrm{Pt}_{2} / \mathrm{C}$ & $\sim 0.57$ & 0.445 & Within $-10 \%, 0.6-1.0 \mathrm{~V}, 10 \mathrm{k}$ cycles & {$[86]$} \\
\hline jagged $\mathrm{Pt}$ nanowires/C & 11.5 & 13.6 & $-12 \%, 0.6-1.0 \mathrm{~V}, 6 \mathrm{k}$ cycles & [71] \\
\hline $\mathrm{PtPb} / \mathrm{Pt} / \mathrm{C}$ core/shell nanoplate & 7.8 & 4.3 & $-7.7 \%, 0.6-1.1 \mathrm{~V}, 50 \mathrm{k}$ cycles & {$[72]$} \\
\hline
\end{tabular}


nanocatalyst design. In recent years, growing attention has been focused on Pt-based nanostructured electrocatalysts with high performance towards ORR (Table 1). The following sections will introduce several typical high activity ORR catalysts.

\subsubsection{Core-Shell Structure}

Core-shell structure, i.e. Pt overlayers coated on foreign metal nanoparticles, is an effective method to improve the ORR activity and stability of Pt-based catalysts, and many bimetallic core-shell Pt-based catalysts demonstrate high ORR activity.

For the synthesis of these Pt-based core-shell nanoparticles, Strasser et al. provided a summary of preparation approaches, including electrochemical dealloying, (electro) chemical leaching, absorbate/thermal-induced segregation, sequential deposition and galvanic displacement using $\mathrm{Cu}$ UPD methods. Among these methods, the Pt monolayer nanoparticles developed by Adzic et al. should be highlighted [66]. As shown in Fig. 8a, their $\mathrm{Pt}_{\mathrm{ML}} / \mathrm{Pd} / \mathrm{C}$ possesses a $\mathrm{Pt}$ monolayer shell and a Pd nanoparticle core. This structure can facilitate superior fuel cell activity and durability. Strikingly, a dramatic increase in stability is also observed through the simple alloying of the core with $\mathrm{Au}$, facilitating 200,000 potential cycles between 0.6 and $1.0 \mathrm{~V}$.

\subsubsection{Facet-Controlled (111) Surface}

Inspired by the results of extended surfaces, especially the superior ORR activity of extended $\mathrm{Pt}_{3} \mathrm{Ni}$-skin (111) surfaces [8], many researchers have turned their attention to the fabrication of well-defined nanoparticles bound with (111) surface.

To mimic $\mathrm{Pt}_{3} \mathrm{Ni}(111)$ single crystals that show extremely high ORR activity, octahedral and icosahedral Pt-based nanostructures enclosed by $\{111\}$ facets have been studied [78, 82, 87-90]. The impressive performance evolution of shaped PtNi nanoparticles in the past 5 years has been summarized by Strasser et al. [43], and show enormous improvements in ORR activity. One representative work is presented in Fig. $8 \mathrm{~b}$ in which Huang et al. prepared Mo-doped $\mathrm{Pt}_{3} \mathrm{Ni}$ nano-octahedra with record-breaking activities, displaying 81- and 73-fold enhancements in specific and mass activity for ORR, respectively, as compared with commercial Pt/C catalysts.

\subsubsection{Nanostructure Thin Films}

$3 \mathrm{M}$ has recently developed a promising class of support-free catalysts, i.e. nanostructure thin films (Fig. 8c) [68]. After slow annealing under $400{ }^{\circ} \mathrm{C}$ in a reductive atmosphere, the highly corrugated surface of the catalyst can be smoothened and the nanostructure thin films can be transformed into mesostructure thin films. This process is similar to that of sputtered/annealed PtNi thin films on glassy carbon. Unlike carbon-supported Pt-based nanoparticles suffering from the severe loss of electrochemical active surface areas (ECSA), the mesostructure thin film preserves a relatively high ECSA. The meso-TF therefore is both highly active and durable for ORR catalysis. However, this high activity along with the thinness of the film can cause cathode water flooding in MEAs, resulting in largely reduced limiting currents. For this reason, a new water management strategy has been developed to alleviate this problem. Other support-free catalysts have been developed by other groups as well [91, 92].

\subsubsection{Hollow Structure}

Generally, there are two strategies to increase the utilization of Pt: reducing particle size or using a hollow structure. By reducing particle size, the proportion of surface atoms can increase. However, in the context of such small-size nanoparticles, the optimization of specific activity along with the avoidance of sintering and aggregation during catalytic reactions remains challenging. In hollow structures, catalytic reactions can take place on both the outer and inner surface, increasing reaction rates and Pt utilization. Moreover, because of the relatively large size of hollow structures, catalyst sintering can be greatly suppressed.

One of these hollow structure nanocatalysts towards ORR is the highly crystalline $\mathrm{Pt}_{3} \mathrm{Ni}$ nanoframes reported by Yang et al. [69]. As illustrated in Fig. 8d, these nanoframes exhibited an extraordinary mass activity of $5.7 \mathrm{~A} \mathrm{mg}^{-1} \mathrm{Pt}$ at $0.9 \mathrm{~V}$. This is more than 10 times greater than that of the U.S. DOE 2020 target $\left(0.44 \mathrm{~A} \mathrm{mg}^{-1} \mathrm{Pt}\right)$. Another notable example is Pt cubic and octahedral nanocages with subnanometer-thick walls, as shown in Fig. 8e, exhibiting distinctive catalytic activities towards ORR [70].

\subsubsection{D Structure with High-Index Facets}

In the search for high-performance electrocatalysts, onedimensional (1D) Pt-alloy nanostructures represent a promising direction for advanced catalysts because these nanostructures possess multiple advantages, such as inherent anisotropic morphology, high flexibility, high surface area, and high conductivity, in comparison with their 0D counterparts. These advantages allow for more effective ORR activity and durability than traditional Pt-alloy NPs. However, conventional large-diameter PtM-based NWs with smooth surfaces (lacking strong electron effect) are not suitable for creating more active sites to maximize electrocatalytic performance, and ultrathin PtM NWs are limited by poor durability. Therefore, the main issue of PtM NWs for ORR is the trade-off between activity and durability, making 

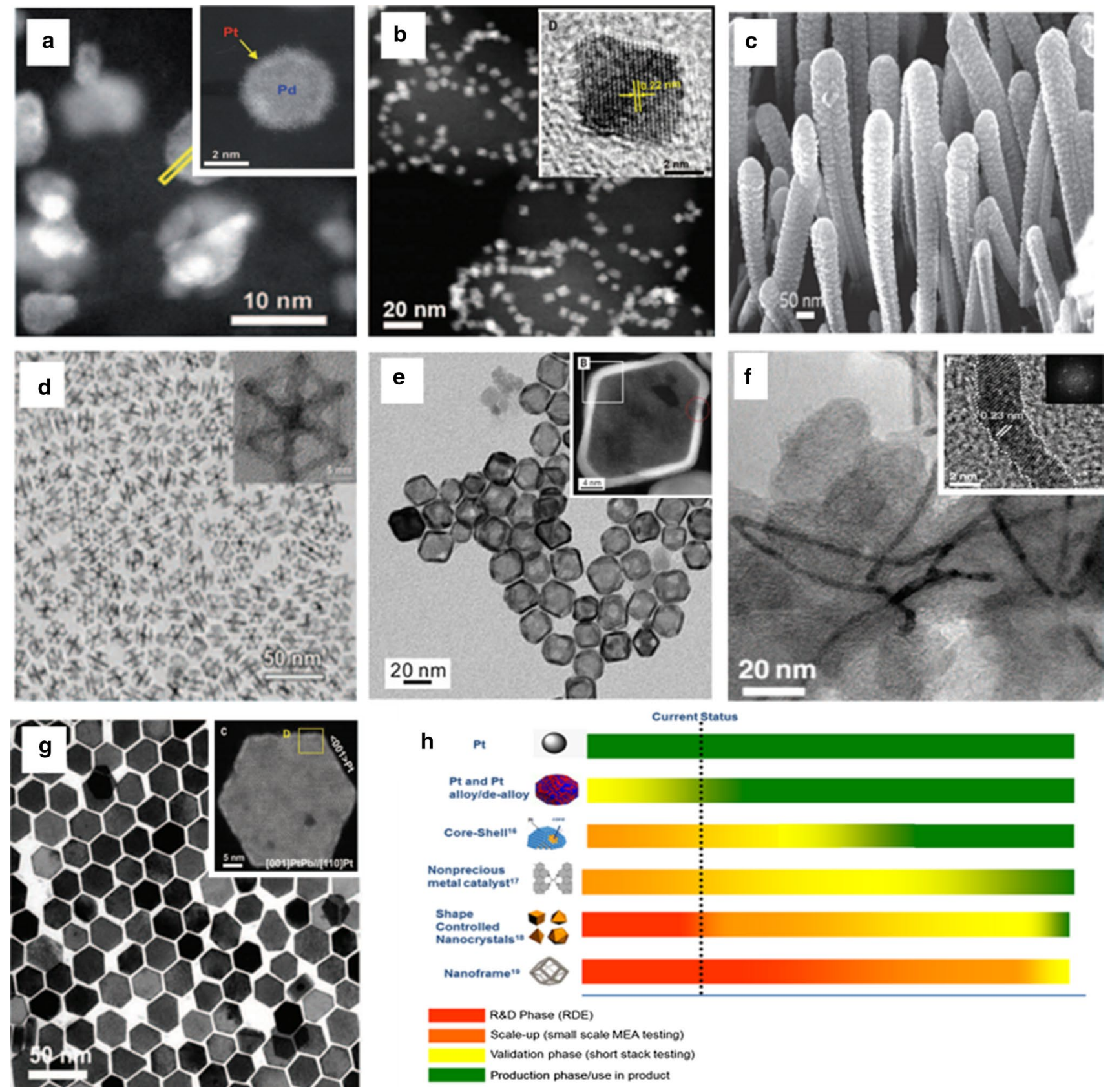

Fig. 8 a HAADF images of a sample of Pt monolayer shell on a Pd core nanoparticle [66]. b HAADF-STEM images of a $\mathrm{Mo}-\mathrm{Pt}_{3} \mathrm{Ni} / \mathrm{C}$ catalyst [67]. c SEM image of NSTF whiskers [68]. d TEM images of $\mathrm{Pt}_{3} \mathrm{Ni}$ nanoframes [69]. e TEM image of $\mathrm{Pt}$ octahedral nanocages and HAADF-STEM image of an individual nanocage [70]. f HRTEM

them impractical for fuel cell devices. In this regard, creating a new class of PtM NWs with high Pt utilization, catalytic activity, and durability is highly desirable, but remains a great challenge $[74,75,93]$. One representative work in this field was conducted by Li et al. [71]. In their work, $\mathrm{Pt} / \mathrm{NiO}$ core/shell nanowires were first synthesized using wet chemistry method followed by thermal annealing images of jagged Pt NWs supported on carbon [71]. $\mathbf{g}$ TEM image of $\mathrm{PtPb}$ hexagonal nanoplates and inset is a HAADF-STEM image of an individual nanoplate [72]. h Development timelines for Pt, Pt alloy/ de-alloy, core-shell, non-precious metal, shape-controlled, and nanoframe ORR electrocatalysts [73]

and electrochemical dealloying, as shown in Fig. 8f. The obtained jagged Pt nanowires possess ECSAs as high as $118 \mathrm{~m}^{2} \mathrm{~g}_{\mathrm{Pt}}^{-1}$, an area-specific ORR activity of $11.5 \mathrm{~mA} \mathrm{~cm}^{-2}$ and a mass ORR activity of $13.6 \mathrm{~A} \mathrm{mg}_{\mathrm{Pt}}^{-1}$ at $0.9 \mathrm{~V}$. The highly stressed, undercoordinated rhombohedral-rich surface configuration of the jagged nanowires was thought to greatly contribute to the enhanced ORR activity. 
$\mathrm{PtPb} / \mathrm{Pt}$ nanoplates were reported by Huang et al. to address the complexity of nanomaterials. Although compressive surface strains are known to boost ORR activity in core-shell structural nanocatalysts, whereas tensile strains impede ORR activity; $\mathrm{PtPb} / \mathrm{Pt}$ nanoplates, with its superior performance, was found to not follow this trend because $\mathrm{Pb}$ atoms are larger than $\mathrm{Pt}$ atoms and should, therefore, exert tensile strain. TEM results in Fig. $8 \mathrm{~g}$ reveal that the strain in $\mathrm{PtPb} / \mathrm{Pt}$ nanoplates is anisotropic in which Top-Pt layers were fully coherent to the $\mathrm{PtPb}$ core, with an $11 \%$ compressive strain along the $[01 \overline{1}] \mathrm{Pt}$ and a $7.5 \%$ tensile strain along [100] Pt; whereas in the edge-Pt layer, the [001] direction of $\mathrm{Pt}$ was fully confined within $\mathrm{PtPb}$, resulting in a $7.5 \%$ tensile strain and small compressive strain (1.0\%) along [110] Pt. This finding is somewhat analogous to alloying Pt with rare earth metals. These results highlight that atomic element distribution has great influences on ORR activity and atomic fine fabrication of catalysts is needed.

Although these advanced Pt-based alloy nanocatalysts; as depicted in Fig. 8h [73], have displayed highly promising performances in rotating disc electrode (RDE) tests, little has been published on their performances in MEA tests. Therefore, merits and limitations should be explored with MEA tests. Unfortunately, some MEA testing performed at General Motors have already indicated that some of these shape-controlled catalysts (e.g. octahedral PtNi) are quite unstable in MEAs, thus emphasizing the need for further MEA evaluations [4].

The results obtained from extended surfaces clearly indicate that the electrocatalytic activity of $\mathrm{Pt}$ is structuresensitive [12, 46, 49], such as stepped surfaces possessing higher activity towards electrooxidation of small organic molecules and ORR than flat low-index planes. Generally, commercial nanoparticle catalysts consist of mixed facets, edges, corners, and other defects. By contrast, shape-controlled nanocrystals should ideally be only bound by highly active facets, with numerous literature reporting nanocrystal catalysts with both well-defined shapes and superior activity. However, these shape-controlled NCs cannot yet replace commercial fine nanoparticle catalysts due to unsatisfactory MEA performances [73]. The future development of shape-controlled NCs faces two issues: (1) how to reduce nanocrystal size and stabilize high-active facets during fuel cell operation; (2) how to achieve scale-up fabrication to meet industrial requirements.

Considering that the prospect of further significant improvements in Pt-based catalyst ORR activity is rather limited, long-term stability has become the most important challenge to be addressed. Several widely accepted factors account for the degradation of Pt-based catalysts, such as $\mathrm{Pt}$ dissolution, Ostwald ripening, particle detachment, leaching of alloying metal and corrosion of carbon support. Fortunately, several effective strategies have been developed to deal with these factors. For example, the stability of Pt-based catalysts can be improved by introducing more stable elements [94-96] such as Au, which is more inert than Pt under ORR conditions and can greatly enhance stability through the alloying or surface decorating of Pt. And although surface $\mathrm{Au}$ atoms were thought to block Pt sites and decrease activity [94], Kodama et al. [99] demonstrated that both activity and stability can be enhanced by depositing $\mathrm{Au}$ atoms selectively on (100) step sites. Furthermore, ordered Pt-based intermetallic alloys also exhibit better stability than corresponding random alloys [81, 84] with carbon-supported ordered intermetallic $\mathrm{Pt}_{3} \mathrm{Co}$ nanoparticles being a representative example [81]. Lastly, compared to nanoparticles, one-dimensional (1D) analogues (CoPt nanowires, Pt nanotubes [92]), 2D structures (PtPb nanoplates), and 3D array networks [68] (nanostructured thin film catalysts produced by $3 \mathrm{M}$ ) possess fewer lattice boundaries and defect sites on their surfaces and are therefore less vulnerable to dissolution and Ostwald ripening.

\section{Non-precious Metal Cathode Catalysts for ORR}

\subsection{Opportunity and Challenges of Non-precious Metal Catalysts}

The cost and scarcity of PGM catalysts severely limit the commercialization of fuel cells. Because of this, there are considerable efforts to find earth-abundant material replacements. Several types of non-precious metal catalysts for ORR have been reported, such as metal oxides, metal nitrides, metal chalcogenides, and carbon-based non-precious metal catalysts. Among them, carbon-based catalysts have attracted the most interest in recent years, especially $\mathrm{Fe} / \mathrm{N} / \mathrm{C}$ catalysts and metal-free nitrogen-doped carbon catalysts [97-99].

Benefiting from the advantages of carbon materials such as high conductivity and extremely high carbon surface area, various carbon-based non-precious metal catalysts are demonstrating comparable activities to PGM catalysts in RDE tests, such as Fe/N/C catalysts reported by Dodelet et al. [100] and nitrogen-doping CNTs reported by Dai et al. [101]. However, these catalysts still cannot compete with PGM catalysts in PEMFCs, including kinetic activity at low overpotential regimes, peak power densities, and stability over $1000 \mathrm{~h}$.

In this section, proposed active site atomic structures of carbon-based catalysts are discussed, followed by discussions on recent breakthroughs of carbon-based catalysts in PEMFCs. Finally, challenges in PEMFCs, including activity decay and mass transportation are discussed. 


\subsection{Structure of Active Site}

The atomic-level understanding of active sites is fundamental to the rational design of carbon-based electrocatalysts because multi-element doping and diversity of carbon

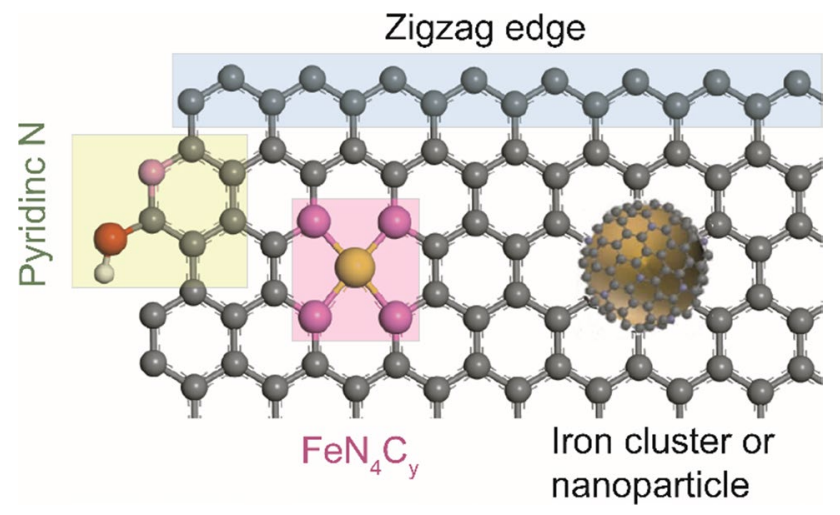

Fig. 9 Illumination of active sites in carbon-based catalysts
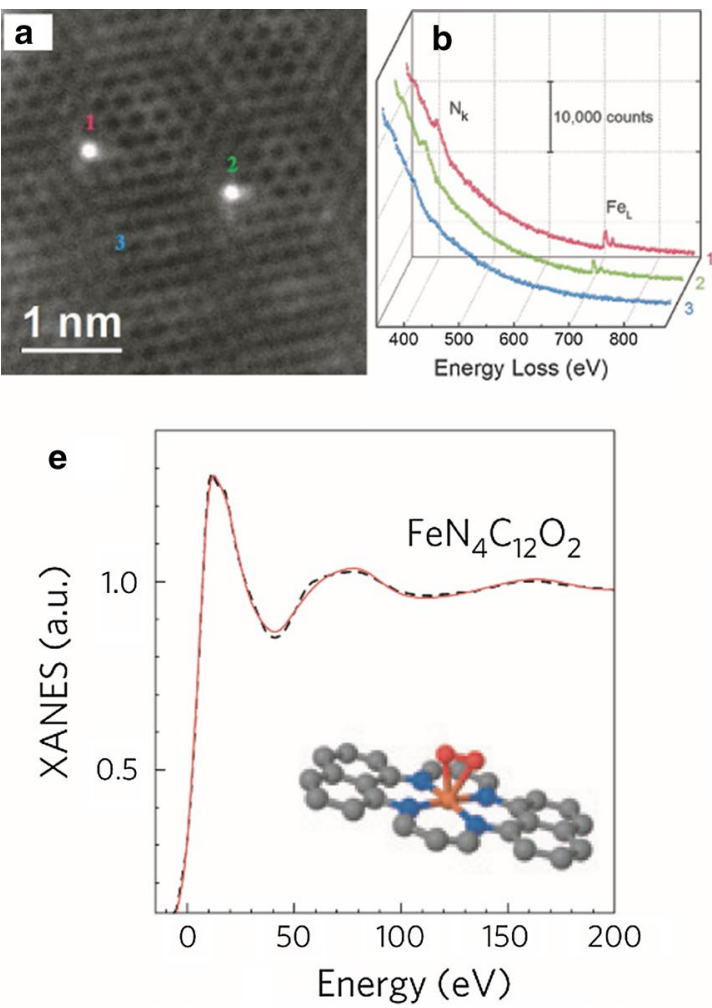

Fig. 10 Experimental evidence of iron-centre active sites. a HAADFSTEM image of individual $\mathrm{Fe}$ atoms (labelled 1 and 2) in a few-layer graphene sheet. [104]. b EEL spectra of the $\mathrm{N} \mathrm{K}$-edge $\left(\mathrm{N}_{\mathrm{k}}\right)$ and $\mathrm{Fe}$ L-edge $\left(\mathrm{Fe}_{\mathrm{L}}\right)$ acquired from single atoms (1 and 2) and few-layer graphene (3), demonstrate the presence of $\mathrm{N}$ around $\mathrm{Fe}$ atoms. [104]. $\mathbf{c}$ Low-temperature scanning tunnelling microscopy image of $\mathrm{FeN}_{4}$ species observed in a few-layer graphene sheet of $\mathrm{Fe} / \mathrm{N} / \mathrm{C}$ [105]. d Simulated STM image for c. The inserted schematic structures rep- elements cause carbon-based catalysts to possess complex structures. Defective carbon sites, pyridinic-type nitrogen, iron-porphyrin-like $\mathrm{FeN}_{4} \mathrm{C}_{\mathrm{y}}$ species and iron cluster/nanoparticles confined in graphene layers are proposed as active sites, as illustrated in Fig. 9. The defect sites of pure carbon have been directly observed to possess moderate ORR activities by employing microelectrodes to measure activity in an electrolyte droplet located in the edge sites and basal planes [102]. Although zigzag edges are proposed to be more ORR active than armchair edges as per density functional theory calculations [103], heteroatom doping, especially iron and nitrogen doping, can improve activity significantly. Therefore, iron-based active sites and nitrogen-based active sites are reviewed as follows.

$\mathrm{FeN}_{4}$ sites are considered to be one of most likely active sites of pyrolysed Fe/N/C catalysts even though its structure is still unknown. Recently, Zelenay et al. [104] reported a direct observation of $\mathrm{FeN}_{4}$ moiety with aberration-corrected scanning transmission electron microscopy and high-resolution electron energy loss spectroscopy (EELS) (Fig. 10a,
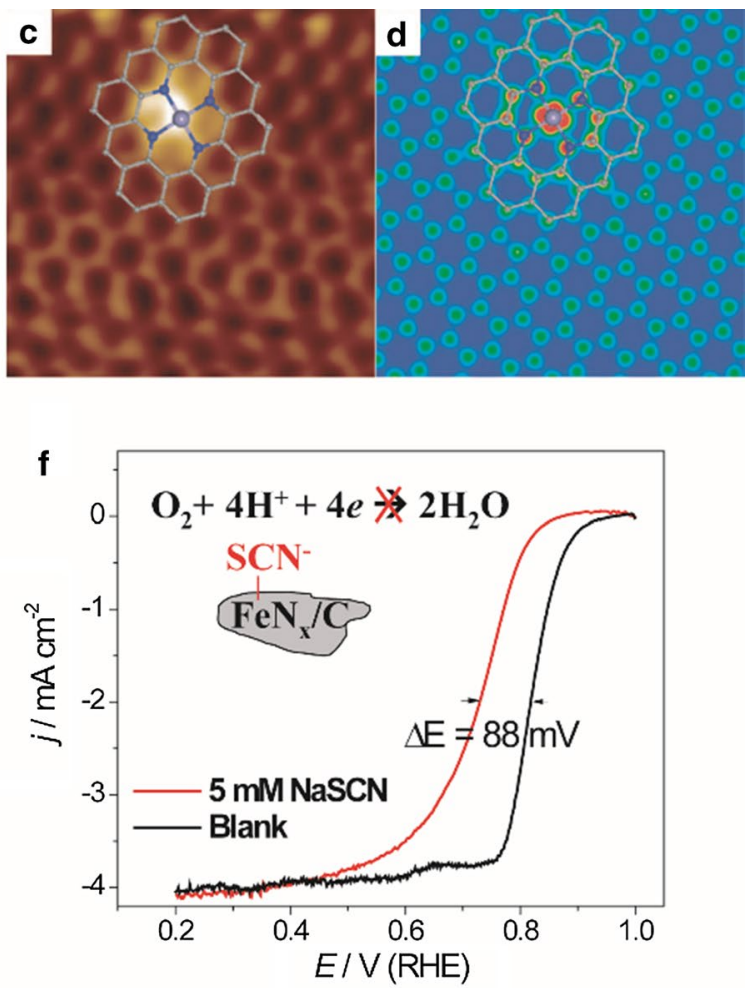

resent the structure of graphene-embedded $\mathrm{FeN}_{4}$. [105]. e Comparison between the K-edge XANES experimental spectrum of $\mathrm{Fe} / \mathrm{N} / \mathrm{C}$ (black dashed lines) and the theoretical spectrum calculated with $\mathrm{FeN}_{4} \mathrm{C}_{12}$ moiety with one $\mathrm{O}_{2}$ molecule adsorbed inside-on mode (solid red lines), the brown sphere represents an iron atom and blue, grey and red spheres representing nitrogen, carbon and oxygen atoms, respectively [106]. $\mathbf{f}$ Effects of $\mathrm{SCN}^{-}$ions $(5 \mathrm{mM})$ on ORR activity of $\mathrm{Fe} / \mathrm{N} / \mathrm{C}$ catalyst in $0.1 \mathrm{M} \mathrm{H}_{2} \mathrm{SO}_{4}$. [107] 
b). As seen in Fig. 10a, single atoms (dots exhibiting bright contrast) are embedded in graphene honeycomb lattices with the co-existence of iron and nitrogen atoms being identified by EELS. Figure 10b clearly shows that iron atoms exist in location 1 and 2 with nitrogen atoms neighbouring iron. Further quantifications of the Fe-to- $\mathrm{N}$ ratio from the EELS data yielded an average composition of $\mathrm{FeN}_{4}$. Another direct observation of $\mathrm{FeN}_{4}$ moiety was reported by Deng et al. [105] using low-temperature scanning tunnelling microscopy (LT-STM) as shown in Fig. 10c with the simulated one being shown in Fig. 10d. The bright dot in Fig. 10c is attributed to the iron centre. And although these direct observations are exciting, especially at atomic levels; as commented by Zelenay et al. [104], the $\mathrm{FeN}_{4}$ embedded in the basal plane is just a small fraction of the isolated $\mathrm{Fe}$ atoms and most of the $\mathrm{Fe}$ is actually positioned at the edge or step of the carbon phase. The Fe atoms in the edge are highly active but critically unstable, making observations not possible, even with low-energy electron beams $(60 \mathrm{keV})$. The analysis region of HRTEM and TEM methods is very local, and therefore, active sites are investigated using Mössbauer, X-ray photoelectron spectroscopy (XPS), X-ray absorption spectroscopy (XAS), and surface probing, all of which can provide structural information of the whole sample.

A representative study of active site determination using X-ray absorption spectroscopy was reported by Jaouen et al. [106] in which highly dispersive iron atoms were prepared by carefully controlling pyrolysis conditions. Here, $\mathrm{Fe}-\mathrm{Fe}$ bonds did not display single iron dispersion in extended X-ray absorption fine structure (EXAFS) analysis and the catalyst was revealed to be a single-iron-atom structure. The X-ray absorption near edge structure (XANES) was perfectly simulated with a porphyrin-like $\mathrm{FeN}_{2+2} \mathrm{C}_{12}$ structure and dioxygen was absorbed in the axial direction, either in sideon mode or in end-on mode. This research also revealed the remarkable importance of carbon matrixes in which compared with varied carbon matrixes in XANES simulations, only a conjunction of two graphene planes was found to perfectly match, meaning electron states of iron centres are significantly affected by the carbon matrix.

Because XAS analysis and structure simulations are based on the average of obtained signals, it is more reasonable to divide the obtained spectrum of $\mathrm{Fe} / \mathrm{N} / \mathrm{C}$ catalysts into a combination of varied structures due to its heterogeneous nature. According to Mössbauer spectra, Dodelet et al. [108] suggested that iron can be divided to five types: low-spin state of $\mathrm{FeN}_{4} / \mathrm{C}$ centre (D1), middle-spin state of $\mathrm{FeN}_{2+2} / \mathrm{C}$ (D2), high-spin state of $\mathrm{N}-\mathrm{FeN}_{2+2} / \mathrm{C}$ (D3) and two other types of iron nanoparticles (D4 and D5). The special structure of five-coordinate $\mathrm{Fe}$, in a high-spin state $\left(\mathrm{N}-\mathrm{FeN}_{2+2} / \mathrm{C}\right.$, D3), is formed in conjugation with two graphene planes $\left(\mathrm{N}_{2+2}\right)$ and coordinate axial $\mathrm{N}$ from the underlayer of the graphene.
In situ spectroscopy can probe events that occur in catalysts under working conditions and Mukerjee et al. [105, 109] carried out in situ XAS to study Fe/N/C catalysts. By characterizing representative iron-based catalysts under reactive conditions, they identified three $\mathrm{FeN}_{4}$-like catalytic centres with distinctly different $\mathrm{Fe}-\mathrm{N}$ switching behaviours (Fe moving towards or away from the $\mathrm{N}_{4}$-plane) during ORR, and demonstrated that ORR activities are essentially governed by the dynamic structures associated with $\mathrm{Fe}^{2+/ 3+}$ redox transition rather than by the static structure of the bare sites. Here, an out-of-plane $\mathrm{FeN}_{4}$ structure, which is more stable in the acid environment, was suggested based on switching behaviours.

Surface probing is another powerful technique used in surface science and coordination chemistry. In studies using surface probing on $\mathrm{Fe} / \mathrm{N} / \mathrm{C}$ catalysts, efforts have been made to apply strong ligands as surface probes, such as $\mathrm{CN}^{-}$developed by Gewirth et al. [110] and halide ions and sulphurcontaining species (e.g. $\mathrm{SCN}^{-}, \mathrm{SO}_{2}$, and $\mathrm{H}_{2} \mathrm{~S}$ ) by Zhou et al. [107], in which strong ligands are added into the electrolyte, coordinating iron centres and hindering oxygen absorption on iron sites to suppress the ORR activity of Fe/N/C catalysts (Fig. 10f). Surface probing can also be used to estimate active site densities on surfaces. $\mathrm{CO}$ was developed as a surface probe of Fe/N/C catalysts by Strasser et al. [111]. In their study, by counting surface active sites through the chemisorption and desorption of $\mathrm{CO}$, the number of active surface iron sites was estimated. This estimate was further combined with mass activity and turnover frequency values (TOF) were calculated (1.5 electrons per site per s). A similar method in the quantification of active sites was developed by Kucernak et al. [112] based on $\mathrm{NO}$ and $\mathrm{NO}_{2}{ }^{-}$probes in which $\mathrm{NO}$ and $\mathrm{NO}_{2}{ }^{-}$were found to stably coordinate to iron centres within the ORR electrochemical window $(0.3-1.0 \mathrm{~V}$ vs. RHE) and reduce to $\mathrm{NH}_{3}$ and $\mathrm{N}_{2}$ in the lower potential region (-0.3-0.3 V vs. RHE), labelled as reductive nitrite stripping. The stripping charge compared with the extent of poisoning allows for the quantification of active sites.

These approaches developed by Strasser et al. [111] and Kucernak et al. [112] allow researchers to easily assess the active site density and turnover frequency of $\mathrm{Fe}-\mathrm{N} / \mathrm{C}$ catalysts. And if surface probes with resolutions capable of distinguishing moieties (e.g. iron in atomic dispersion and iron clusters) are developed, it can be combined with spectroscopy techniques to obtain crucial information on reaction procedures of the surface and become important tools in the study of Fe/N/C catalysts, tremendously helpful in gaining further insights.

In comparison with $\mathrm{Fe} / \mathrm{N} / \mathrm{C}$ catalysts, metal-free catalysts have several notable advantages, including good stability due to a lack of metal site leaching and metal-catalysed Fenton reactions (discussed in Sect. 4.3), as well as excellent resistance to poisoning ( $\mathrm{CO}, \mathrm{SO}_{2}$ et al.). These 
promising properties have led to increased research into heteroatom-doped carbon materials, especially nitrogen doping. After an initial study on $\mathrm{N}$ doping in 2009 by Dai et al. [101], metal-free catalysts have rapidly developed and various heteroatom-doped carbon-based catalysts have been investigated, including intramolecular doping (such as sulphur [114], phosphorous [115], iodine [116] and fluorine doping [117]) and intermolecular doping (such as poly(diallyldimethylammonium chloride with its strong electron withdraw ability [118]). As suggested by $\mathrm{Hu}$ et al. $[119,120]$, dopants induce charge redistribution, breaking the electron symmetry of hexatomic rings, and induce the facilitation of $\mathrm{O}_{2}$ chemisorption and electron transfer for ORR regardless of the electronegativity of the dopant compared with carbon.

Three types of nitrogen species are mainly formed on nitrogen-doped carbon by thermal treatment: pyrrolic-type $\mathrm{N}$, pyridinic-type $\mathrm{N}$, and graphitic-type $\mathrm{N}$ (also called quaternary $\mathrm{N}$ ), and currently there is debate on whether activity is created by pyridinic $\mathrm{N}$ or graphitic $\mathrm{N}$. Experimentally, pyridinic-type $\mathrm{N}$ has been proven to be an active species by Guo et al. [113]. In their study, three model catalysts were prepared on highly oriented pyrolytic graphite (HOPG) predominated by pyridinic-type $\mathrm{N}$, graphite-type $\mathrm{N}$ and edge carbon sites. The XPS of model catalysts were employed to confirm the type of nitrogen and quantify the contents as shown in Fig. 11a. The ORR activity in acid electrolyte demonstrated that the pyridinic-type $\mathrm{N}$ model catalyst possessed better activity than graphite type $\mathrm{N}$ (Fig. 11b). The carbon neighbouring pyridinic $\mathrm{N}(\alpha-\mathrm{C})$ has been proposed to be an active atom in alkaline electrolytes by Qiao et al. [121]. The same phenomenon in acid electrolyte was also observed by Guo et al. [113] As shown in Fig. 11c, nitrogen underwent a significant change from pyridinic type to pyridonic type after ORR tests. This nitrogen change suggests that $\alpha$-carbon reacts with $\mathrm{OH}$ species, as illuminated in Fig. 11d, signifying that ORR occurs at the $\alpha$-carbon.

\subsection{Milestone of $\mathrm{Fe} / \mathrm{N} / \mathrm{C}$ in Fuel Cells}

The peak power in $\mathrm{H}_{2} / \mathrm{O}_{2}$ PEMFCs that are often available in published works is currently the most promising parameter to achieve commercialization targets. As summarized in Table 2, the leading group of peak power range from 0.9 to $1.0 \mathrm{~W} \mathrm{~cm}^{-2}$ with high kinetic activity and optimized assembly of catalysis layers in respective cases. Aside from initial performance, decay in PEMFCs (short-term and long-term stabilities) and performance in $\mathrm{H}_{2}$ /air PEMFCs are the two largest obstacles for $\mathrm{Fe} / \mathrm{N} / \mathrm{C}$ catalyst commercialization. Here, both short-term decay and long-term decay of Fe/N/C occur in PEMFCs with more than $40 \%$ loss in the initial $50 \mathrm{~h}$. This loss is most likely caused by Fenton reactions $\left(\mathrm{Fe}^{2+} / \mathrm{H}_{2} \mathrm{O}_{2}\right)$ and metal ion absorption by Nafion ionomers, and will be discussed in this section. Long-term stability is seldom reported, especially at high operation potentials $(E>0.50 \mathrm{~V})$ in which validated $\mathrm{Fe} / \mathrm{N} / \mathrm{C}$ catalysts in practical $\mathrm{H}_{2}$ /air PEMFC systems become more meaningful in discussions of commercialization and mass transportation of
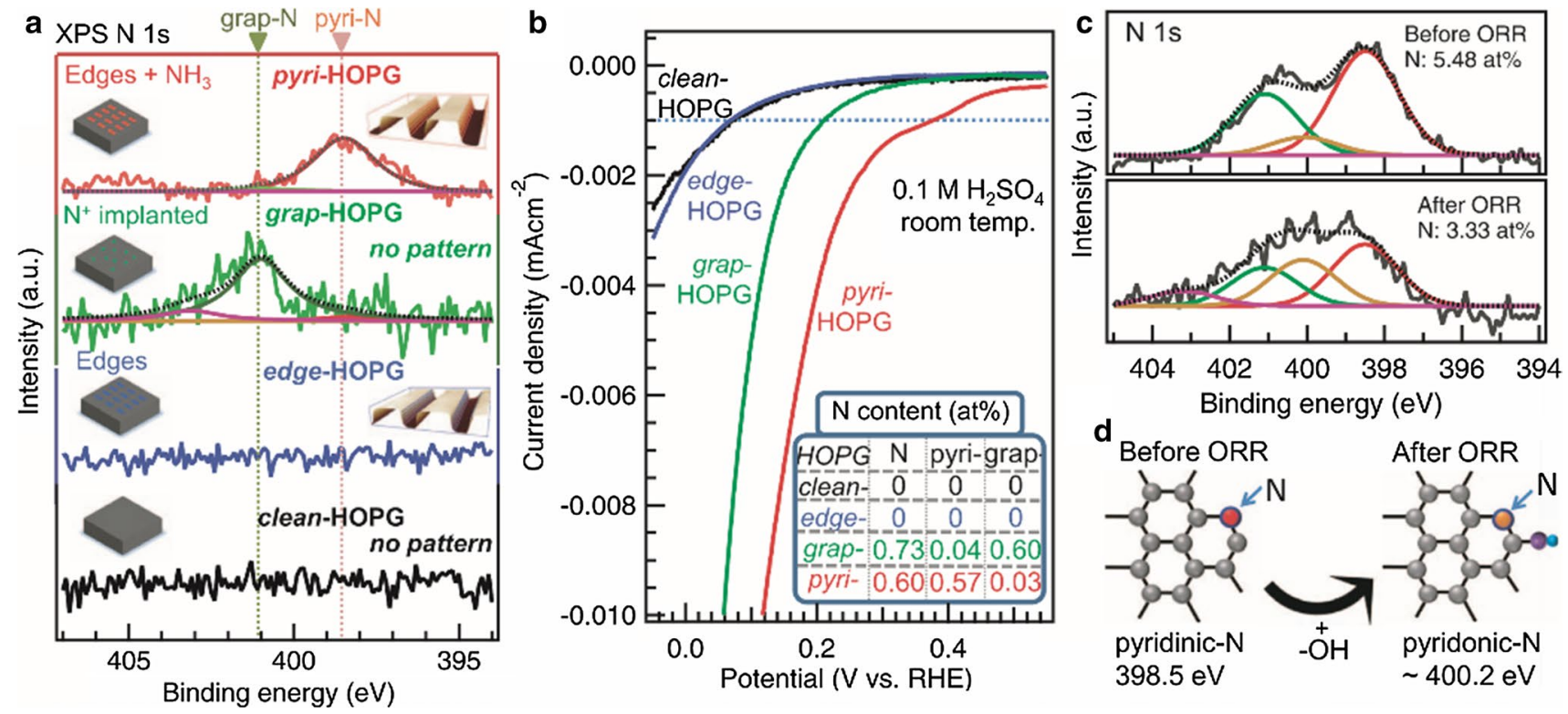

Fig. 11 Modeling pyridinic-N as the active site [113]. a N 1s XPS spectra of model catalysts. b ORR results for model catalysts corresponding to the samples shown in a. Nitrogen contents of the model catalysts are shown as the inset in b. $\mathbf{c} \mathrm{N} 1 \mathrm{~s}$ XPS of the N-HOPG model catalyst before and after ORR. d Scheme of the formation of pyridonic $\mathrm{N}$ by the attachment of $\mathrm{OH}$ to the carbon atom next to pyridinic $\mathrm{N}$ 
Table 2 State-of-the-art PEMFC performances of published Fe/N/C materials

\begin{tabular}{|c|c|c|c|c|}
\hline $\begin{array}{l}\text { Potential @ } \\
44 \mathrm{~mA} \mathrm{~cm}^{-2} \\
\left(\mathrm{~V}_{\text {iR-free }}\right)\end{array}$ & $\begin{array}{l}\text { Power Den- } \\
\text { sity @ } 0.6 \mathrm{~V} \\
\left(\mathrm{~W} \mathrm{~cm}^{-2}\right)\end{array}$ & $\begin{array}{l}\text { Peak } \\
\text { Power } \\
\left(\mathrm{W} \mathrm{cm}^{-2}\right)\end{array}$ & $\begin{array}{l}\text { Back } \\
\text { pressure } \\
\text { (bar) }\end{array}$ & References \\
\hline$\sim 0.86^{\mathrm{a}}$ & 0.32 & 0.45 & 1 & [100] \\
\hline$\sim 0.887^{\mathrm{a}}$ & 0.75 & 0.91 & 1 & {$[122]$} \\
\hline$\sim 0.875^{\mathrm{c}}$ & 0.53 & 0.63 & 1 & [106] \\
\hline 0.88 & 0.82 & 1.03 & 2 & [123] \\
\hline 0.871 & 0.73 & 0.94 & 1 & \\
\hline N/A & 0.86 & 1.06 & 1.38 & [124] \\
\hline$\sim 0.877$ & $\sim 0.69$ & 0.924 & 1 & [125] \\
\hline 0.87 & $\sim 0.67$ & 0.94 & 1 & {$[104,126]$} \\
\hline N/A & 0.78 & 0.98 & 2 & [127] \\
\hline \multirow[t]{2}{*}{$0.859^{\mathrm{d}}$} & 0.99 & 1.141 & 2.5 & {$[128]^{\mathrm{e}}$} \\
\hline & 0.96 & 1.11 & 2 & \\
\hline N/A & 0.54 & 0.98 & 2 & [129] \\
\hline $0.85^{\mathrm{b}}$ & $\sim 0.35$ & 0.73 & 1 & [130] \\
\hline$\sim 0.85^{\mathrm{c}}$ & 0.42 & 0.7 & 1.7 & [131] \\
\hline N/A & N/A & 0.45 & 2 & [132] \\
\hline
\end{tabular}

${ }^{\mathrm{a}} 105 \mu \mathrm{m}$ of average thickness in the catalyst layer is used in conversion

${ }^{\mathrm{b}} 78 \mu \mathrm{m}$ of average thickness in the catalyst layer is used in conversion

${ }^{\mathrm{c}}$ Non-iR-corrected

${ }^{\mathrm{d}} 30 \mu \mathrm{m}$ of average thickness in the catalyst layer is used in conversion

${ }^{\mathrm{e}}$ The kinetic current (in the first row) is obtained in the cell with $1.9 \mathrm{mg} \mathrm{cm}^{-2} \mathrm{Fe} / \mathrm{N} / \mathrm{C}$ catalyst loading, and power density (in the second and third rows) is obtained in the cell with $2.8 \mathrm{mg} \mathrm{cm}^{-2}$ catalyst loading oxygen becomes critical. In Sect. 4.4, mass transportation of non-precious metal catalysts will be discussed.

$\mathrm{Fe} / \mathrm{N} / \mathrm{C}$ catalysts start with metal, nitrogen and carbon precursors combined high-temperature pyrolysis; a necessary process to form ORR active sites, with creative methods being applied to complete such complex processes. Here, breakthroughs in $\mathrm{Fe} / \mathrm{N} / \mathrm{C}$ preparation in recent years with high PEMFC performance will be reviewed as follows.

A breakthrough in the kinetic activity of Fe/N/C catalysts was made by Dodelet et al. [100, 106, 122] using thermally treated precursors in an $\mathrm{Ar} / \mathrm{NH}_{3}$ atmosphere (Fig. 12a, b). The activity comparison between treatment in $\mathrm{Ar}$ and $\mathrm{NH}_{3}$ is shown in Fig. 12b. From this, it can be seen that Fe/N/C obtained from $\mathrm{NH}_{3}$ thermal treatments clearly has better activity than from Ar thermal treatments. The iR-free cell voltage at $44 \mathrm{~mA} \mathrm{~cm}^{-2}$ (kinetic activity) of $\mathrm{Fe} / \mathrm{N} / \mathrm{C}$ in $\mathrm{NH}_{3}$ is $\sim 0.875 \mathrm{~V}$. This is very close to DOE intermediate targets in 2018 ( $0.88 \mathrm{~V}$ iR-free), with the final target in 2020 being $0.9 \mathrm{~V}_{\text {iR-free }}$ [3]. The researchers proposed that the higher ORR activity of $\mathrm{NH}_{3}$-pyrolysed materials correlates with the higher basicity. As suggested in Fig. 12a, there are pyridinic $\mathrm{N}$ neighbouring $\mathrm{FeN}_{4} \mathrm{C}_{\mathrm{y}}$ species adjusting the micro-environment. The protonation of these pyridinic $\mathrm{N}$ can tune basicity, and therefore improve activity [134]. These $\mathrm{FeN}_{4} \mathrm{C}_{\mathrm{y}}$ species (proposed as D3 in Mössbauer spectrum) only appear using the $\mathrm{NH}_{3}$ thermal treatment method. Therefore, highly active single-iron atoms are only formed in abundant microporous (provides abundant conjugation of graphene planes) and highly nitrogen-doped $\mathrm{Fe} / \mathrm{N} / \mathrm{C}$ catalysts prepared using the $\mathrm{NH}_{3}$ thermal treatment method. The Lewis basicity of graphitic carbon matrixes, controlled by carbon defect densities, can also tune single-atom iron ORR activities as suggested by Mukerjee et al. [135] in which
Fig. 12 a Illumination of a higher $\mathrm{N}$ content of $\mathrm{Fe} / \mathrm{N} / \mathrm{C}$ prepared in $\mathrm{NH}_{3}$ pyrolysis than that in Ar. $\mathbf{b}$ Comparison of PEMFC performance of $\mathrm{Fe} / \mathrm{N} / \mathrm{C}$ catalysts prepared in $\mathrm{NH}_{3}$ and $\operatorname{Ar}[106]$. c Schematic of highly stable $\mathrm{Fe} / \mathrm{N} / \mathrm{C}$ catalysts derived with polyaniline coating. $\mathbf{d}$ Stability test of polyaniline-derived $\mathrm{Fe} / \mathrm{N} / \mathrm{C}$ catalysts [133] a Pyrolysis in Ar vs. Pyrolysis in $\mathbf{N H}_{3}$
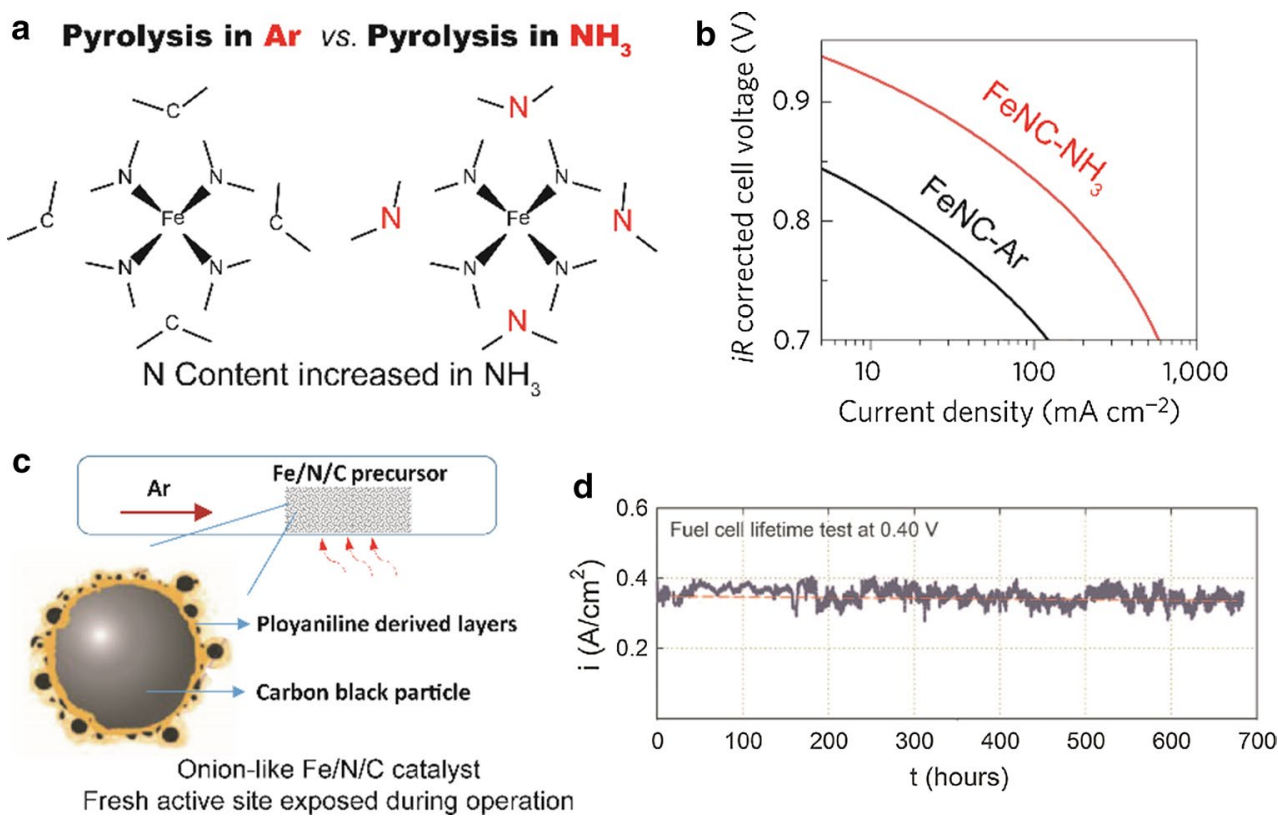
they proposed that by enhancing the electron withdrawing capability of the carbon basal plane, the e.g. orbitals $\left(\mathrm{d}_{\mathrm{z} 2}\right)$ of centre $\mathrm{Fe}$ ions will downshift, weakening the interactions between $\mathrm{Fe}$ ions and ORR intermediates, leading to higher ORR activity.

To improve the stability of $\mathrm{Fe} / \mathrm{N} / \mathrm{C}$ catalysts, an onionlike structure was suggested and prepared by Zelenay et al. (Fig. 12c) [133] in which the corrosion of carbon layers led to the leaching out of surface active sites and fresh active sites being exposed. Using this method, polyanilinederived $\mathrm{Fe} / \mathrm{N} / \mathrm{C}$ catalysts exhibited a 680 -h stable work at $0.4 \mathrm{~V}$ (Fig. 12d). This is significantly better compared with $\mathrm{NH}_{3}$-pyrolysed catalysts. However, the tested current remained at $0.4 \mathrm{~V}$, and because this voltage is mainly in the diffusion-controlled regime, the real decay of kinetic activity could possibly be masked.

The introduction of sulphur in Fe/N/C catalysts can improve ORR activity and Zhou et al. [123] reported an excellent $\mathrm{Fe} / \mathrm{N} / \mathrm{C}$ catalyst using sulphur doping that was prepared with $\mathrm{Fe}(\mathrm{SCN})_{3}$ as iron and sulphur precursors. This catalyst was prepared through a modified Zelenay method [133] as illuminated in Fig. 13a and achieved peak power densities of $1.03 \mathrm{~W} \mathrm{~cm}^{-2}\left(P_{\text {back pressure }}=2\right.$ bar $)$ in a $\mathrm{H}_{2} / \mathrm{O}_{2}$
PEMFC (Fig. 13b). Sulphur doping in Fe/N/C catalysts can: (1) create abundant micropores which host a huge number of active sites [123]; and (2) form a thiophene-like structure (C-S-C) which reduces electron localization around the $\mathrm{Fe}$ centre, improving oxygenated specie interactions and therefore facilitate complete $4 \mathrm{e}^{-}$ORR in acid solution [136]. Recently, Chen et al. [124] employed dual nitrogen sources in the preparation of a $\mathrm{Fe} / \mathrm{N} / \mathrm{C}$ catalyst which led to the formation of abundant pores that facilitate oxygen transfer, as shown in Fig. 13c. The peak power density achieved with this ORR catalyst in $\mathrm{H}_{2} / \mathrm{O}_{2}$ PEMFC was reported to be $1.06 \mathrm{~W} \mathrm{~cm}^{-2}\left(\mathrm{P}_{\text {back pressure }}=1.37 \mathrm{bar}\right)$.

The dissolution of metal during electrochemical processes is directly related to the decay of PEMFC performance (discussed in Sect. 4.4). Therefore, metal-free catalysts are becoming more popular because of its benefits to catalyst stability. There are plenty of studies that show nonmetal heteroatom doping carbon materials providing significant activities for ORR [139-145]. However, there are typically no sufficient efforts to verify whether these materials are indeed free of any trace metals. A metal-free catalyst in the strictest sense does not possess any metal elements, and if it does, the metal presence should not influence catalyst
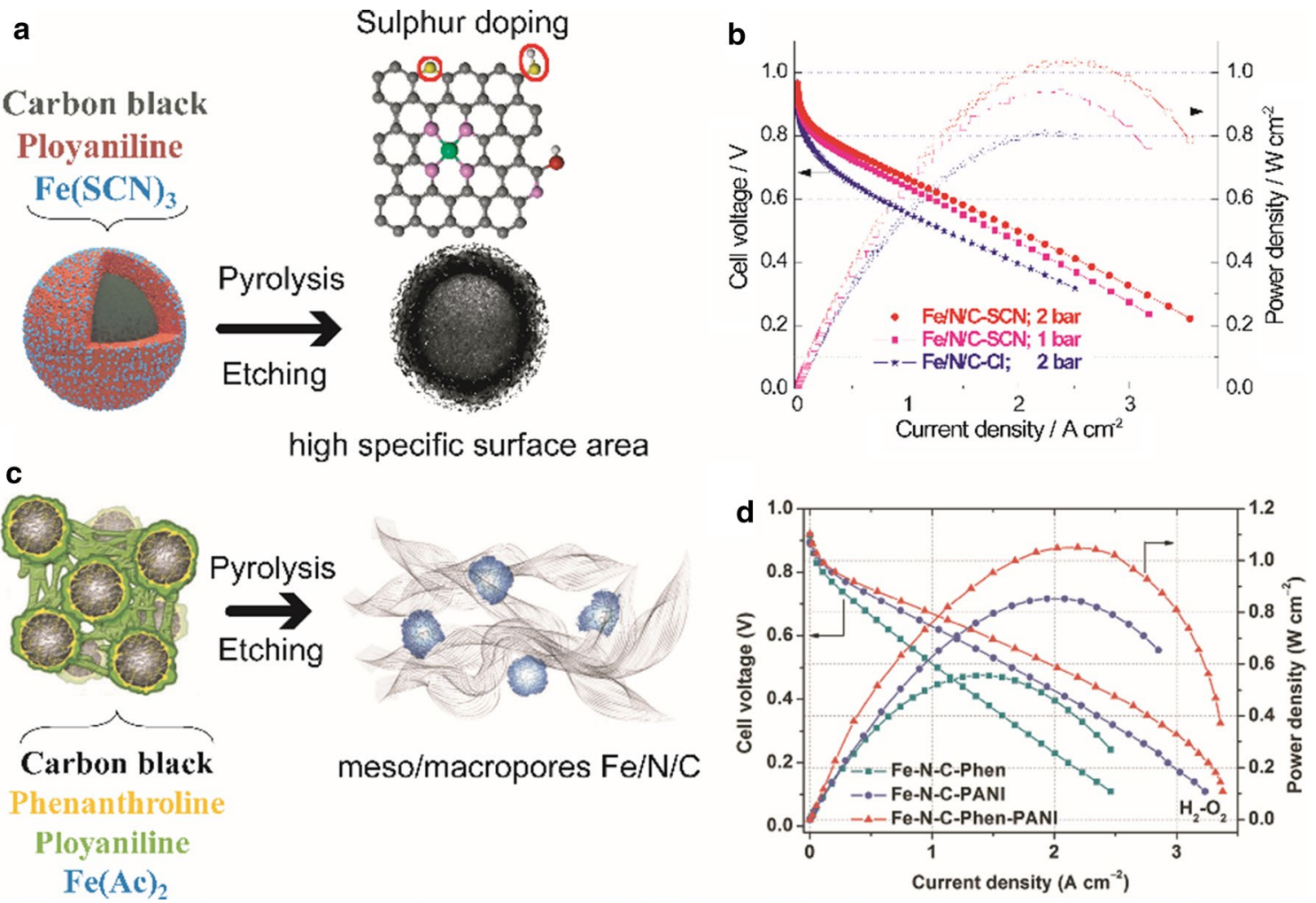

Fig. 13 a Schematic of sulphur doping in Fe/N/C catalysts, b Polarization (left, filled symbols) and power density (right, open symbols) plots for $\mathrm{H}_{2}-\mathrm{O}_{2}$ PEMFCs with $\mathrm{Fe} / \mathrm{N} / \mathrm{C}-\mathrm{SCN}$ and $\mathrm{Fe} / \mathrm{N} / \mathrm{C}-\mathrm{Cl}$ as cathode catalysts, [123]. c Synthesis schematic of Fe/N/C-Phen-PANI with dual N-content polymer precursor (phenanthroline (Phen) and polyaniline (PANI)), d Polarization (left) and power density (right) plots for $\mathrm{H}_{2}-\mathrm{O}_{2}$ PEMFCs with Fe/N/C-Phen-PANI. [124] 
Fig. 14 a Metal-free growth of nitrogen-doped CNTs for ORR. [137]. b ORR polarization curves of NCNTs and undoped CNTs in oxygen-saturated $0.5 \mathrm{M} \mathrm{H}_{2} \mathrm{SO}_{4}$ [137]. c PEMFC polarization curve and power density of vertically aligned nitrogen-doped carbon nanotube (VA-NCNT) arrays. Cathode catalyst loading $0.16 \mathrm{mg} \mathrm{cm}^{-2}$, Nafion/VA-NCNT $=1 / 1 . \mathrm{H}_{2} /$ $\mathrm{O}_{2}: 80{ }^{\circ} \mathrm{C}, 100 \%$ relative humidity, 2 bar back pressure [138]
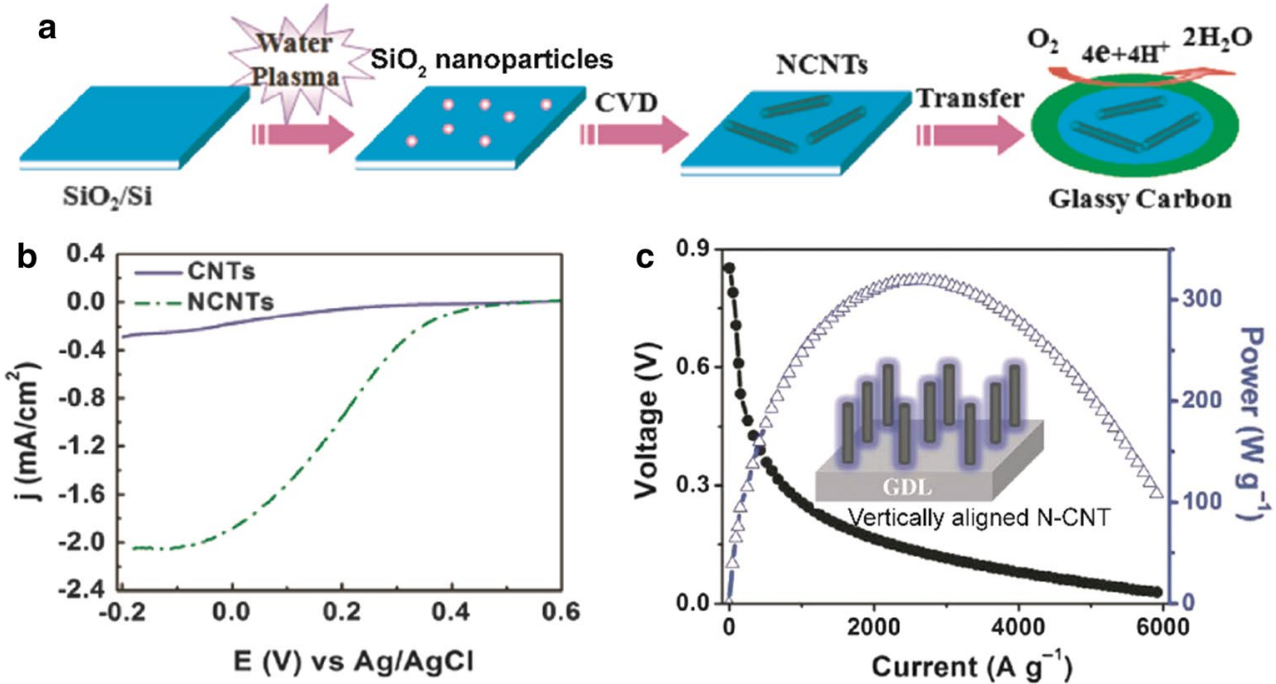

properties. Currently, there are no "metal-free" catalysts that can conform to this, as evidenced by the works of Pumera et al. [146] and Schuhmann et al. [147]. A comprehensive review can be referred in the literature [148].

The strictest case of metal-free catalysts in the literature was reported by Dai et al. [137] As demonstrated in Fig. 14a, Dia et al. prepared $\mathrm{SiO}_{2} / \mathrm{Si}$ nanoparticles using water-plasma etching. These $\mathrm{SiO}_{2}$ nanoparticles subsequently acted as metal-free catalysts to grow N-doping CNTs through chemical vapour deposition, with $\mathrm{CH}_{4}$ and $\mathrm{NH}_{3}$ gas being used as carbon and nitrogen sources. This strict metalfree N-CNT was tested for ORR, as shown in Fig. 14b, and exhibited an ORR activity which was higher than CNT in an acid electrolyte, but was generally lower than typical values of Fe/N/C catalysts. N-doped carbon was applied for the first time in PEMFCs by Dai et al. [138] as illustrated in Fig. 14c using VA-NCNT as ORR catalysts and achieved peak power densities of roughly $0.32 \mathrm{~W} \mathrm{~cm}^{-2}$.

\subsection{Decay of Catalytic Activity}

Stability is a significant obstacle for the commercialization of Fe/N/C catalysts. A phenomenon is usually observed in stability tests in which Fe leaching-out occurs at low potentials $(<0.7 \mathrm{~V})$ without direct adverse effects on ORR activity, and carbon oxidation occurs at high potentials $(>0.9 \mathrm{~V})$ with observable activity decay [149-151]. Based on this phenomenon, four possible reasons are suggested for the decay (schematic illuminated in Fig. 15a) [150, 152]: (1) leaching of metal active sites [153] such as metal dissolution observed in Fe/CoPc causing activity loss. However, this activity loss is only observed if purging with $\mathrm{O}_{2}$, and under Ar, the catalyst remained stable. It was suggested that $\mathrm{Fe}^{2+}$ oxidizes to $\mathrm{Fe}^{3+}$ in the presence of $\mathrm{O}_{2}$, reducing its ionic radius, making it less stable in macrocycles [154];
(2) protonation and anion absorption in proton exchange ionomers. Dodelet et al. proposed that pyridinic N, neighbouring to $\mathrm{FeN}_{4}$ sites in $\mathrm{NH}_{3}$-pyrolzed materials, becomes protonated and binds with anion ionomers [155], decreasing surface basicity and is responsible for initial activity losses; (3) active sites are flooded as oxidized carbon change hydrophobic surfaces into hydrophilic surfaces [149, 156]; (4) free radical species attack carbon matrixes [150, 157], causing Fenton reagents to form during ORR with Fe existence, leading to corrosion of catalyst and membrane.

Rapid decay in $\mathrm{H}_{2} / \mathrm{O}_{2}$ fuel cell performance is usually observed with $\mathrm{Fe} / \mathrm{N} / \mathrm{C}$ catalysts at the beginning of testing as demonstrated in Fig. 15b, especially in the first $\sim 15 \mathrm{~h}$ [123, 149, 158]. One hypothesis to explain this decay suggested by Dodelet et al. was that water flooding leads to rapid decay [149]. This hypothesis is supported by quantitative calculations of carbon oxidation elapsed times. Thermodynamically, carbon is oxidized at a potential higher than $0.207 \mathrm{~V}$ versus SHE. Consequently, the surface becomes hydrophilic after carbon is functionalized with oxygen-contained species. The elapsed time of surface carbon oxidation is conducted based on carbon oxidation current densities and special surface areas. After a 15-h oxidation, the calculated ratio between oxidation carbon and original surface oxidation ranges from $38 \%$ (totally oxidized to $-\mathrm{COOH}$ with $4 e^{-}$) to $100 \%$ (partially oxidized to $-\mathrm{COH}$ with $e^{-}$). At such oxidation degrees, the surface gains high affinity to water, leading to severe water flooding. In contrast, Chen et al. [157] proposed an alternative hypothesis. They calculated the electrochemical surface area of the catalyst by monitoring the double-layer capacitance through cyclic voltammetry and found that the majority of micropores are wetted at beginning of life, and a slightly wetting of additional catalyst layers occurs during the stability test. However, they conclude that such a small increase in wetting cannot explain 
Fig. 15 a Schematic description of proposed decay process of active sites. b Performance decay of $\mathrm{H}_{2} / \mathrm{O}_{2}$ fuel cells with different $\mathrm{Fe} / \mathrm{N} / \mathrm{C}$ cathodes operating at $0.5 \mathrm{~V}[149,158]$. c Current density versus cumulative charge at $0.5 \mathrm{~V}$ for four $\mathrm{Fe} / \mathrm{N} / \mathrm{C}$ catalysts with different Fe leaching rates [150]. The numbers appearing at the end of each sample are the demetallation amounts of Fe during a given voltammetric protocol
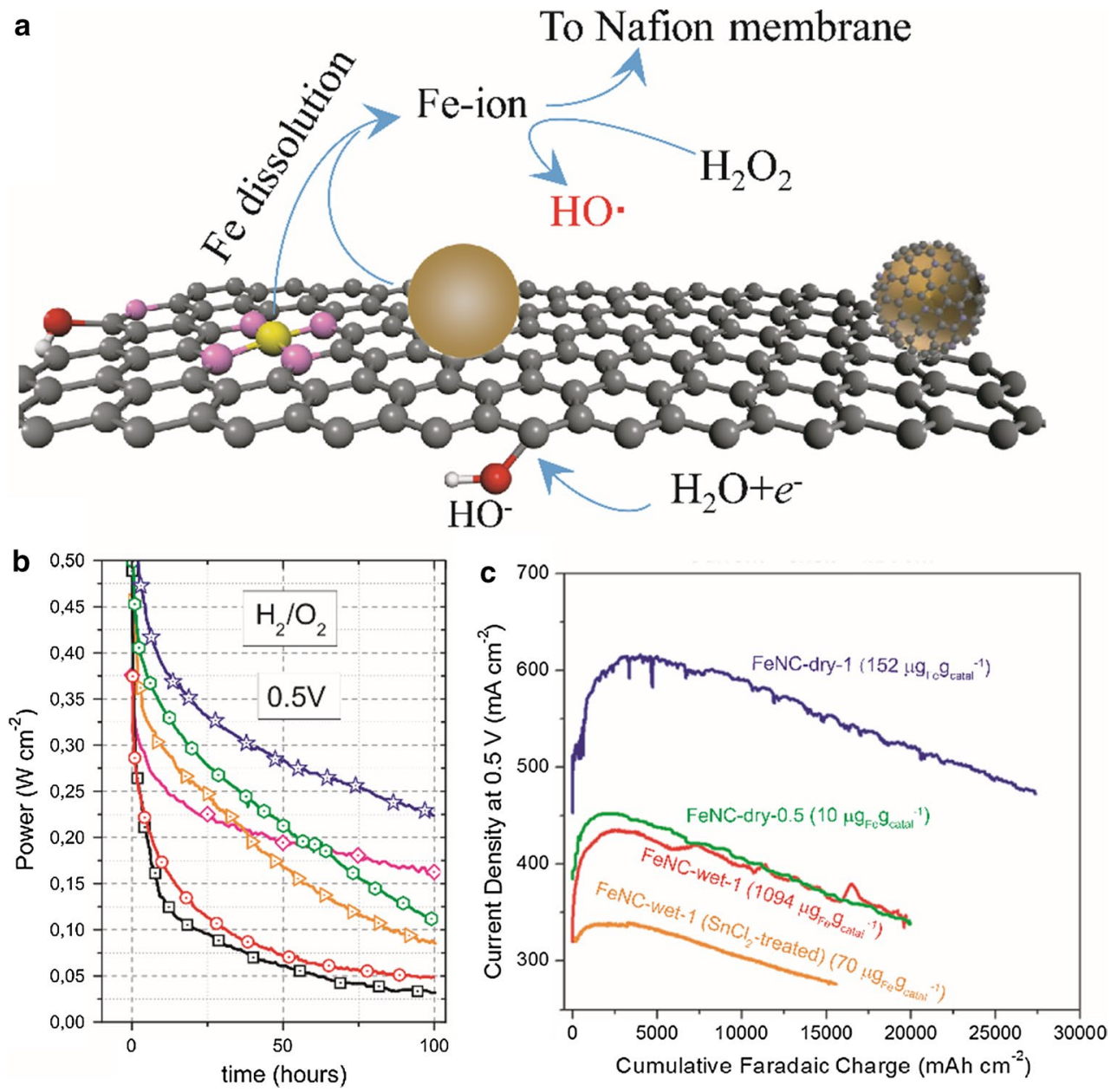

the significant performance losses observed. Therefore, the micropore flooding mechanism cannot fully explain the initial rapid decay.

Because of this, Dodelet et al. [159] recently changed their hypothesis to the demetallation in micropores. They agree that catalysts are wetted at beginning of life, and that it is hydrophobic. Literature [159-161] states that hydrophobic walls provide little resistance towards water and ion movement, and flowing speeds are up to $1 \mathrm{~m} \mathrm{~s}^{-1}$ at $1 \mathrm{~atm}$ differential pressure. $\mathrm{Fe} / \mathrm{N} / \mathrm{C}$ catalysts in this case possess abundant interconnected open-end slit-shaped micropores which facilitate the flow of hydrated protons. Dodelet et al. proposed that $\mathrm{FeN}_{4}$ species which are hosted in the micropores are slowly leached out, and this Fe leaching is dramatically accelerated with the fast flow of hydrated protons. Therefore, they suggest that the disappearance of $\mathrm{FeN}_{4}$ species in micropores is responsible for the initial fast decay of $\mathrm{Fe} / \mathrm{N} / \mathrm{C}$ catalysts.

However, for Fe leaching, Choi et al. [150] prepared four catalysts with a wide range of Fe leaching rates in a liquid electrolyte (Fig. 15c). Here, the trend in fuel cell durability over the first $50 \mathrm{~h}$ is similar for all catalysts. Therefore, demetallation has no effect on the initial rapid decay. One important phenomenon in Fig. 15c is that all four catalysts displayed almost identical slopes of current versus cumulative charge in which the latter parameter is proportional to the cumulative number of $\mathrm{O}_{2}$ molecules that have been reduced on the catalyst surface. Hence, this cumulative charge is also proportional to the total amount of $\mathrm{H}_{2} \mathrm{O}_{2}$ byproducts formed on the catalyst surface, and therefore to the cumulative amount of radical oxygen species formed through Fenton reactions. This suggests that the initial rapid decay of $\mathrm{Fe} / \mathrm{N} / \mathrm{C}$ catalysts mainly stem from radical oxygen species produced by Fenton reactions.

\subsection{Mass Transportation}

The low density of active sites in $\mathrm{Fe} / \mathrm{N} / \mathrm{C}$ catalysts requires high catalyst loading $\left(\sim 4 \mathrm{mg} \mathrm{cm}^{-2}\right)$ to achieve sufficient current density, resulting in $\sim 100 \mu \mathrm{m}$ thick catalyst layers (CLs) that are much thicker than $(\sim 10 \mu \mathrm{m})$ Pt-based CLs. The CL morphology and construction of thick $\mathrm{Fe} / \mathrm{N} / \mathrm{C}$ electrodes have significant impacts on mass and charge transport, further affecting fuel cell performances. 


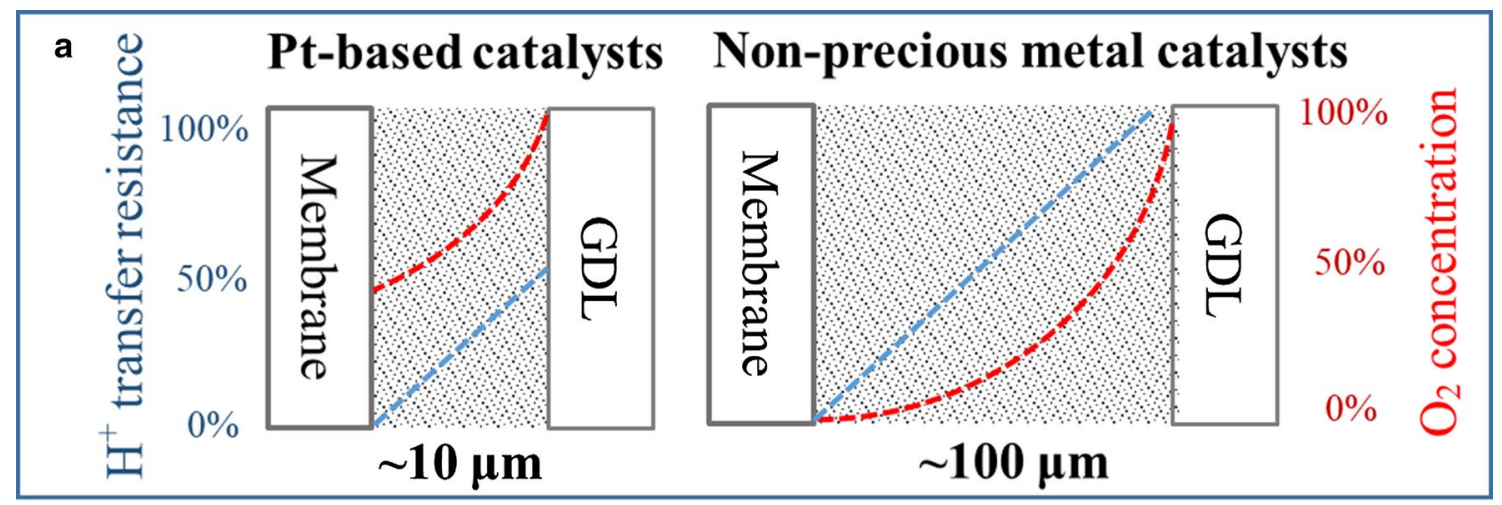

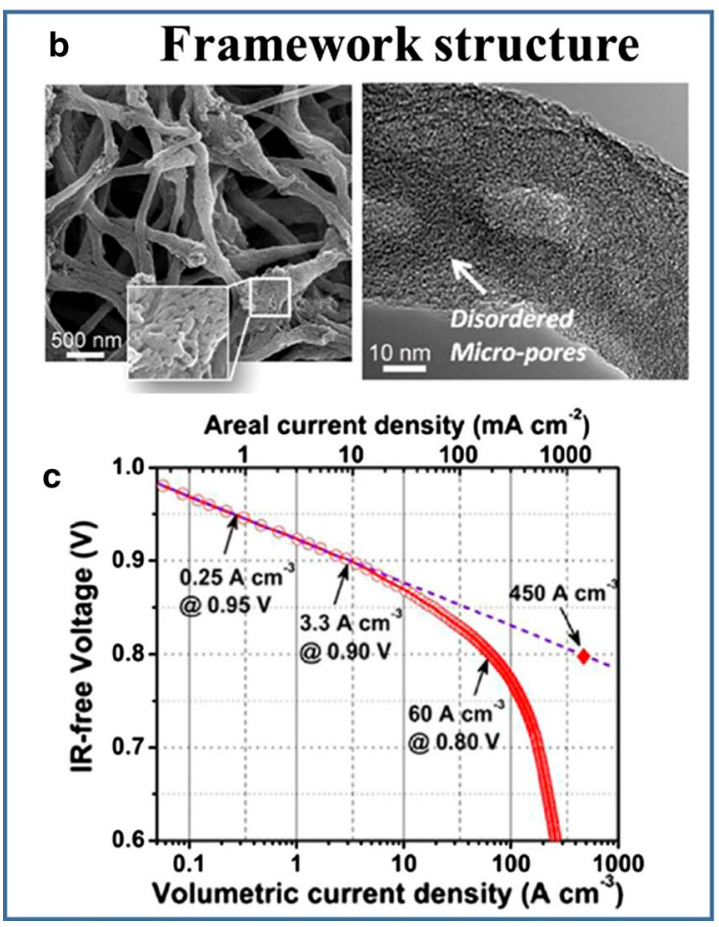

Fig. 16 a Comparison of $\mathrm{O}_{2}$ and proton transfer between thick catalysts layer of non-precious metal catalysts and thin Pt-based catalysts layer. b SEM image of the Fe/N/CF nano-network catalyst [162]. c Tafel plot for the kinetic activity of Fe/N/CF obtained from a single fuel cell test [162]. d Illustration of hydrophobic dimethyl silicon

Generally, the resistance of mass/charge transport is in the order of oxygen transport $>$ proton transfer $>$ electron transfer. Oxygen transport is frequently the limiting factor in thick $\mathrm{Fe} / \mathrm{N} / \mathrm{C}$ electrodes with oxygen concentrations decreasing in gradient as shown in Fig. 16a. Oxygen become depleted in zones close to the membrane of thick $\mathrm{CLs}$ of $\mathrm{Fe} / \mathrm{N} / \mathrm{C}$, causing $\mathrm{H}_{2}$ /air PEMFC performances to deteriorate because oxygen concentrations are only $20 \%$. Figure 16a also shows that proton transfer resistances increase in the direction away from the membrane. Proton transfer can also become a limiting factor in PEMFCs with $\mathrm{Fe} / \mathrm{N} / \mathrm{C}$ cathodes, especially operating at roughly $1 \mathrm{~A} \mathrm{~cm}^{-2}$

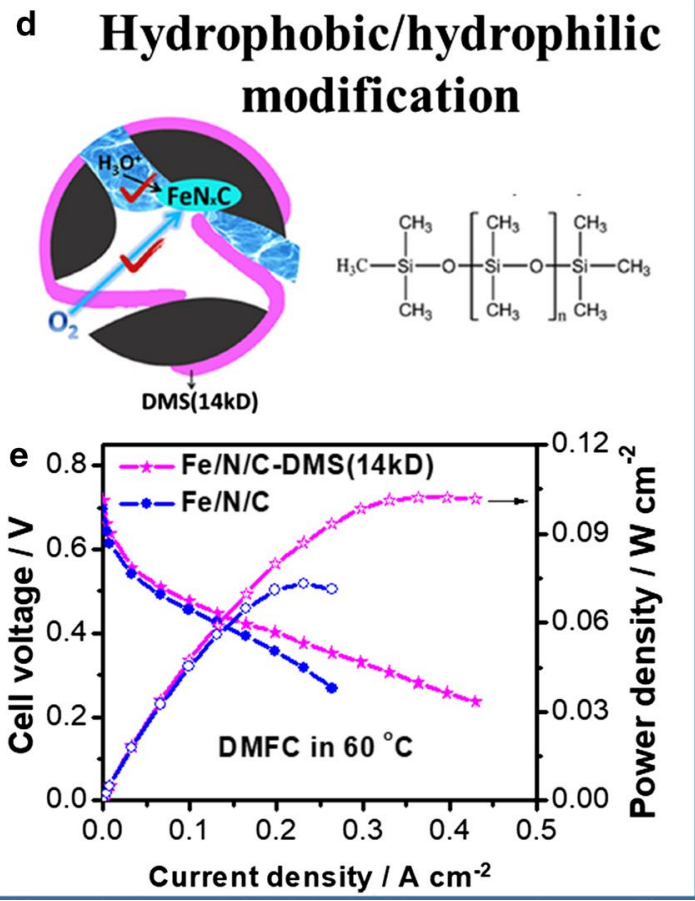

oil (DMS) just partially penetrating into the micropores with masstransport channels open, forming a robust triple-phase interface in micropores [163]. e Polarization curves and power density curves of DMFCs with Fe/N/C-DMS cathodes [163]

[160]. Limitations of electron transfer occur in some cases of $\mathrm{Fe} / \mathrm{N} / \mathrm{C}$ catalysts because of zeolitic imidazolate frameworks (ZIF) or metal-organic frameworks (MOF). Electron transfer is usually facilitated by carbon additions through either the carbonization of polymer coatings [128] or the directly use of carbon networks [161]. Nevertheless, mass transportation is a major problem in $\mathrm{Fe} / \mathrm{N} / \mathrm{C}$ cathodes.

There are two strategies to optimize mass transportation. One is to tune pore distribution using framework substrates, and the other is to tune surface wettability using hydrophobic additives. 
An ideal electrode structure as proposed by Liu et al. [162] should possess micropores with high densities of active sites and reactant/product should transfer directly to and from these active sites through macropores with minimal transport resistance. Based on this, Liu et al. [162] prepared an interconnected porous nano-network Fe/N/C catalyst as shown in Fig. 16b. This network structure can facilitate mass transportation through its macropores between the interconnected nanofibers. More importantly, each nanofiber was predominantly microporous, containing uniformly and densely dispersed catalytic sites throughout the fibre. The PEMFC performance as shown in Fig. 16c produced a measured area current activity of $9.9 \mathrm{~mA} \mathrm{~cm}^{-2}$ at $0.9 \mathrm{~V}_{\mathrm{iR} \text {-free }}$ and a peak power density of $0.9 \mathrm{~W} \mathrm{~cm}{ }^{-2}$. Other framework substrate methods, such as a combination of various carbon materials [164-166] and synthesis with silica template [131, 167,168 ] or $\mathrm{NaCl}$ template [169], were also found to create abundant channels/pores to facilitate mass transportation.

Hydrophilic and hydrophobic channels in cathodes can transfer water and gas, respectively. Rational dispersion of these channels can effectively prevent water flooding. Zhou et al. [163] constructed a triple-phase interface in the micropores of $\mathrm{Fe} / \mathrm{N} / \mathrm{C}$ catalysts by controlling the distribution of dimethyl silicon oil (DMS); a hydrophobic additive, so as to partially penetrate the micropores. This elaborately constructed $\mathrm{Fe} / \mathrm{N} / \mathrm{C}$-based DMFC delivered high power densities (102 and $130 \mathrm{~mW} \mathrm{~cm}^{-2}$ at 60 and $80^{\circ} \mathrm{C}$, respectively) and durability comparable to that of Pt/C-based DMFCs as illustrated in Fig. 16d, e.

It is worth noting that gas and water should be designed to transfer in hydrophobic and hydrophilic channels, respectively. Up to now, investigations on $\mathrm{Fe} / \mathrm{N} / \mathrm{C}$ cathodes are mostly focused on the optimization of pore distribution as well as hydrophobic additives to provide transfer highways. Multi-scaled studies need to be conducted in the future. At the microscale level, the distribution and micro-environments of active sites should be considered. At the mesoscale level, electron, proton, and water transfer should be orderly designed in 3D frameworks to provide primary transfer. At the macroscale level, macro-channels should be designed as confluences of meso-/micro-channels, acting as "highways of mass transportation".

\section{Conclusion and Outlook}

The development of advanced electrocatalysts for lowtemperature fuel cells has gained increasing attention in recent years, including anode and cathode electrocatalysts. The insights gained from model catalysts of bulk singlecrystal planes provide guidance for the fundamental design and understanding of new catalysts. Shape-controlled nanocrystals, especially Pt NCs with high-index facets, have been demonstrated to significantly enhance activity and stability towards anode catalytic reactions. The study of nanomaterials with high-index facets has opened exciting new avenues to design exceptional catalytic properties for fuel cell catalysts. Despite significant progresses, future challenges remain such as the scale-up production of small-sized $(<10 \mathrm{~nm})$ NCs with high-index facets, especially alloy NCs, and MEA tests of NCs with highindex facets.

Currently, Pt-based catalysts are still the most effective catalysts for ORR, with the insights gained from bulk singlecrystal planes and Pt-skin model surfaces providing great guidance for improvements. As for nanoscale catalysts, $\mathrm{Pt}$ NCs bound with $\{111\}$ facets and Pt-skin-like surfaces on multi-metallic materials are crucial for the enhancement of activity and stability through the tuning of adsorption properties of reactive intermediates as well as spectator species. Single-atom noble-metal catalysts stabilized by electronic conductive supports and single atomic layer of preciousmetal catalysts on high-index non-noble-metal NCs are two possible directions to significantly reduce noble-metal usage. And although numerous reports claim substantial enhancements in ORR activity and stability in RDE tests through Pt-alloying approaches, it still remains unclear whether these active alloy catalysts can perform similarly in fuel cells and be stable for long periods of time (several hundred or thousand hours). To advance the development of ORR catalysts, the gap in ORR performance between RDE and fuel cell measurements needs to be addressed in the future.

Despite the superior electrocatalytic properties in activity and durability of Pt-based catalysts, studies on nonprecious metal catalysts have also achieved remarkable progress. Novel carbon-based nanomaterials have recently been discovered as alternative ORR catalysts, possessing the potential to reduce fuel cell costs dramatically. Although the initial activity of carbon-based catalysts is its most promising parameter (close to commercial target in PEMFCs), it is still 1-2 orders of magnitude lower than that of precious metal catalysts. Further improvements in intrinsic activity and active site densities need to be made before scale-up commercialization can occur. The fabrication of Fe/N/C catalysts with abundant single-metal-atom sites is another effective approach to improve catalytic activity. However, the poor stability of these $\mathrm{Fe} / \mathrm{N} / \mathrm{C}$ catalysts remains the biggest challenge for its application. These $\mathrm{Fe} / \mathrm{N} / \mathrm{C}$ catalysts may benefit from multi-nuclear metal sites due to the precise conversion of a redox mediator acting as a quenching agent for radical oxygen species. Combined with the challenges of increasing active sites, the challenge of increasing mass transportation in catalyst layers also needs to be addressed. This mass transportation may be optimized by elaborate structural constructions in MEA engineering based on the knowledge of highly developed nanomaterial science. 
Acknowledgements This study was financially supported by the National Key Research and Development Program of China (2017YFA0206500) and the National Science Foundation of China (21621091, 21373175, 91645121, 21573183, and 21703184).

Open Access This article is distributed under the terms of the Creative Commons Attribution 4.0 International License (http://creativeco mmons.org/licenses/by/4.0/), which permits use, duplication, adaptation, distribution and reproduction in any medium or format, as long as you give appropriate credit to the original author(s) and the source, provide a link to the Creative Commons license and indicate if changes were made.

\section{References}

1. Zhou, Z.Y., Tian, N., Li, J.T., et al.: Nanomaterials of high surface energy with exceptional properties in catalysis and energy storage. Chem. Soc. Rev. 40, 4167-4185 (2011)

2. Tian, N., Xiao, J., Zhou, Z.Y., et al.: Pt-group bimetallic nanocrystals with high-index facets as high performance electrocatalysts. Faraday Discuss. 162, 77-89 (2013)

3. Fuel Cell Multi-Year Research, Development and Demonstration Plan.: https://energy.gov/sites/prod/files/2017/05/f34/fcto_myrdd _fuel_cells.pdf

4. Kongkanand, A., Mathias, M.F.: The priority and challenge of high-power performance of low-platinum proton-exchange membrane fuel cells. J. Phys. Chem. Lett. 7, 1127-1137 (2016)

5. Bing, Y., Liu, H., Zhang, L., et al.: Nanostructured Pt-alloy electrocatalysts for PEM fuel cell oxygen reduction reaction. Chem. Soc. Rev. 39, 2184-2202 (2010)

6. Tian, N., Zhou, Z.Y., Sun, S.G.: Platinum metal catalysts of high-index surfaces: from single-crystal planes to electrochemically shape-controlled nanoparticles. J. Phys. Chem. C 112, 19801-19817 (2008)

7. Tian, N., Zhou, Z.Y., Sun, S.G., et al.: Synthesis of tetrahexahedral platinum nanocrystals with high-index facets and high electro-oxidation activity. Science 316, 732-735 (2007)

8. Stamenkovic, V.R., Fowler, B., Mun, B.S., et al.: Improved oxygen reduction activity on $\mathrm{Pt}_{3} \mathrm{Ni}(111)$ via increased surface site availability. Science 315, 493-497 (2007)

9. Xia, D., Liu, S., Wang, Z., et al.: Methanol-tolerant MoN electrocatalyst synthesized through heat treatment of molybdenum tetraphenylporphyrin for four-electron oxygen reduction reaction. J. Power Sources 177, 296-302 (2008)

10. Isogai, S., Ohnishi, R., Katayama, M., et al.: Composite of TiN nanoparticles and few-walled carbon nanotubes and its application to the electrocatalytic oxygen reduction reaction. ChemAsian J. 7, 286-289 (2012)

11. Vante, N.A., Tributsch, H.: Energy conversion catalysis using semiconducting transition metal cluster compounds. Nature 323, 431-432 (1986)

12. Sun, S.G., Chen, A.C.: Effects of ethylene glycol (EG) concentration and $\mathrm{pH}$ of solutions on electrocatalytic properties of $\mathrm{Pt}(111)$ electrode in EG oxidation-A comparison study with adjacent planes of platinum single crystal situated in [110] and [011] crystallographic zones. Electrochim Acta 39(7), 969-973 (1994)

13. Sheng, T., Tian, N., Zhou, Z.Y., et al.: Designing Pt-based electrocatalysts with high surface energy. ACS Energy Lett. 2, 1892-1900 (2017)

14. Huang, X.Q., Zhao, Z.P., Fan, J.M., et al.: Amine-assisted synthesis of concave polyhedral platinum nanocrystals having $\{411\}$ high-index facets. J. Am. Chem. Soc. 133, 4718-4721 (2011)

15. Li, Y.Y., Jiang, Y.X., Chen, M.H., et al.: Electrochemically shape-controlled synthesis of trapezohedral platinum nanocrystals with high electrocatalytic activity. Chem. Commun. 48, 9531-9533 (2012)
16. Zhang, L., Chen, D., Jiang, Z., et al.: Facile syntheses and enhanced electrocatalytic activities of Pt nanocrystals with hkk high-index surfaces. Nano Res. 5, 181-189 (2012)

17. Lin, H.X., Lei, Z.C., Jiang, Z.Y., et al.: Supersaturation-dependent surface structure evolution: from ionic, molecular to metallic micro/nanocrystals. J. Am. Chem. Soc. 135, 9311-9314 (2013)

18. Chen, M., Wu, B., Yang, J., et al.: Small adsorbate-assisted shape control of Pd and Pt nanocrystals. Adv. Mater. 24, 862-879 (2012)

19. Jin, M., Zhang, H., Xie, Z., et al.: Palladium concave nanocubes with high-index facets and their enhanced catalytic properties. Angew. Chem. Int. Edit. 50, 7850-7854 (2011)

20. Xia, B.Y., Wu, H.B., Wang, X., et al.: Highly concave platinum nanoframes with high-index facets and enhanced electrocatalytic properties. Angew. Chem. Int. Edit. 52, 12337-12340 (2013)

21. Yu, T., Kim, D.Y., Zhang, H., et al.: Platinum concave nanocubes with high-index facets and their enhanced activity for oxygen reduction reaction. Angew. Chem. Int. Edit. 50, 2773-2777 (2011)

22. Zhou, Z.Y., Huang, Z.Z., Chen, D.J., et al.: High-index faceted platinum nanocrystals supported on carbon black as highly efficient catalysts for ethanol electrooxidation. Angew. Chem. Int. Edit. 49, 411-414 (2010)

23. Zhou, Z.Y., Shang, S.J., Tian, N., et al.: Shape transformation from $\mathrm{Pt}$ nanocubes to tetrahexahedra with size near $10 \mathrm{~nm}$. Electrochem. Commun. 22(Supplement C), 61-64 (2012)

24. Liu, S., Tian, N., Xie, A.Y., et al.: Electrochemically seed-mediated synthesis of sub-10 $\mathrm{nm}$ tetrahexahedral Pt nanocrystals supported on graphene with improved catalytic performance. J. Am. Chem. Soc. 138, 5753-5756 (2016)

25. Liu, H.X., Tian, N., Brandon, M.P., et al.: Tetrahexahedral Pt nanocrystal catalysts decorated with $\mathrm{Ru}$ adatoms and their enhanced activity in methanol electrooxidation. ACS Catal. 2, 708-715 (2012)

26. Chen, Q.S., Zhou, Z.Y., Vidal-Iglesias, F.J., et al.: Significantly enhancing catalytic activity of tetrahexahedral Pt nanocrystals by Bi adatom decoration. J. Am. Chem. Soc. 133, 12930-12933 (2011)

27. Liu, H.X., Tian, N., Brandon, M.P., et al.: Enhancing the activity and tuning the mechanism of formic acid oxidation at tetrahexahedral Pt nanocrystals by Au decoration. Phys. Chem. Chem. Phys. 14, 16415-16423 (2012)

28. Rao, L., Zhang, B.W., Li, Y.Y., et al.: Electrochemical and spectroscopic studies of ethanol oxidation on nano-cubic Pt modified by Tin adatoms. J. Electrochem. 20, 395-400 (2014)

29. Sun, S.G., Clavilier, J., Bewick, A.: The mechanism of electrocatalytic oxidation of formic acid on Pt (100) and Pt (111) in sulphuric acid solution: an emirs study. J. Electroanal. Chem. Interfacial Electrochem. 240, 147-159 (1988)

30. Deng, Y.J., Tian, N., Zhou, Z.Y., et al.: Alloy tetrahexahedral Pd-Pt catalysts: enhancing significantly the catalytic activity by synergy effect of high-index facets and electronic structure. Chem. Sci. 3, 1157-1161 (2012)

31. Chen, Q., Yang, Y., Cao, Z., et al.: Excavated cubic platinum-tin alloy nanocrystals constructed from ultrathin nanosheets with enhanced electrocatalytic activity. Angew. Chem. Int. Edit. 55, 9021-9025 (2016)

32. Zhang, N., Bu, L., Guo, S., et al.: Screw thread-like platinumcopper nanowires bounded with high-index facets for efficient electrocatalysis. Nano Lett. 16, 5037-5043 (2016)

33. Liu, T., Huang, R., Liu, S., et al.: Electrochemically shape-controlled formation of concave AuPd alloy nanoparticles on ITO substrate. Sci. Sin. Chim. 47, 671 (2017)

34. Liu, T., Huang, R., Tian, X.C., et al.: Electrochemical preparation of AuPd alloy nanoparticles and their catalytic properties towards ethanol oxidation. Sci. Sin. Chim. 46, 908 (2016)

35. Zhang, H., Jin, M., Xia, Y.: Noble-metal nanocrystals with concave surfaces: synthesis and applications. Angew. Chem. Int. Edit. 51, 7656-7673 (2012) 
36. Lu, B.A., Du, J.H., Sheng, T., et al.: Hydrogen adsorptionmediated synthesis of concave Pt nanocubes and their enhanced electrocatalytic activity. Nanoscale 8, 11559-11564 (2016)

37. Jia, Y., Jiang, Y., Zhang, J., et al.: Unique excavated rhombic dodecahedral $\mathrm{PtCu}_{3}$ alloy nanocrystals constructed with ultrathin nanosheets of high-energy 110 facets. J. Am. Chem. Soc. 136, 3748-3751 (2014)

38. Huang, L., Zhan, M., Wang, Y.C., et al.: Syntheses of carbon paper supported high-index faceted Pt nanoparticles and their performance in direct formic acid fuel cells. J. Electrochem. 22, 123-128 (2016)

39. Liu, Z., Jackson, G.S., Eichhorn, B.W.: PtSn intermetallic, coreshell, and alloy nanoparticles as CO-tolerant electrocatalysts for H2 oxidation. Angew. Chem.-Int. Edit. 49, 3173-3176 (2010)

40. Ma, S.Y., Li, H.H., Hu, B.C., et al.: Synthesis of low Pt-based quaternary PtPdRuTe nanotubes with optimized incorporation of Pd for enhanced electrocatalytic activity. J. Am. Chem. Soc. 139, 5890-5895 (2017)

41. Chang, J., Feng, L., Liu, C., et al.: $\mathrm{Ni}_{2} \mathrm{P}$ enhances the activity and durability of the Pt anode catalyst in direct methanol fuel cells. Energy Environ. Sci. 7, 1628-1632 (2014)

42. Wang, D., Subban, C.V., Wang, H., et al.: Highly stable and COtolerant $\mathrm{Pt} / \mathrm{Ti}_{0.7} \mathrm{~W}_{0.3} \mathrm{O}_{2}$ electrocatalyst for proton-exchange membrane fuel cells. J. Am. Chem. Soc. 132, 10218-10220 (2010)

43. Mistry, H., Varela, A.S., Kühl, S., et al.: Nanostructured electrocatalysts with tunable activity and selectivity. Nat. Rev. Mater. 1, 1-14 (2016)

44. Kang, Y., Pyo, J.B., Ye, X., et al.: Synthesis, shape control, and methanol electro-oxidation properties of Pt-Zn Alloy and $\mathrm{Pt}_{3} \mathrm{Zn}$ intermetallic nanocrystals. ACS Nano 6, 5642-5647 (2012)

45. Stephens, I.E.L., Bondarenko, A.S., Gronbjerg, U., et al.: Understanding the electrocatalysis of oxygen reduction on platinum and its alloys. Energy Environ. Sci. 5, 6744-6762 (2012)

46. Kuzume, A., Herrero, E., Feliu, J.M.: Oxygen reduction on stepped platinum surfaces in acidic media. J. Electroanal. Chem. 599, 333-343 (2007)

47. Strmcnik, D., Kodama, K., van der Vliet, D., et al.: The role of non-covalent interactions in electrocatalytic fuel-cell reactions on platinum. Nat. Chem. 1, 466-472 (2009)

48. Escudero-Escribano, M., Malacrida, P., Hansen, M.H., et al.: Tuning the activity of Pt alloy electrocatalysts by means of the lanthanide contraction. Science 352, 73-76 (2016)

49. Gomez-Marin, A.M., Rizo, R., Feliu, J.M.: Oxygen reduction reaction at Pt single crystals: a critical overview. Catal. Sci. Technol. 4, 1685-1698 (2014)

50. Maciá, M.D., Campiña, J.M., Herrero, E., et al.: On the kinetics of oxygen reduction on platinum stepped surfaces in acidic media. J. Electroanal. Chem. 564, 141-150 (2004)

51. Rizo, R., Herrero, E., Feliu, J.M.: Oxygen reduction reaction on stepped platinum surfaces in alkaline media. Phys. Chem. Chem. Phys. 15, 15416-15425 (2013)

52. Zhang, J., Vukmirovic, M.B., Xu, Y., et al.: Controlling the catalytic activity of platinum-monolayer electrocatalysts for oxygen reduction with different substrates. Angew. Chem.-Int. Edit. 44, 2132-2135 (2005)

53. Zhang, J., Vukmirovic, M.B., Sasaki, K., et al.: Mixed-metal Pt monolayer electrocatalysts for enhanced oxygen reduction kinetics. J. Am. Chem. Soc. 127, 12480-12481 (2005)

54. Stephens, I.E.L., Bondarenko, A.S., Perez-Alonso, F.J., et al.: Tuning the activity of $\mathrm{Pt}(111)$ for oxygen electroreduction by subsurface alloying. J. Am. Chem. Soc. 133, 5485-5491 (2011)

55. Adzic, R.R., Zhang, J., Sasaki, K., et al.: Platinum monolayer fuel cell electrocatalysts. Top. Catal. 46, 249-262 (2007)

56. Kuttiyiel, K.A., Sasaki, K., Su, D., et al.: Pt monolayer on Austabilized PdNi core-shell nanoparticles for oxygen reduction reaction. Electrochim. Acta 110, 267-272 (2013)

57. Kuttiyiel, K.A., Sasaki, K., Choi, Y., et al.: Bimetallic IrNi core platinum monolayer shell electrocatalysts for the oxygen reduction reaction. Energy Environ. Sci. 5, 5297-5304 (2012)
58. Ghosh, T., Vukmirovic, M.B., DiSalvo, F.J., et al.: Intermetallics as novel supports for $\mathrm{Pt}$ monolayer $\mathrm{O}_{2}$ reduction electrocatalysts: potential for significantly improving properties. J. Am. Chem. Soc. 132, 906-907 (2010)

59. Gong, K., Su, D., Adzic, R.R.: Platinum-monolayer shell on AuNi0.5Fe nanoparticle core electrocatalyst with high activity and stability for the oxygen reduction reaction. J. Am. Chem. Soc. 132, 14364-14366 (2010)

60. Kuttiyiel, K.A., Choi, Y., Hwang, S.M., et al.: Enhancement of the oxygen reduction on nitride stabilized Pt-M ( $\mathrm{M}=\mathrm{Fe} \mathrm{Co}$, and Ni) core-shell nanoparticle electrocatalysts. Nano Energy 13, 442-449 (2015)

61. Kuttiyiel, K.A., Choi, Y., Sasaki, K., et al.: Tuning electrocatalytic activity of Pt monolayer shell by bimetallic $\operatorname{Ir}-\mathrm{M}(\mathrm{M}=\mathrm{Fe}$ $\mathrm{Co}, \mathrm{Ni}$ or $\mathrm{Cu}$ ) cores for the oxygen reduction reaction. Nano Energy 29, 261-267 (2016)

62. Kuttiyiel, K.A., Sasaki, K., Choi, Y.M., et al.: Nitride stabilized $\mathrm{PtNi}$ core-shell nanocatalyst for high oxygen reduction activity. Nano Lett. 12, 6266-6271 (2012)

63. Stamenkovic, V., Mun, B.S., Mayrhofer, K.J.J., et al.: Changing the activity of electrocatalysts for oxygen reduction by tuning the surface electronic structure. Angew. Chem. Int. Edit. 45, 2897-2901 (2006)

64. van der Vliet, D.F., Wang, C., Li, D., et al.: Unique electrochemical adsorption properties of Pt-skin surfaces. Angew. Chem.-Int. Edit. 124, 3193-3196 (2012)

65. Stamenkovic, V.R., Mun, B.S., Arenz, M., et al.: Trends in electrocatalysis on extended and nanoscale Pt-bimetallic alloy surfaces. Nat. Mater. 6, 241-247 (2007)

66. Sasaki, K., Naohara, H., Cai, Y., et al.: Core-protected platinum monolayer shell high-stability electrocatalysts for fuel-cell cathodes. Angew. Chem.-Int. Edit. 49, 8602-8607 (2010)

67. Huang, X., Zhao, Z., Cao, L., et al.: High-performance transition metal-doped $\mathrm{Pt}_{3} \mathrm{Ni}$ octahedra for oxygen reduction reaction. Science 348, 1230-1234 (2015)

68. van der Vliet, D.F., Wang, C., Tripkovic, D., et al.: Mesostructured thin films as electrocatalysts with tunable composition and surface morphology. Nat. Mater. 11, 1051-1058 (2012)

69. Chen, C., Kang, Y., Huo, Z., et al.: Highly crystalline multimetallic nanoframes with three-dimensional electrocatalytic surfaces. Science 343, 1339-1343 (2014)

70. Zhang, L., Roling, L.T., Wang, X., et al.: Platinum-based nanocages with subnanometer-thick walls and well-defined, controllable facets. Science 349, 412-416 (2015)

71. Li, M., Zhao, Z., Cheng, T., et al.: Ultrafine jagged platinum nanowires enable ultrahigh mass activity for the oxygen reduction reaction. Science 354, 1414-1419 (2016)

72. Bu, L., Zhang, N., Guo, S., et al.: Biaxially strained PtPb/Pt core/ shell nanoplate boosts oxygen reduction catalysis. Science 354, 1410-1414 (2016)

73. Banham, D., Ye, S.: Current status and future development of catalyst materials and catalyst layers for proton exchange membrane fuel cells: an industrial perspective. ACS Energy Lett. 2, 629-638 (2017)

74. Bu, L., Ding, J., Guo, S., et al.: A general method for multimetallic platinum alloy nanowires as highly active and stable oxygen reduction catalysts. Adv. Mater. 27, 7204-7212 (2015)

75. Bu, L., Guo, S., Zhang, X., et al.: Surface engineering of hierarchical platinum-cobalt nanowires for efficient electrocatalysis. Nat. Commun. 7, 11850 (2016)

76. Zhao, X., Chen, S., Fang, Z., et al.: Octahedral Pd@ $\mathrm{Pt}_{1.8} \mathrm{Ni}$ core-shell nanocrystals with ultrathin PtNi alloy shells as active catalysts for oxygen reduction reaction. J. Am. Chem. Soc. 137, 2804-2807 (2015)

77. Beermann, V., Gocyla, M., Willinger, E., et al.: Rh-doped Pt-Ni octahedral nanoparticles: understanding the correlation between 
elemental distribution, oxygen reduction reaction, and shape stability. Nano Lett. 16, 1719-1725 (2016)

78. Choi, S.I., Xie, S., Shao, M., et al.: Synthesis and characterization of $9 \mathrm{~nm} \mathrm{Pt}-\mathrm{Ni}$ octahedra with a record high activity of $3.3 \mathrm{~A} / \mathrm{mgPt}$ for the oxygen reduction reaction. Nano Lett. 13, 3420-3425 (2013)

79. Ding, J., Bu, L., Guo, S., et al.: Morphology and phase controlled construction of Pt-Ni nanostructures for efficient electrocatalysis. Nano Lett. 16, 2762-2767 (2016)

80. Zou, L., Li, J., Yuan, T., et al.: Structural transformation of carbon-supported $\mathrm{Pt}_{3} \mathrm{Cr}$ nanoparticles from a disordered to an ordered phase as a durable oxygen reduction electrocatalyst. Nanoscale 6, 10686-10692 (2014)

81. Wang, D., Xin, H.L., Hovden, R., et al.: Structurally ordered intermetallic platinum-cobalt core-shell nanoparticles with enhanced activity and stability as oxygen reduction electrocatalysts. Nat. Mater. 12, 81-87 (2013)

82. Cui, C., Gan, L., Li, H.H., et al.: Octahedral PtNi nanoparticle catalysts: exceptional oxygen reduction activity by tuning the alloy particle surface composition. Nano Lett. 12, 5885-5889 (2012)

83. Zhang, C., Hwang, S.Y., Trout, A., et al.: Solid state chemistryenabled scalable production of octahedral Pt-Ni alloy electrocatalyst for oxygen reduction reaction. J. Am. Chem. Soc. 136, 7805-7808 (2014)

84. Chung, D.Y., Jun, S.W., Yoon, G., et al.: Highly durable and active PtFe nanocatalyst for electrochemical oxygen reduction reaction. J. Am. Chem. Soc. 137, 15478-15485 (2015)

85. Wang, X., Vara, M., Luo, M., et al.: Pd@Pt core-shell concave decahedra: a class of catalysts for the oxygen reduction reaction with enhanced activity and durability. J. Am. Chem. Soc. 137, 15036-15042 (2015)

86. Shen, L.L., Zhang, G.R., Miao, S., et al.: Core-shell nanostructured $\mathrm{Au} @ \mathrm{Ni}_{\mathrm{m}} \mathrm{Pt}_{2}$ electrocatalysts with enhanced activity and durability for oxygen reduction reaction. Acs Catal. 6, 1680$1690(2016)$

87. Huang, X., Zhao, Z., Chen, Y., et al.: A rational design of carbon-supported dispersive Pt-based octahedra as efficient oxygen reduction reaction catalysts. Energy Environ. Sci. 7, 2957-2962 (2014)

88. Lu, B.A., Sheng, T., Tian, N., et al.: Octahedral PtCu alloy nanocrystals with high performance for oxygen reduction reaction and their enhanced stability by trace Au. Nano Energy 33, 65-71 (2017)

89. Wu, J., Gross, A., Yang, H.: Shape and composition-controlled platinum alloy nanocrystals using carbon monoxide as reducing agent. Nano Lett. 11, 798-802 (2011)

90. Wei, L., Zhou, Z.Y., Chen, S.P., et al.: Electrochemically shapecontrolled synthesis in deep eutectic solvents: triambic icosahedral platinum nanocrystals with high-index facets and their enhanced catalytic activity. Chem. Commun. 49, 11152-11154 (2013)

91. Zhu, C., Du, D., Eychmüller, A., et al.: Engineering ordered and nonordered porous noble metal nanostructures: synthesis, assembly, and their applications in electrochemistry. Chem. Rev. 115, 8896-8943 (2015)

92. Chen, Z.W., Waje, M., Li, W.Z., et al.: Supportless Pt and PtPd nanotubes as electrocatalysts for oxygen-reduction reactions. Angew. Chem. Int. Edit. 46, 4060-4063 (2007)

93. Huang, X., Zhu, E., Chen, Y., et al.: A facile strategy to $\mathrm{Pt}_{3} \mathrm{Ni}$ nanocrystals with highly porous features as an enhanced oxygen reduction reaction catalyst. Adv. Mater. 25, 2974-2979 (2013)

94. Zhang, J., Sasaki, K., Sutter, E., et al.: Stabilization of platinum oxygen-reduction electrocatalysts using gold clusters. Science 315, 220-222 (2007)
95. Kang, Y., Snyder, J., Chi, M., et al.: Multimetallic core/interlayer/ shell nanostructures as advanced electrocatalysts. Nano Lett. 14, 6361-6367 (2014)

96. Wang, C., van der Vliet, D., More, K.L., et al.: Multimetallic Au/ $\mathrm{FePt}_{3}$ nanoparticles as highly durable electrocatalyst. Nano Lett. 11, 919-926 (2011)

97. Sebastián, D., Serov, A., Artyushkova, K., et al.: High performance and cost-effective direct methanol fuel cells: $\mathrm{Fe}-\mathrm{N}-\mathrm{C}$ methanol-tolerant oxygen reduction reaction catalysts. Chemsuschem 9, 1986-1995 (2016)

98. Chen, C., Lai, Y.J., Zhou, Z.Y., et al.: Thermo-stability and activity site structure of $\mathrm{Fe} / \mathrm{N} / \mathrm{C}$ electrocatalyst for oxygen reduction reaction. J. Electrochem. 23, 400-408 (2017)

99. Sun, T., Tian, B., Lu, J., et al.: Recent advances in Fe (or Co)/N/C electrocatalysts for the oxygen reduction reaction in polymer electrolyte membrane fuel cells. J. Mater. Chem. A 5, 1893318950 (2017)

100. Lefevre, M., Proietti, E., Jaouen, F., et al.: Iron-based catalysts with improved oxygen reduction activity in polymer electrolyte fuel cells. Science 324, 71-74 (2009)

101. Gong, K., Du, F., Xia, Z., et al.: Nitrogen-doped carbon nanotube arrays with high electrocatalytic activity for oxygen reduction. Science 323, 760-764 (2009)

102. Shen, A., Zou, Y., Wang, Q., et al.: Oxygen reduction reaction in a droplet on graphite: direct evidence that the edge is more active than the basal plane. Angew. Chem.-Int. Edit. 53, 10804-10808 (2014)

103. Jiang, Y., Yang, L., Sun, T., et al.: Significant contribution of intrinsic carbon defects to oxygen reduction activity. ACS Catal. 5, 6707-6712 (2015)

104. Chung, H.T., Cullen, D.A., Higgins, D., et al.: Direct atomiclevel insight into the active sites of a high-performance PGMfree ORR catalyst. Science 357, 479-484 (2017)

105. Deng, D., Chen, X., Yu, L., et al.: A single iron site confined in a graphene matrix for the catalytic oxidation of benzene at room temperature. Sci. Adv. 1, e1500462 (2015)

106. Zitolo, A., Goellner, V., Armel, V., et al.: Identification of catalytic sites for oxygen reduction in iron- and nitrogen-doped graphene materials. Nat. Mater. 14, 937-944 (2015)

107. Wang, Q., Zhou, Z.Y., Lai, Y.J., et al.: Phenylenediamine-based $\mathrm{FeN}_{x} / \mathrm{C}$ catalyst with high activity for oxygen reduction in acid medium and its active-site probing. J. Am. Chem. Soc. 136, 10882-10885 (2014)

108. Kramm, U.I., Herranz, J., Larouche, N., et al.: Structure of the catalytic sites in $\mathrm{Fe} / \mathrm{N} / \mathrm{C}$-catalysts for $\mathrm{O}_{2}$-reduction in PEM fuel cells. Phys. Chem. Chem. Phys. 14, 11673-11688 (2012)

109. Li, J., Ghoshal, S., Liang, W., et al.: Structural and mechanistic basis for the high activity of iron-nitrogen-carbon electrocatalysts toward oxygen reduction. Energy Environ. Sci. 9, 2418-2432 (2016)

110. Thorum, M.S., Hankett, J.M., Gewirth, A.A.: Poisoning the oxygen reduction reaction on carbon-supported $\mathrm{Fe}$ and $\mathrm{Cu}$ electrocatalysts: evidence for metal-centered activity. J. Phys. Chem. Lett. 2, 295-298 (2011)

111. Sahraie, N.R., Kramm, U.I., Steinberg, J., et al.: Quantifying the density and utilization of active sites in non-precious metal oxygen electroreduction catalysts. Nat. Commun. 6, 8618 (2015)

112. Malko, D., Kucernak, A., Lopes, T.: In situ electrochemical quantification of active sites in $\mathrm{Fe}-\mathrm{N} / \mathrm{C}$ non-precious metal catalysts. Nat. Commun. 7, 13285 (2016)

113. Guo, D., Shibuya, R., Akiba, C., et al.: Active sites of nitrogendoped carbon materials for oxygen reduction reaction clarified using model catalysts. Science 351, 361-365 (2016)

114. Jeon, I.Y., Zhang, S., Zhang, L., et al.: Edge-selectively sulfurized graphene nanoplatelets as efficient metal-free 
electrocatalysts for oxygen reduction reaction: the electron spin effect. Adv. Mater. 25, 6138-6145 (2013)

115. Liu, Z.W., Peng, F., Wang, H.J., et al.: Phosphorus-doped graphite layers with high electrocatalytic activity for the $\mathrm{O}_{2}$ reduction in an alkaline medium. Angew. Chem.-Int. Edit. 50, 3257-3261 (2011)

116. Yao, Z., Nie, H., Yang, Z., et al.: Catalyst-free synthesis of iodine-doped graphenevia a facile thermal annealing process and its use for electrocatalytic oxygen reduction in an alkaline medium. Chem. Commun. 48, 1027-1029 (2012)

117. Sun, X., Zhang, Y., Song, P., et al.: Fluorine-doped carbon blacks: highly efficient metal-free electrocatalysts for oxygen reduction reaction. Acs Catal. 3, 1726-1729 (2013)

118. Wang, S., Yu, D., Dai, L.: Polyelectrolyte functionalized carbon nanotubes as efficient metal-free electrocatalysts for oxygen reduction. J. Am. Chem. Soc. 133, 5182-5185 (2011)

119. Zhao, Y., Yang, L., Chen, S., et al.: Can boron and nitrogen Codoping improve oxygen reduction reaction activity of carbon nanotubes? J. Am. Chem. Soc. 135, 1201-1204 (2013)

120. Wu, Q., Yang, L., Wang, X., et al.: From carbon-based nanotubes to nanocages for advanced energy conversion and storage. Account. Chem. Res. 50(2), 435-444 (2017)

121. Xing, T., Zheng, Y., Li, L.H., et al.: Observation of active sites for oxygen reduction reaction on nitrogen-doped multilayer graphene. ACS Nano 8(7), 6856-6862 (2014)

122. Proietti, E., Jaouen, F., Lefevre, M., et al.: Iron-based cathode catalyst with enhanced power density in polymer electrolyte membrane fuel cells. Nat. Commun. 2, 416 (2011)

123. Wang, Y.C., Lai, Y.J., Song, L., et al.: S-doping of an Fe/N/C ORR catalyst for polymer electrolyte membrane fuel cells with high power density. Angew. Chem.-Int. Edit. 54(34), 99079910 (2015)

124. Fu, X., Zamani, P., Choi, J.Y., et al.: In situ polymer graphenization ingrained with nanoporosity in a nitrogenous electrocatalyst boosting the performance of polymer-electrolyte-membrane fuel cells. Adv. Mater. 29, 1604456 (2017)

125. Liu, D.J.: Novel non-PGM catalysts from rationally designed 3-D precursors. In: 2015 DOE Hydrogen and Fuel Cells Program and Vehicle Technologies Office Annual Merit Review and Peer Evaluation Meeting (2015)

126. Zelenay, P.: Non-precious metal fuel cell cathodes: catalyst development and electrode structure design. In: Hydrogen and Fuel Cells Program 2016 Annual Merit Review and Peer Evaluation Meeting (2016)

127. Chokai, M., Daidou, T., Nabae, Y.: Development of Pt-free carbon-based catalyst for PEFC cathode prepared from polyacrylonitrile. ECS Trans. 64, 261-270 (2014)

128. Liu, Q., Liu, X., Zheng, L., et al.: The solid-phase synthesis of an $\mathrm{Fe}-\mathrm{N}-\mathrm{C}$ electrocatalyst for high-power proton-exchange membrane fuel cells. Angew. Chem.-Int. Edit. 57, 1204-1208 (2018)

129. Wang, J., Huang, Z., Liu, W., et al.: Design of N-coordinated dual-metal sites: a stable and active Pt-free catalyst for acidic oxygen reduction reaction. J. Am. Chem. Soc. 139, 17281-17284 (2017)

130. Yuan, S., Shui, J.L., Grabstanowicz, L., et al.: A highly active and support-free oxygen reduction catalyst prepared from ultrahighsurface-area porous polyporphyrin. Angew. Chem. Int. Edit. 52, 8349-8353 (2013)

131. Serov, A., Artyushkova, K., Atanassov, P.: Fe-N-C oxygen reduction fuel cell catalyst derived from carbendazim: synthesis, structure, and reactivity. Adv. Energy Mater. 4, 1301735 (2014)

132. Liu, G., Li, X., Ganesan, P., et al.: Studies of oxygen reduction reaction active sites and stability of nitrogen-modified carbon composite catalysts for PEM fuel cells. Electrochim. Acta 55, 2853-2858 (2010)
133. Wu, G., More, K.L., Johnston, C.M., et al.: High-performance electrocatalysts for oxygen reduction derived from polyaniline, iron, and cobalt. Science 332, 443-447 (2011)

134. Kramm, U.I., Lefevre, M., Larouche, N., et al.: Correlations between mass activity and physicochemical properties of $\mathrm{Fe} / \mathrm{N} / \mathrm{C}$ catalysts for the ORR in PEM fuel cell via ${ }^{57} \mathrm{Fe}$ Mossbauer spectroscopy and other techniques. J. Am. Chem. Soc. 136, 978-985 (2014)

135. Ramaswamy, N., Tylus, U., Jia, Q., et al.: Activity descriptor identification for oxygen reduction on nonprecious electrocatalysts: linking surface science to coordination chemistry. J. Am. Chem. Soc. 135, 15443-15449 (2013)

136. Shen, H., Gracia-Espino, E., Ma, J., et al.: Synergistic effects between atomically dispersed $\mathrm{Fe}-\mathrm{N}-\mathrm{C}$ and $\mathrm{C}-\mathrm{S}-\mathrm{C}$ for the oxygen reduction reaction in acidic media. Angew. Chem.-Int. Edit. 56, 13800-13804 (2017)

137. Yu, D., Zhang, Q., Dai, L.: Highly efficient metal-free growth of nitrogen-doped single-walled carbon nanotubes on plasmaetched substrates for oxygen reduction. J. Am. Chem. Soc. 132, 15127-15129 (2010)

138. Shui, J., Wang, M., Du, F., et al.: N-doped carbon nanomaterials are durable catalysts for oxygen reduction reaction in acidic fuel cells. Sci. Adv. 1, e1400129 (2015). https://doi.org/10.1126/sciad v. 1400129

139. Chen, Z., Higgins, D., Chen, Z.: Nitrogen doped carbon nanotubes and their impact on the oxygen reduction reaction in fuel cells. Carbon 48, 3057-3065 (2010)

140. Liang, J., Jiao, Y., Jaroniec, M., et al.: Sulfur and nitrogen dualdoped mesoporous graphene electrocatalyst for oxygen reduction with synergistically enhanced performance. Angew. Chem.-Int. Edit. 51, 11496-11500 (2012)

141. Yang, Z., Yao, Z., Li, G., et al.: Sulfur-doped graphene as an efficient metal-free cathode catalyst for oxygen reduction. ACS Nano 6, 205-211 (2012)

142. Sheng, Z.H., Gao, H.L., Bao, W.J., et al.: Synthesis of boron doped graphene for oxygen reduction reaction in fuel cells. J. Mater. Chem. 22, 390-395 (2012)

143. Lin, Z., Waller, G.H., Liu, Y., et al.: Simple preparation of nanoporous few-layer nitrogen-doped graphene for use as an efficient electrocatalyst for oxygen reduction and oxygen evolution reactions. Carbon 53, 130-136 (2013)

144. Sun, X., Song, P., Zhang, Y., et al.: A class of high performance metal-free oxygen reduction electrocatalysts based on cheap carbon blacks. Sci. Rep. 3, 2505 (2013)

145. Choi, C.H., Chung, M.W., Kwon, H.C., et al.: B, N- and P, $\mathrm{N}$-doped graphene as highly active catalysts for oxygen reduction reactions in acidic media. J. Mater. Chem. A 1, 3694-3699 (2013)

146. Wang, L., Ambrosi, A., Pumera, M.: "Metal-free" catalytic oxygen reduction reaction on heteroatom-doped graphene is caused by trace metal impurities. Angew. Chem.-Int. Edit. 52, 1381813821 (2013)

147. Masa, J., Zhao, A., Xia, W., et al.: Trace metal residues promote the activity of supposedly metal-free nitrogen-modified carbon catalysts for the oxygen reduction reaction. Electrochem. Commun. 34, 113-116 (2013)

148. Masa, J., Xia, W., Muhler, M., et al.: On the role of metals in nitrogen-doped carbon electrocatalysts for oxygen reduction. Angew. Chem.-Int. Edit. 54, 10102-10120 (2015)

149. Zhang, G., Chenitz, R., Lefèvre, M., et al.: Is iron involved in the lack of stability of $\mathrm{Fe} / \mathrm{N} / \mathrm{C}$ electrocatalysts used to reduce oxygen at the cathode of PEM fuel cells? Nano Energy 29, 111-125 (2016)

150. Choi, C.H., Baldizzone, C., Polymeros, G., et al.: Minimizing operando demetallation of $\mathrm{Fe}-\mathrm{N}-\mathrm{C}$ electrocatalysts in acidic medium. Acs Catal. 6, 3136-3146 (2016) 
151. Choi, C.H., Baldizzone, C., Grote, J.P., et al.: Stability of Fe$\mathrm{N}-\mathrm{C}$ catalysts in acidic medium studied by operando spectroscopy. Angew. Chem. Int. Edit. 54, 12753-12757 (2015)

152. Banham, D., Ye, S., Pei, K., et al.: A review of the stability and durability of non-precious metal catalysts for the oxygen reduction reaction in proton exchange membrane fuel cells. J. Power Sources 285, 334-348 (2015)

153. Deng, D., Yu, L., Chen, X., et al.: Iron encapsulated within pod-like carbon nanotubes for oxygen reduction reaction. Angew. Chem. Int. Edit. 52, 371-375 (2013)

154. Biloul, A., Gouérec, P., Savy, M., et al.: Oxygen electrocatalysis under fuel cell conditions: behaviour of cobalt porphyrins and tetraazaannulene analogues. J. Appl. Electrochem. 26, 1139-1146 (1996)

155. Herranz, J., Jaouen, F., Lefèvre, M., et al.: Unveiling N-protonation and anion-binding effects on $\mathrm{Fe} / \mathrm{N} / \mathrm{C}$ catalysts for $\mathrm{O}_{2}$ reduction in proton-exchange-membrane fuel cells. J. Phys. Chem. C 115, 16087-16097 (2011)

156. Yang, L., Larouche, N., Chenitz, R., et al.: Activity, performance, and durability for the reduction of oxygen in PEM fuel cells, of $\mathrm{Fe} / \mathrm{N} / \mathrm{C}$ electrocatalysts obtained from the pyrolysis of metal-organic-framework and iron porphyrin precursors. Electrochim. Acta 159(Supplement C), 184-197 (2015)

157. Choi, J.Y., Yang, L., Kishimoto, T., et al.: Is the rapid initial performance loss of $\mathrm{Fe} / \mathrm{N} / \mathrm{C}$ non precious metal catalysts due to micropore flooding? Energy Environ. Sci. 10, 296-305 (2017)

158. Shao, M., Chang, Q., Dodelet, J.P., et al.: Recent advances in electrocatalysts for oxygen reduction reaction. Chem. Rev. 116(6), 3594-3657 (2016)

159. Chenitz, R., Kramm, U.I., Lefevre, M., et al.: A specific demetalation of $\mathrm{Fe}-\mathrm{N}_{4}$ catalytic sites in the micropores of $\mathrm{NC}_{-}$ $\mathrm{Ar}+\mathrm{NH}_{3}$ is at the origin of the initial activity loss of the highly active $\mathrm{Fe} / \mathrm{N} / \mathrm{C}$ catalyst used for the reduction of oxygen in PEM fuel cells. Energy Environ. Sci. (2018). https://doi. org/10.1039/C7EE02302B

160. Banham, D., Kishimoto, T., Sato, T., et al.: New insights into non-precious metal catalyst layer designs for proton exchange membrane fuel cells: improving performance and stability. J. Power Sources 344, 39-45 (2017)

161. Zhang, C., Wang, Y.C., An, B., et al.: Networking pyrolyzed zeolitic imidazolate frameworks by carbon nanotubes improves conductivity and enhances oxygen-reduction performance in polymer-electrolyte-membrane fuel cells. Adv. Mater. 29, 1604556 (2017)

162. Shui, J., Chen, C., Grabstanowicz, L., et al.: Highly efficient nonprecious metal catalyst prepared with metal-organic framework in a continuous carbon nanofibrous network. P. Natl. Acad. Sci. 112, 10629-10634 (2015)

163. Wang, Y.C., Huang, L., Zhang, P., et al.: Constructing a triplephase interface in micropores to boost performance of Fe/N/C catalysts for direct methanol fuel cells. ACS Energy Lett. 2, 645-650 (2017)

164. Zhang, S., Liu, B., Chen, S.: Synergistic increase of oxygen reduction favourable $\mathrm{Fe}-\mathrm{N}$ coordination structures in a ternary hybrid of carbon nanospheres/carbon nanotubes/graphene sheets. Phys. Chem. Chem. Phys. 15, 18482 (2013)

165. Zhang, S., Zhang, H., Liu, Q., et al.: Fe-N doped carbon nanotube/graphene composite: facile synthesis and superior electrocatalytic activity. J. Mater. Chem. A 1, 3302 (2013)

166. Liu, Q., Zhang, H., Zhong, H., et al.: N-doped graphene/carbon composite as non-precious metal electrocatalyst for oxygen reduction reaction. Electrochim. Acta 81, 313-320 (2012)
167. Liang, H.W., Wei, W., Wu, Z.S., et al.: Mesoporous metalnitrogen-doped carbon electrocatalysts for highly efficient oxygen reduction reaction. J. Am. Chem. Soc. 135, 16002-16005 (2013)

168. Cheon, J.Y., Kim, T., Choi, Y., et al.: Ordered mesoporous porphyrinic carbons with very high electrocatalytic activity for the oxygen reduction reaction. Sci. Rep. 3, 2715 (2013)

169. Ding, W., Li, L., Xiong, K., et al.: Shape fixing via salt recrystallization: a morphology-controlled approach to convert nanostructured polymer to carbon nanomaterial as a highly active catalyst for oxygen reduction reaction. J. Am. Chem. Soc. 137, 5414-5420 (2015)

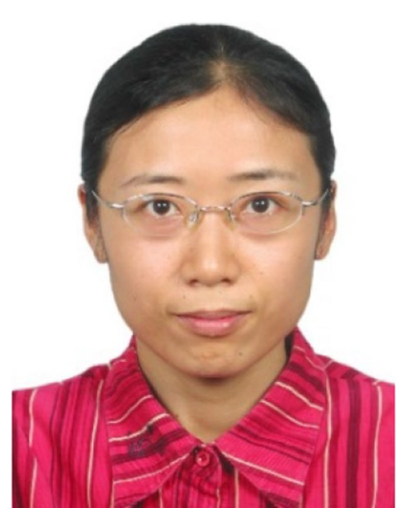

Na Tian received her Ph.D. degree from Xiamen University in 2007 and is now a professor at this University. Her research interests focus on metal nanocrystals with high-energy surfaces, electrocatalysts for oxygen reduction reaction, oxidation of small organic molecules, and $\mathrm{CO}_{2}$ reduction.

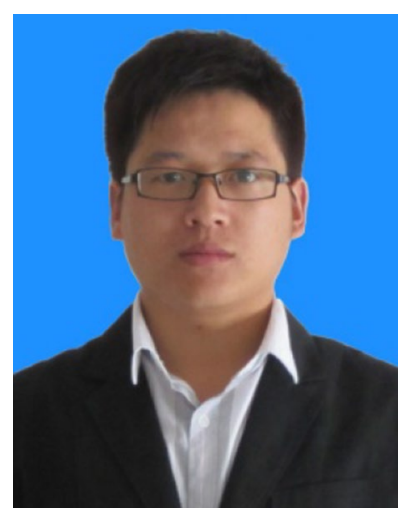

Bang-An Lu obtained his M.S. from Harbin Engineering University in 2012 . He is currently pursuing a Ph.D. program in Physical Chemistry at Xiamen University. His research interests focus on exploring novel oxygen reduction reaction catalysts.

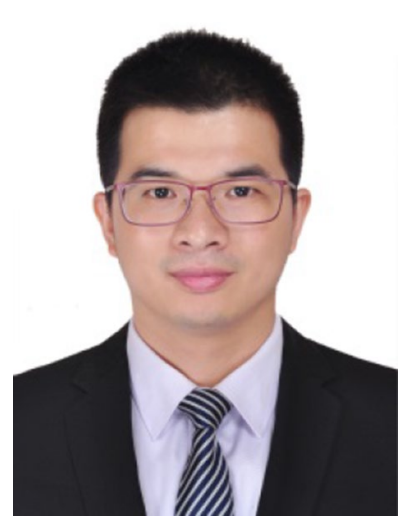

Xiao-Dong Yang received his $\mathrm{Ph} . \mathrm{D}$. degree in material science and engineering from Xi' an Jiaotong University in 2014, and then spent 3 years as a post-doctoral fellow at Xiamen University. He became a Lecturer at Huaqiao University in 2017. His current research focuses on the development of polymer electrolyte fuel cells and electrocatalysts. 


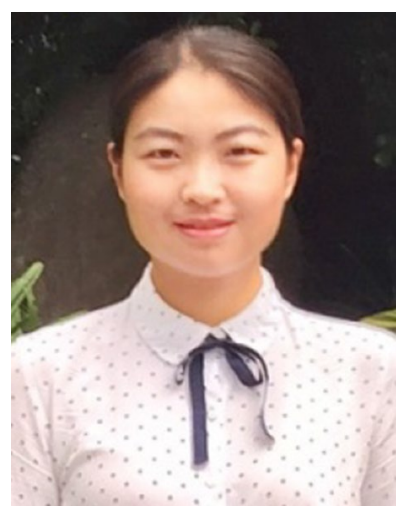

Rui Huang obtained her Ph.D. degree from Xiamen University in 2013, and then did 3 years of postdoctoral research at the Collaborative Innovation Center of Chemistry for Energy Materials. She is actually an engineer at the Department of Chemistry. Her research interests include electrocatalysis, controlled synthesis of nanomaterials, and electrochemical in situ FTIR spectroscopy.

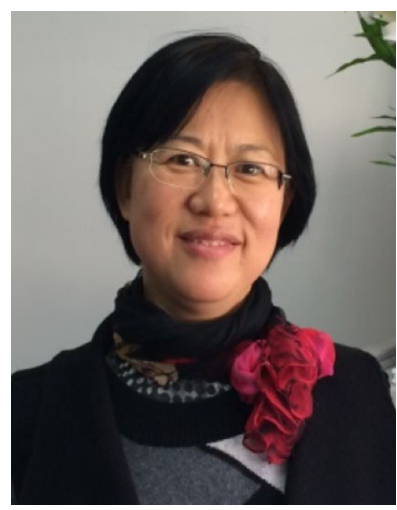

Yan-Xia Jiang received her Ph.D. degree from Jilin University in 1999, and then joined the department of Chemistry at Xiamen University and was promoted to full professor in 2007. Her current research interests include electrochemical surface science, electrocatalysis and spectroelectrochemistry.

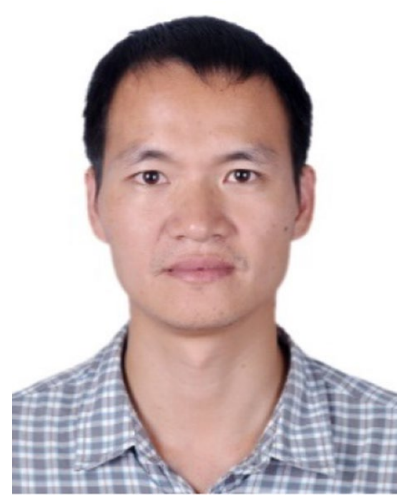

Zhi-You Zhou received his Ph.D. degree in 2004 from Xiamen University and is a professor at the College of Chemistry and Chemical Engineering. His research interests include electrocatalysis, non-precious metal catalysts, fuel cells, and electrochemical in situ FTIR spectroscopy.

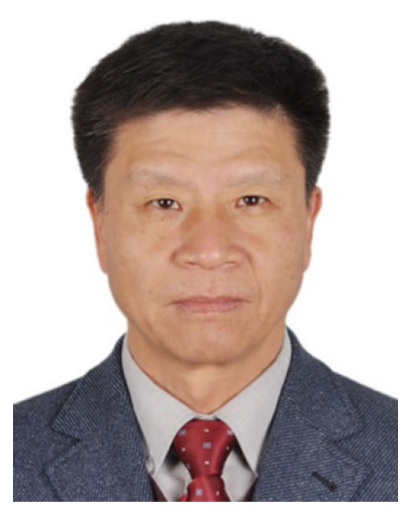

Shi-Gang Sun obtained Doctorat d'Etat in 1986 from Université Pierre et Marie Curie (Paris VI), France, and is a professor of chemistry at Xiamen University. His research interests include electrocatalysis, electrochemical surface science, spectroelectrochemistry, and electrochemical energy conversion and storage. $\mathrm{He}$ has been elected Academician of Chinese Academy of Sciences, Fellow of Royal Society of Chemistry and Fellow of International Society of Electrochemistry. 